\title{
Mine Safety Impoundment Inspection and Verification Tool: Mining and Industrial Safety Technology and Training Innovation
}

Eric W. Baker

West Virginia University

Follow this and additional works at: https://researchrepository.wvu.edu/etd

\section{Recommended Citation}

Baker, Eric W., "Mine Safety Impoundment Inspection and Verification Tool: Mining and Industrial Safety Technology and Training Innovation" (2011). Graduate Theses, Dissertations, and Problem Reports. 3371. https://researchrepository.wvu.edu/etd/3371

This Thesis is protected by copyright and/or related rights. It has been brought to you by the The Research Repository @ WVU with permission from the rights-holder(s). You are free to use this Thesis in any way that is permitted by the copyright and related rights legislation that applies to your use. For other uses you must obtain permission from the rights-holder(s) directly, unless additional rights are indicated by a Creative Commons license in the record and/ or on the work itself. This Thesis has been accepted for inclusion in WVU Graduate Theses, Dissertations, and Problem Reports collection by an authorized administrator of The Research Repository @ WVU. For more information, please contact researchrepository@mail.wvu.edu. 
Mine Safety Impoundment Inspection and Verification Tool:

Mining and Industrial Safety Technology and Training Innovation

Eric W. Baker, EIT

Thesis submitted to the
College of Engineering and Mineral Resources
at West Virginia University
in partial fulfillment of the requirements
for the degree of
Master of Science
In
Civil Engineering

John Quaranta, P.E., Ph.D., Chair

Hema Siriwardane, P.E., Ph.D.

Leslie Hopkinson, Ph.D

Department of Civil and Environmental Engineering

Morgantown, West Virginia

2011

Keywords: coal impoundment, impoundment inspection, dam safety 


\section{ABSTRACT \\ Mine Safety Impoundment Inspection and Verification Tool: Mining and Industrial Safety Technology and Training Innovation}

\section{Eric W. Baker, EIT}

The purpose of this investigation primarily focuses on coal impoundment safety and early hazard potential awareness as well as addressing the need for adapting a field hardened computer so that its more advanced technology may be applied to the mining industry. The purpose was to develop a protocol based on West Virginia State and federal laws and regulations and use a mobile field computer into the inspection system for coal waste impoundments. The inspection template was constructed using paper forms presently used by MSHA and the West Virginia Water Research Institute and iterated after conducting a number of field trials. Throughout the duration of conducting field trials, many new features were created such as the inclusion photos with corresponding GPS coordinates as well as a means of recording the entire path the inspector travels while inspecting. Some features were also amended to include more text fields which will allow the inspector to comment on problems as they arise in the field instead of commenting on all problems on one part of the inspection form. A method was developed for saving the inspection file and exporting it to supplementary software for obtaining a finalized output report, which automatically populates based on the inspection information available in the file.

Overall, the procedure developed with the technology and software met the tasks within the scope of the investigation. The benefits of this mobile field computer include the ability to store more information for a field inspection including geotagged photos and expedite the inspection process by providing a resource for email and automated data storage. Utilizing the mobile field computer for impoundment inspection will improve the quality of the inspection practice as well because the information can be time stamped, which will show the time duration spent on each portion of the dam. Time stamping can be employed as a method of guaranteeing that the inspection is performed correctly and more importantly, may persuade inspectors to be more thorough in their practice. The automated inspection form will improve the coal impoundment inspection practice and the overall safety rating of coal impoundments because of its improved ability to foresee potential hazards. Further analysis of this technology to include a more refined procedure as well as a means to meet the federal requirement of obtaining mine official signatures should be considered for industrial preparation. 


\section{ACKNOWLEDGEMENTS}

The author would like to thank all the people who committed their time and effort to the success of this health and safety improvement investigation. Persons of particular importance include Dr. John Quaranta for serving as the P.I. and advisor, Melissa O'Neal for contributing her time to help with software issues and compiling the final report, and York Grow of Earth Vector Systems, Charlottesville, VA, for all of his technical support. The author would also like to thank Dr. Leslie Hopkinson and Dr. Hema Siriwardane for serving as committee members. Without the help of these individuals, this investigation would not have been successful.

In addition to his colleagues, the author would like to extend his gratitude to the Department of Civil and Environmental Engineering and the Water Research Institute at West Virginia University for taking on the responsibility of this project. The research discussed throughout this dissertation was funded by Wheeling Jesuit University, Wheeling, WV. 


\section{TABLE OF CONTENTS}

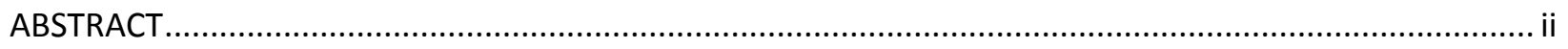

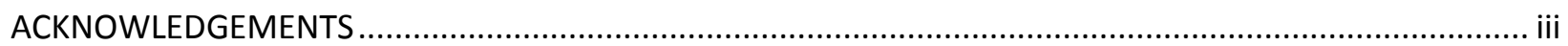

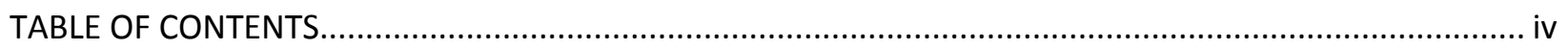

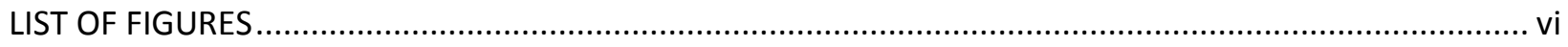

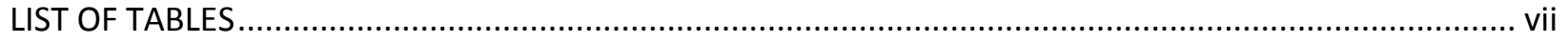

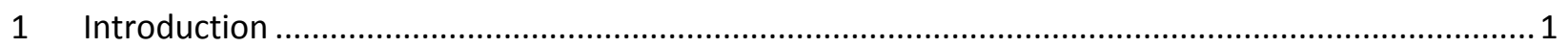

1.1 Promulgation of Coal Waste Impoundment Inspection ....................................................... 1

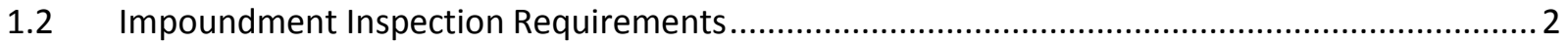

1.3 Terms and Conditions Related to a Routine Coal Impoundment Inspection ............................. 3

1.4 How the Inspection Form is Evaluated and Used ............................................................. 5

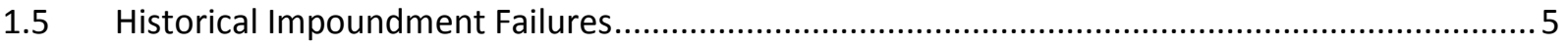

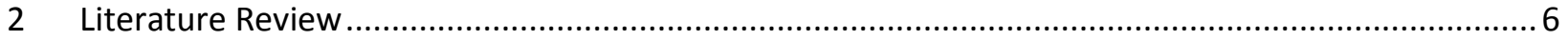

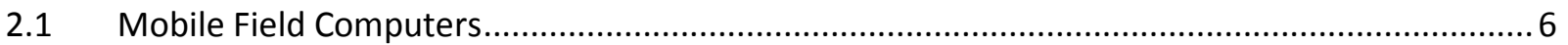

2.2 Terrasync/Pathfinder Office Software Evaluation ............................................................ 12

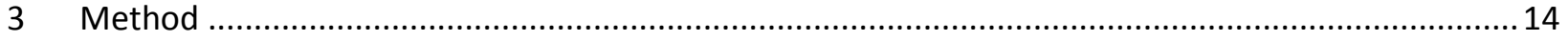

3.1 Microsoft Excel Electronic Inspection Form ..................................................................... 14

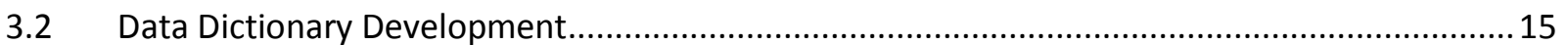

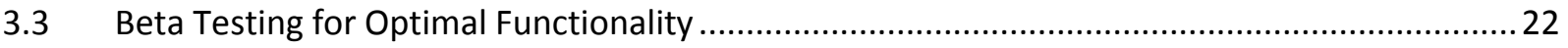

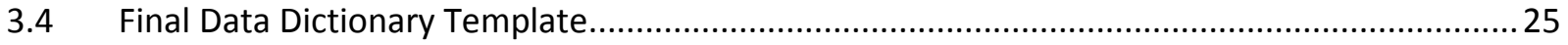

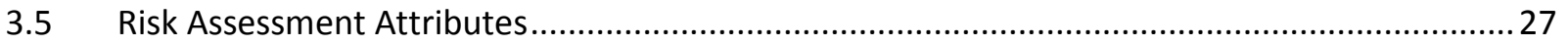

3.6 Using the Yuma in the Field/Uploading in the Office ..........................................................2 29

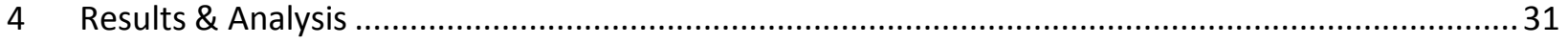

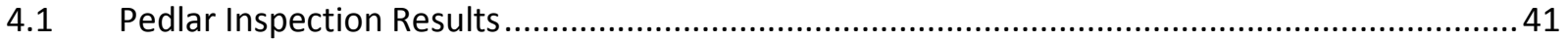

4.1.1 Pedlar Inspections over Aerial Imagery ....................................................................... 42

4.1.2 Differential Correction Report ..................................................................................... 45

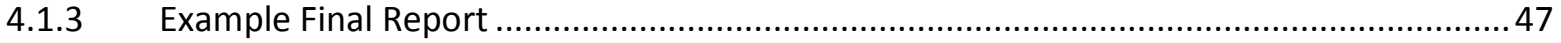

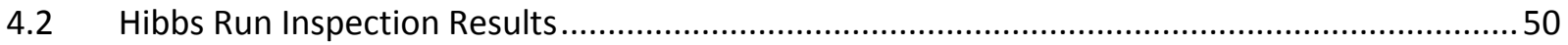

4.2.1 Hibbs Run Inspections over Aerial Imagery …............................................................... 50

4.2.2 Differential Correction Report ….............................................................................. 53 


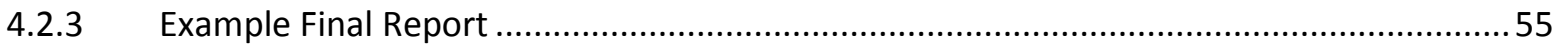

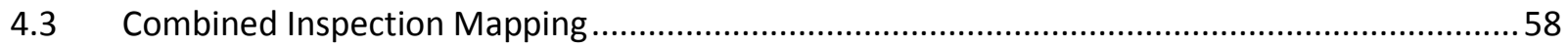

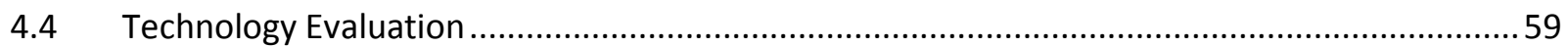

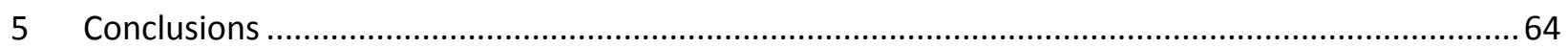

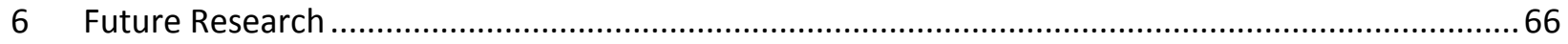

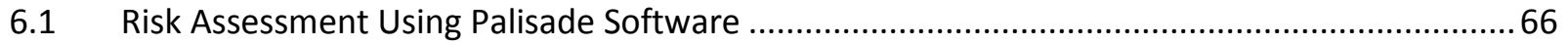

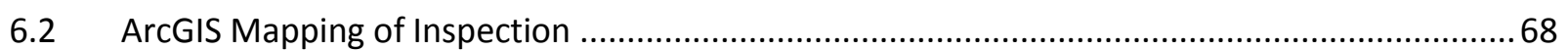

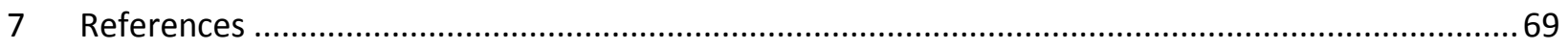

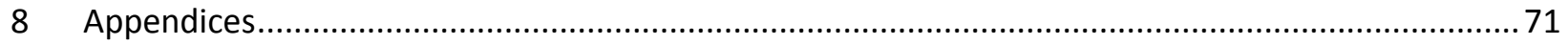

8.1 Inspection Template Created Using Microsoft Excel ............................................................ 71

$8.2 \quad$ Hyperlinked Form Created with Microsoft Excel ................................................................... 73

8.3 Example Access Database of Hibbs Run - Inspection 3 …................................................. 78 


\section{LIST OF FIGURES}

1. General information feature and coinciding attributes. 15

2. Minimum position setting on point feature. 16

3. Data dictionary dropdown menu. 17

4. Text attribute with set character length. 17

5. Attributes for additional photos/comments. 18

6. Auto-generated time attribute. 19

7. Screen shot of template in Trimble Terrasync. 20

8. Conditional setting for describing erosion based on answer that erosion is present. 21

9. Illustration of conditional attributes appearing after answer was provided that trash racks are not clear and open. 28

10. Flow chart showing basic electronic data collection process. 30

11. Differential Correction Wizard showing Uniontown, PA CORS station. 33

12. Changing of world imagery coordinate system in ArcGIS to match recorded inspection routes. $\quad 34$

13. Export of imagery map from ArcGIS with world file for use in Pathfinder Office. 35

14. Adding imagery map into Pathfinder Office as background file. 36

15. Use of Pathfinder Office export utility to create Access database for inspection. 37

16. Use of Access export utility to create excel file for inspection. 38

17. Complexity of inspection information used for output report. 39

18. Output report template tab inserted into inspection excel file. 40

19. Pedlar1 inspection mapped over aerial imagery. $\quad 42$

20. Pedlar2 inspection mapped over aerial imagery. 43

21. Pedlar3 inspection mapped over aerial imagery. $\quad 44$

22. Page 1 of example populated output report for Pedlar inspection. 48

23. Page 2 of example populated output report for Pedlar inspection. 49

24. HibbsRun1 inspection mapped over aerial imagery. 50

25. HibbsRun2 inspection mapped over aerial imagery. 51

26. HibbsRun3 inspection mapped over aerial imagery. 52

27. Page 1 of example populated output report for Hibbs Run inspection. 56 
28. Page 2 of example populated output report for Hibbs Run inspection.

29. Combined map of Pedlar inspections over aerial imagery.

30. Combined map of Hibbs Run inspections over aerial imagery.

31. Evaluation form regarding technology and inspection process.

32. Evaluation form regarding technology and inspection process.

\section{LIST OF TABLES}

1. Comparison of Selected Field Computers Based on Physical Characteristics

$10-11$ \& Key Features in Subtask 3.2. 


\section{Introduction}

Coal waste impoundments are a critical part of any underground and surface mining operations. Impoundments are used for water supply and treatment, sediment control, and the precipitation and disposal of fine coal waste, which is known as slurry in the mining industry (U.S. Department of Labor 2007). Inspection is important to the life of the coal impoundment, the health of the natural habitat surrounding the site, and most importantly, the safety of the human resources on the site. Any problem related to an impoundment that is left unattended can cause a massive release of slurry, resulting in probable damage to wildlife and property as well the potential for loss of life.

\subsection{Promulgation of Coal Waste Impoundment Inspection}

The inspection of coal waste impoundments is required by the Federal Mine Safety and Health Act of 1977 (Public Law 91-173). Section 103(a) of the Act set many of the initial rules and regulations for mine inspections and investigations and is shown below.

SEC. 103. (a) Authorized representatives of the Secretary or the Secretary of Health, Education, and Welfare shall make frequent inspections and investigations in coal or other mines each year for the purpose of (1) obtaining, utilizing, and disseminating information relating to health and safety conditions, the causes of accidents, and the causes of diseases and physical impairments originating in such mines, (2) gathering information with respect to mandatory health or safety standards, (3) determining whether an imminent danger exists, and (4) determining whether there is compliance with the mandatory health or safety standards or with any citation, order, or decision issued under this title or other requirements of this Act. In carrying out the requirements of this subsection, no advance notice of an inspection shall be provided to any person, except that in carrying out the requirements of clauses (1) and (2) of this subsection, the Secretary of Health, Education, and Welfare may give advance notice of inspections. In carrying out the requirements of clauses (3) and (4) of this subsection, the Secretary shall make inspections of each underground coal or other mine in its entirety at least four times a year, and of each surface coal or other mine in its entirety at least two times a year. The Secretary shall develop guidelines for additional inspections of mines based on criteria including, but not limited to, the hazards found in mines subject to this Act, and his experience under this Act and other health and safety laws. For the purpose of making any inspection or investigation under this Act, the Secretary, or the Secretary of Health, Education, and Welfare, with respect to fulfilling his responsibilities under this Act, or any authorized representative of the Secretary or the Secretary of Health, Education, and Welfare, shall have a right of entry to, upon, or through any coal or other mine.

In essence, the purpose of inspection is for obtaining information related to health and safety conditions, gathering information with respect to health and safety standards, determining whether any 
dangers exist, and determining whether there is compliance with the mandatory health and safety standards issued in the Act (United States Department of Labor 1977).

Binder (2002) explains that negligence law and the duty of reasonable care, when applied to dam safety, extends to those injured by negligence, and that even inspectors may be liable for negligence for failure to discover problems. Negligence liability consists of a failure to exercise reasonable care to either prevent or minimize foreseeable risks. Binder (2002) indicates that negligence could develop from poor training, lack of employee experience, and ignorance of plans. Field inspection of dams is designed to prevent accidents (Binder 2002).

\subsection{Impoundment Inspection Requirements}

After the Federal Mine Safety and Health Act of 1977 (Mine Act) came the creation of the Mine Safety and Health Administration (MSHA) in 1978. The following mission statement for MSHA is primarily to enforce the Mine Act and to reduce and eliminate all types of health and safety hazards:

The mission of the Mine Safety and Health Administration (MSHA) is to administer the provisions of the Federal Mine Safety and Health Act of 1977 (Mine Act), as amended by the Mine Improvement and New Emergency Response Act of 2006 (MINER Act), and to enforce compliance with mandatory safety and health standards as a means to eliminate fatal accidents; to reduce the frequency and severity of nonfatal accidents; to minimize health hazards; and to promote improved safety and health conditions in the Nation's mines.

The Mine Safety and Health Administration has since shaped the mine industry by creating important safety procedures for inspection and operation. MSHA now provides inspection procedures and frequencies for dam inspection as well as an Impoundment Inspection Form (U.S. Department of Labor 2007)for keeping records of the performed inspections. Guidelines are made available for dealing with the hazard-potential classifications and abandonment of coal waste impoundments. In addition, the Mine Safety and Health Administration produced many types of training programs to qualify individuals for performing tasks associated with mine safety.

The Coal Mine Safety and Health (CMS\&H) Administrator, appointed to do so under the Assistant Secretary for MSHA, has the main responsibility over enforcing the Mine Act and employing regulations as they apply to coal mining operations. There are inspectors, specialists, and supervisors who share the responsibility by conducting thorough inspections of coal waste impoundments on underground and surface mine sites. CMS\&H District Managers have the responsibility of making sure the inspections are 
performed routinely and guaranteeing that design plans have been reviewed and approved/disapproved (U.S. Department of Labor 2007). For the scope of this assessment, impoundment specialist and inspector duties have been further reviewed and explained.

There are two typical inspections performed by MSHA personnel on any active underground or surface mine site having coal waste impoundments. The first type of inspection is most frequently known as the complete safety and health, or the regular inspection, which must be fully documented on the inspection form at the time of the inspection. The form includes a precise checklist of the most important inspection criteria for a coal impoundment. The pre-inspection preparation primarily consists of a review of the Uniform Mine File, a sheet with basic impoundment plan requirements, to gain knowledge of what should to be taken into account throughout the inspection (U.S. Department of Labor 2007). The inspector will perform his duties by following the criteria supplied on the impoundment inspection form and report his findings.

The MSHA impoundment specialist performs duties very similar to that of a normal safety and health inspector who evaluates the site conditions for hazards and signs of instability; however, his or her work will be performed in greater detail. The impoundment specialist completes the Impoundment Inspection Form but does not limit him/herself to the space available because a specialist will more than likely have more characteristics to consider than what is provided on the simplified inspection form. The specialist also has the duty of communicating with equipment operators and other personnel working on site, as they are a good source of information for construction problems and modifications made to the initial design plan for the coal waste impoundment. When construction is taking place throughout multiple work day shifts, it is recommended that inspections are performed on alternate shifts so that the specialist may have contact with all construction personnel. One additional responsibility that the impoundment specialist has is to photograph any potentially unusual or hazardous site conditions or any components that are soon to be covered or filled, such as a foundation or internal drain (U.S. Department of Labor 2007).

\subsection{Terms and Conditions Related to a Routine Coal Impoundment Inspection}

Coal waste impoundment inspection involves traveling to the site of a coal refuse containment dam and evaluating it for potential failure modes based on its physical properties. After identifying these potential failure modes, a screening is performed to uncover and disregard those modes that are 
improbable for occurring onsite and clearly non-credible. A risk analysis is then performed to classify each failure mode as a low, significant, or high hazard characteristic (U.S. Department of the Interior 2010). A high hazard potential is assigned to impoundments where failure will most likely result in a loss of human life. A significant hazard potential is used to describe an impoundment that almost certainly poses no risk to human life; however, economic loss, environmental damage, and disruption of support facilities can occur. Low hazard potential impoundments carry no probable loss of life and very low economic or environmental damage (U.S. Department of Labor 2007).

The hazard potential classification is used not for the present condition of the dam, but for the engineering criteria for designing the impoundment. As the potential for loss of life and property damage increases, the criteria used to design the impoundment becomes more stringent. An example presented in the MSHA Handbook for 2007 notes that a high hazard potential impoundment is designed with sufficient spillway-discharge capacity and storage capacity to handle runoff from a maximum flood without allowing the embankment to be overtopped, whereas impoundments with lower hazard potential are designed for smaller amounts of rainfall. The hazard potential criteria are also included on the coal impoundment inspection form provided by MSHA so that the inspector is able to take the hazard potential classification into account during a routine inspection. Following the inspection, adjustments to the potential classification may need to be made so that it remains applicable to the coal impoundment.

Chapter $2 \S 2 a$ of the 2007 U.S Department of Labor MSHA Handbook provides regular guidelines to follow for the frequency for coal impoundment inspection. In this section, it is stated that any impoundment associated with active underground mines should be inspected at least once every quarter during the routine safety and health inspection. For an impoundment on the site of an active surface mine, an inspection should occur every six months during the time of a typical safety/health inspection. For surface or underground mine impoundments that possess a high hazard potential, an inspection should take place every quarter and be performed by an impoundment specialist. Moreover, high hazard potential impoundments experiencing periods of considerable rainfall, snowmelt, or any type of seismic activity should see an increased number of inspections during those periods. For a surface mine impoundment holding a significant hazard status, an inspection performed by an impoundment specialist is recommended every six months; however, for an impoundment on an underground mine site with the same hazard potential, quarterly inspections are required, two of which must be performed by an impoundment specialist (U.S. Department of Labor 2007). 


\subsection{How the Inspection Form is Evaluated and Used}

After the impoundment has been inspected, the inspector must follow some procedures required by state and federal regulations for correct handling of the impoundment inspection form. Foremost, the form must be countersigned by a mine foreman, superintendant or assistant superintendant, or a person designated to take responsibility for health and safety. West Virginia State Code 38CSR2, Part 22.7.b. states that the qualified professional engineer shall promptly provide a certified report that the impoundment has been constructed and maintained according to the approved plan. The document must also report any appearances of instability, structural weakness, or other potential hazard. The depths and elevations of impoundment waters, monitoring procedures and instrumentation, and any structural aspects that could affect the stability of the dam must be reported as well. These requirements originate from Federal Code 30CFR §77.216-3.

\subsection{Historical Impoundment Failures}

The most catastrophic coal waste impoundment failure occurred in Logan County, West Virginia at the Buffalo Creek Mine. On February 26, 1972, about 132 million gallons of coal waste water rushed through Buffalo Creek Hollow, killing 125 and injuring about 1100. Roughly 1000 homes were destroyed leaving 4000 homeless (West Virginia Division of Culture and History 2010). The disaster changed the way that the public saw coal waste impoundments and initiated the creation of the Mine Safety and Health Administration as well as coal mine impoundment inspection.

One of the largest scale tragedies took place in Martin County, Kentucky, where on October 11, 2000, a 72-acre surface impoundment containing coal waste ruptured, spilling about 309 million gallons into an adjacent mine opening. The coal slurry then flowed through the mine, emptying into neighboring water bodies and contaminating local drinking water; however, the impoundment failure fortunately resulted in no loss of life (National Research Council 2002). Nonetheless, this particular mine disaster had a substantial effect on the way impoundments are inspected in the twenty-first century.

Congress appointed the National Research Council to detect new methods of inspecting impoundments so that these types of incidents do not occur in the future. The NRC assigned members to a committee, which had three major entities to investigate. The committee first studied the engineering design standards and practices used at the time so that they could consider new alternatives for the evaluation, improvement, and monitoring of coal waste impoundments. The National Research Council committee 
also checked the accuracy of the mine mapping and evaluated more accurate ways to observe how underground mines can affect coal waste impoundments. The last task the committee was given involved more conservative procedures for underground mining to reduce the amount of coal slurry. The options included more productive use of the waste and safer disposal options (National Research Council 2002).

The most recent sludge spill internationally occurred on October 8, 2010 in Hungary, where nearly 200 million gallons of red sludge made its way to the Danube River, killing eight and injuring hundreds. The impoundment was on the site of an alumina plant, which converts bauxite into alumina for the manufacturing of aluminum. The managing director of the company was blamed for the resulting injuries because of his failure to prepare emergency warning and rescue plans in the case of an impoundment breach (Bilefsky 2010). This recent failure to foresee warning signs of an impoundment failure in addition to prepare and distribute emergency action plans is sufficient evidence that improved inspection practice is necessary not only in the United States, but in other countries as well.

\section{Literature Review}

\subsection{Mobile Field Computers}

A literature review was performed to determine the best suited mobile field computer and software that may be integrated and used for coal impoundment inspection. A mobile field computer, considered here, is a hand-held device designed to withstand rugged use such as rain, dust, and high impacts. Six select mobile field computers were examined to assess their application for use during routine coal impoundment inspection. The six field computers evaluated are listed below:

- Motion F5v (Motion Computing Inc. 2010)

- Intermec CN3e (Intermec Technologies Corp. 2009)

- Intermec CS40 (Intermec Technologies Corp. 2010)

- Trimble Ranger (Trimble Navigation Limited 2005 2005-2009)

- Trimble Yuma (Trimble Navigation Limited 2009 2009-2010)

- Panasonic U1 Ultra Toughbook (Panasonic Corp. 2010) 
The selected mobile field computers were compared for critical features using the checklist discussed in Table 1. It was discovered that most field computers are equipped with normal Windows operating systems and are capable of uploading and storing data as well as emailing and navigating via Global Positioning Systems. The most suitable mobile computers for coal mine impoundment inspection were reviewed and compared based on the following criteria:

- Electronic based check-listing software with a standard or custom template that must be completed during routine field inspections

- GPS for georeferencing field observations and geotagging photographs

- Tracking of field observations over time as well as time stamped data to guarantee time of field inspection

- Input areas for data storage and graphing so field data may be compared over time to evaluate impoundment performance

- Ability to upload data to office computer for storage and printing

- Field computer is already in use by government or industry and has proven itself in the field

- Ability to email alerts or text message MSHA District Engineer or Tech Support for assessment of information more rapidly

- Ability to upload and store MSHA Inspection Manual and Emergency Action Plan (EAP) for ease of access

- Ability of software program to mark fields and alarm the inspector of any missing information (equipment should be equipped with speaker for ability to alert inspector by sound)

- Ability to load and store completed inspection reports

- Ability to record inspection path with GPS and store map of routine route traveled

After examining the required components for a coal mine impoundment inspection tool, a decision has to be made concerning which field computer best met the constraints. The first requirement for the equipment is that it must have electronic based check-listing software with a template to be completed during each routine inspection. For any piece of equipment with a Windows operating system, the ability to upload software is nearly endless. The Motion F5v, Trimble Yuma, and Panasonic U1 Toughbook each come with Windows 7 Professional, a full Windows operating system capable of uploading and running any software. 
Time stamping data and tracking observations over time are more dependent on the software than the mobile field computer itself, however, any Excel file created will be time stamped with the "last modified" title. Therefore, the F5v, Yuma, and Toughbook were the best suited field computers because of their ability to run Microsoft Office. Microsoft Excel has the additional potential of creating a cell that time stamps data as it is altered. As a result, any field computer running Microsoft Excel on Windows 7 Pro had two potential resources for time stamping data in the field.

Pertaining to data storage and graphing, the three viable field computers previously mentioned would provide the best practical results. All six potential field computers are capable of storing data; however, the field computers with Windows 7 Pro and Microsoft Office have the ability to store inspection data and reports as Excel and/or Word files and may be opened in the field at any time for ease of access. Since the Palisade software uses Excel as a database, it is very talented at graphing results and comparing to historical data. In addition to storing and graphing data, the Motion F5v, Trimble Yuma, and Panasonic Toughbook all have the means of storing the MSHA Inspection Manual as well as the Emergency Action Plan for any mine site. These documents can then be opened up as PDF files by the Adobe Reader add-on to Windows 7 Pro.

As well as having the capacity to store data on its own solid state hard drive, the three most feasible pieces of equipment have the ability to connect to a desktop computer via USB or Bluetooth so that the data can be safely stored in the office. In addition, each piece of equipment has an express card slot so that a wireless $3 G$ or $4 G$ network may be used to email inspection reports to an MSHA District Office upon completion of a routine inspection. Having this amount of potential can account for an approximate time stamp as well as save time and possibly a failure. Text messaging would only be an option for the Intermec devices since they are the only field computers that have mobile phone features. The internet service in the field would work from a cellular phone network; on the other hand, only the two Intermec mobile computers have any form of cell phone feature.

An additional feature is the integration of a sound alarm to unmarked fields or pertinent information regarding a potential failure or problem. Besides alerting the inspector on screen, an audible alarm may follow to make sure the inspector is aware that an important feature has been missed, if the software and field computer can coincide to do so.

Regarding the GPS capability of the suitable equipment, every mobile computer is proficient at georeferencing locations and geotagging photographs during inspections. For mobile field computers 
with GPS capability, the average accuracy ranges from 2 -5 meters. The Trimble Ranger has better accuracy ( $1-3$ meters) because it is more suitable for GPS navigation and routing. In any instance, all of the evaluated field computers are able to georeference locations on site and geotag photographs of suspicious occurrences or possible failure modes.

Each field computer has field experience and has proven its durability in the course of many different applications and conditions. The Motion F5v has seen much experience with making route planning more efficient and eliminating the re-entering of data by automating inspection forms, both of which are germane to the intended purpose of the mine inspection field computer. The Intermec $\mathrm{CN} 3$ models were used to streamline data tracking and inspection processes by PBS\&J during the Hurricane Katrina recovery. The use of this piece of equipment helped homeless residents find new homes much quicker and increased the accuracy of the home search procedure to 90 percent. The Intermec CS40 has the best camera of the six field computers, and it has sufficient storage space as well as a compact lightweight structure; conversely, it is the least tolerable to harmful field conditions such as impact resistance. The Trimble Ranger has been available for years now and is the oldest of the field computers evaluated. The Ranger is popular among the surveying industry because of its size and capability in the field. Excluding the GPS accuracy, The Trimble Yuma has every feature of the Ranger and a few improvements as well. A few extra features of the Yuma include two cameras including video recording capability and a much larger memory for storage and loading. The last field computer examined was the Panasonic U1 Ultra, which is very similar to the Yuma vis-à-vis physical characteristics and overall qualifications to perform. 


\begin{tabular}{|c|c|c|c|c|c|c|}
\hline $\begin{array}{c}\text { Product } \\
\text { Specifications for } \\
\text { Physical Use }\end{array}$ & Motion F5v & Intermec CN3e & Intermec CS40 & Trimble Ranger & $\begin{array}{l}\text { Trimble } \\
\text { Yuma }\end{array}$ & $\begin{array}{l}\text { Panasonic U1 } \\
\text { Ultra }\end{array}$ \\
\hline $\begin{array}{l}\text { SPECIFICATION } \\
\text { DATABASE }\end{array}$ & $\begin{array}{l}\text { (Motion } \\
\text { Computing Inc. } \\
\text { 2010) }\end{array}$ & $\begin{array}{c}\text { (Intermec } \\
\text { Technologies } \\
\text { Corp. 2009) }\end{array}$ & $\begin{array}{c}\text { (Intermec } \\
\text { Technologies } \\
\text { Corp. 2010) }\end{array}$ & $\begin{array}{c}\text { (Trimble } \\
\text { Navigation } \\
\text { Limited 2005 } \\
\text { 2005-2009) }\end{array}$ & $\begin{array}{c}\text { (Trimble } \\
\text { Navigation } \\
\text { Limited 2009 } \\
\text { 2009-2010) }\end{array}$ & $\begin{array}{c}\text { (Panasonic Corp. } \\
\text { 2010) }\end{array}$ \\
\hline \multicolumn{7}{|l|}{$\begin{array}{c}\text { DURABILITY } \\
\text { CHARACTERISTICS }\end{array}$} \\
\hline DISPLAY SCREEN & $10.4^{\prime \prime}$ & $3.5^{\prime \prime}$ & $2.8^{\prime \prime}$ & $3.8^{\prime \prime}$ & 7" & $5.6^{\prime \prime}$ \\
\hline \multicolumn{7}{|l|}{ LED BACKLIGHT } \\
\hline \multicolumn{7}{|l|}{ TOUCH SCREEN } \\
\hline $\begin{array}{c}\text { SCREEN } \\
\text { PROTECTION }\end{array}$ & Gorilla Glass & & & & & \\
\hline WEIGHT & $3.3 \mathrm{lb}$ & $1.25 \mathrm{lb}$ & $.43 \mathrm{lb}$ & $2.1 \mathrm{lb}$ & $2.6 \mathrm{lb}$ & $2.3 \mathrm{lb}$ \\
\hline DIMENSIONS & $10^{\prime \prime} \times 10^{\prime \prime} \times .95^{\prime \prime}$ & $7.7^{\prime \prime} \times 3.2^{\prime \prime} \times 1.3^{\prime \prime}$ & $5.3^{\prime \prime} \times 2.5^{\prime \prime} \times .94^{\prime \prime}$ & $10.5^{\prime \prime} \times 5.2^{\prime \prime} \times 1.9^{\prime \prime}$ & $5.5^{\prime \prime} \times 9^{\prime \prime} \times 2^{\prime \prime}$ & $7.2^{\prime \prime} \times 5.9^{\prime \prime} \times 2.2^{\prime \prime}$ \\
\hline BATTERY LIFE & 4 hours & 14.8 hours & NA & 30 hours & 8 hours & 9 hours \\
\hline \multicolumn{7}{|l|}{$\begin{array}{l}\text { MEETS MIL-STD-810 } \\
\text { SPECS FOR IMPACT }\end{array}$} \\
\hline $\begin{array}{c}\text { WATER AND DUST } \\
\text { RESISTANCE }\end{array}$ & IP54 rated & IP64 rated & IP54 rated & IP67 rated & IP67 rated & IP65 rated \\
\hline \multicolumn{7}{|l|}{$\begin{array}{c}\text { COMMUNICATION } \\
\text { CAPABILITIES }\end{array}$} \\
\hline \multicolumn{7}{|l|}{ BLUETOOTH } \\
\hline \multicolumn{7}{|l|}{ WiFi } \\
\hline \multicolumn{7}{|l|}{ GPS } \\
\hline \multicolumn{7}{|l|}{$\begin{array}{l}\text { OPERATING SYSTEM } \\
\text { \& SOFTWARE }\end{array}$} \\
\hline OPERATING SYSTEM & Windows 7 Pro & $\begin{array}{c}\text { Windows Mobile } \\
5.0,6.1\end{array}$ & $\begin{array}{l}\text { Windows Mobile } \\
6.5\end{array}$ & $\begin{array}{c}\text { Windows Mobile } \\
5.0\end{array}$ & $\begin{array}{l}\text { Windows } 7 \\
\text { Pro }\end{array}$ & Windows 7 Pro \\
\hline $\begin{array}{l}\text { SYSTEM MEMORY } \\
\text { (RAM) }\end{array}$ & $1 \mathrm{~GB}-4 \mathrm{~GB}$ & $128 \mathrm{MB}$ & $256 \mathrm{MB}$ & $64 \mathrm{MB}$ & $1 \mathrm{~GB}$ & $2 \mathrm{~GB}$ \\
\hline $\begin{array}{l}\text { STORAGE } \\
\text { (SSD/HDD) }\end{array}$ & $\begin{array}{c}\text { 160GB HDD } \\
\text { 64-128GB SSD }\end{array}$ & $\begin{array}{l}2 \mathrm{~GB} \text { miniSD card } \\
\text { slot }\end{array}$ & $\begin{array}{l}\text { 32GB microSD } \\
\text { card slot }\end{array}$ & $256 \mathrm{MB}$ & $32 \mathrm{~GB} S S D$ & 64GB SSD \\
\hline $\begin{array}{l}\text { SD CARD, USB, OR } \\
\text { SMARTCARD }\end{array}$ & $\begin{array}{c}\text { USB \& } \\
\text { SmartCard }\end{array}$ & $\operatorname{miniSD}$ & microSD & SD slot & SD slot & $\begin{array}{l}\text { SD slot \& } \\
\text { SmartCard }\end{array}$ \\
\hline \multicolumn{7}{|l|}{ Adobe Reader } \\
\hline \multicolumn{7}{|l|}{ ACCESSORIES } \\
\hline $\begin{array}{l}\text { INTEGRATED } \\
\text { CAMERA }\end{array}$ & $\begin{array}{l}\text { 3.0MP rear- } \\
\text { facing }\end{array}$ & 2.0MP w/flash & $3.2 \mathrm{MP} w /$ flash & & $\begin{array}{l}\text { 2.0MP outer } \\
\text { 1.3MP inner } \\
\text { (vids \& pics) } \\
\end{array}$ & $\begin{array}{l}\text { 2.0MP with dual } \\
\text { LED light }\end{array}$ \\
\hline \multicolumn{7}{|l|}{$\begin{array}{l}\text { INTEGRATED } \\
\text { SPEAKER }\end{array}$} \\
\hline \multicolumn{7}{|l|}{ MICROPHONE } \\
\hline SECURITY & $\begin{array}{l}\text { fingerprint } \\
\text { reader }\end{array}$ & NA & NA & $\begin{array}{l}\text { passcode } \\
\text { protection }\end{array}$ & $\begin{array}{l}\text { passcode } \\
\text { protection }\end{array}$ & $\begin{array}{c}\text { fingerprint } \\
\text { reader/passcode } \\
\text { protection }\end{array}$ \\
\hline Product Capabilities & Motion F5v & Intermec CN3e & Intermec CS40 & Trimble Ranger & Trimble & Panasonic U1 \\
\hline
\end{tabular}




\begin{tabular}{|c|c|c|c|c|c|c|}
\hline for Scope of Work & & & & & Yuma & Ultra \\
\hline $\begin{array}{l}\text { SPECIFICATION } \\
\text { DATABASE }\end{array}$ & $\begin{array}{l}\text { (Motion } \\
\text { Computing Inc. } \\
\text { 2010) }\end{array}$ & $\begin{array}{l}\text { (Intermec } \\
\text { Technologies } \\
\text { Corp. 2009) }\end{array}$ & $\begin{array}{l}\text { (Intermec } \\
\text { Technologies } \\
\text { Corp. 2010) }\end{array}$ & $\begin{array}{c}\text { (Trimble } \\
\text { Navigation } \\
\text { Limited 2005 } \\
\text { 2005-2009) }\end{array}$ & $\begin{array}{c}\text { (Trimble } \\
\text { Navigation } \\
\text { Limited 2009 } \\
\text { 2009-2010) }\end{array}$ & $\begin{array}{l}\text { (Panasonic Corp. } \\
\text { 2010) }\end{array}$ \\
\hline \multicolumn{7}{|l|}{$\begin{array}{l}\text { GEOREFERENCING } \\
\text { CAPABILITIES \& } \\
\text { COMMUNICATIONS }\end{array}$} \\
\hline \multicolumn{7}{|l|}{ GEOTAGGING } \\
\hline GPS SENSITIVITY & NA & NA & $10 \mathrm{~m}$ & $1-3 m$ & $2-5 m$ & $2-5 m$ \\
\hline ROUTE MAPPING & & NA & NA & & & \\
\hline \multicolumn{7}{|l|}{$\begin{array}{l}\text { RELAY OF REPORT BY } \\
\text { EMAIL }\end{array}$} \\
\hline \multicolumn{7}{|l|}{$\begin{array}{c}\text { MEMORY/UPLOAD } \\
\text { OPTIONS } \\
\end{array}$} \\
\hline \multicolumn{7}{|l|}{ STORING MANUALS } \\
\hline \multicolumn{7}{|l|}{$\begin{array}{c}\text { INSPECTION } \\
\text { TEMPLATE UPLOAD }\end{array}$} \\
\hline \multicolumn{7}{|l|}{$\begin{array}{l}\text { TIME STAMPED } \\
\text { DATA }\end{array}$} \\
\hline \multicolumn{7}{|l|}{$\begin{array}{l}\text { RISK/EVENT TREE } \\
\text { SOFTWARE UPLOAD }\end{array}$} \\
\hline \multicolumn{7}{|l|}{$\begin{array}{l}\text { EAP/MSHA MANUAL } \\
\text { UPLOAD }\end{array}$} \\
\hline \multicolumn{7}{|l|}{$\begin{array}{c}\text { HISTORICAL } \\
\text { INSPECTION } \\
\text { ARCHIVE } \\
\end{array}$} \\
\hline \multicolumn{7}{|l|}{$\begin{array}{l}\text { ABILITY TO GRAPH } \\
\text { NEW VS. OLD DATA }\end{array}$} \\
\hline \multicolumn{7}{|l|}{$\begin{array}{c}\text { UPLOAD TO OFFICE } \\
\text { COMPUTER TO } \\
\text { PRINT } \\
\end{array}$} \\
\hline ADOBE READER & & & & & & \\
\hline
\end{tabular}

Table 1: Comparison of Selected Field Computers Based on Physical Characteristics \& Key Features in Subtask 3.2

After examining all six mobile field computers based on the preceding criteria requested for performance, one emerged as the most suitable piece of equipment. The Trimble Yuma, because of its higher International Protection Rating against water as well as the ability to capture video, is the recommended mobile field computer for coal impoundment inspection. The IP67 rating of the Trimble Yuma establishes that it may be submerged in 1 meter of water for 30 minutes without penetration through the protective case. The IP65 rating does not include the verification for immersion in water, which may be an asset to inspecting a coal impoundment. The ability to capture video is another important benefit to the mine inspection tool because of the need for inspectors to view the 
construction process and the movement of water through the impoundment. Poor construction and internal pore pressure are two of the main hazards to impoundments, and having the ability to capture live feed of these two active events could save an impoundment before it fails completely. An additional feature of the Yuma is the presence of two cameras to make photography easier, and according to consumer reviews, the Yuma has better screen visualization in the sunlight. In view of these features only being available on the Trimble Yuma, it is recommended as the most beneficial mobile field computer to the purpose of making coal mine impoundments safer and increasing employee productivity.

\subsection{Terrasync/Pathfinder Office Software Evaluation}

The Trimble ${ }^{\circledR}$ Terrasync and Pathfinder software was evaluated based on features and relevance to performing a coal impoundment dam inspection. The Terrasync software is proficient at collecting Geologic Information Systems data when it is paired with a receiver and field computer, both of which are available for the purpose of this study. The software has the ability of integrating photos into the data collection by pairing with a Trimble device capable of taking pictures. The software also stamps each photo with the time, date, and geographic location at which the picture was taken. The photos can retain an accuracy up to 4 in. when the software is being used with a Trimble ProXH receiver (Trimble Navigation Limited 2011), a piece of equipment which will be available for the purpose of this research.

The software can also use data dictionaries previously created with the Trimble Pathfinder Office software, which is GIS structured. The data dictionary is a tool used by organizations for creating and customizing attributes which are related to geographical locations on a work site. The dictionary has the primary use of prompting the inspectors to enter specific information in the fields in the form, which ensures that all necessary data has been collected. The attribute values may be organized by using the structure of an electronic form. These data capture forms can store data entered by the user as well as geographical data and time-stamped geotagged photos. The data forms may be modified in many ways to ensure that they maximize worker productivity in addition to remaining user-friendly (Trimble Navigation Limited 2011).

Overall, the Terrasync software improves worker productivity and eliminates connection errors between devices. The software can be simply uploaded onto a paired Trimble field computer and GPS receiver for use in the field. The Pathfinder Office Software is vital for analyzing the collected data and verifying that it does not contain any errors or unwanted data. In addition to finding errors, coordinates and 
attributes may be edited to guarantee that only the suitable data is exported to the GIS (Trimble Navigation Limited 2011).

Terrasync and Pathfinder software has been used in the field for many applications including the mapping of hiking trails for the USACE and the redevelopment of New Orleans local surveys after Hurricane Katrina. Pathfinder Office was used after the devastating Hurricane Katrina for creating local maps because most were previously kept on paper only and lost in the water. Consequently, Pathfinder Office was used to create the data dictionary to be used in the field for collecting new data. An ArcGIS database was built so that all the mobile GPS units could share the same information and upload to the same location. According to some, the creation of the data dictionary was the crucial step in collecting the cultural resource data and increased productivity greatly throughout the project (Trimble Navigation Limited 2010).

Additionally, the West Virginia Water Research Institute and USACE relied on the Trimble software to assist in capturing data in the Dolly Sods Wilderness, an area used during World War II for explosives testing. Employees of the WVWRI and USACE performed a survey of the hiking trails in the Wilderness area because traveling away from the trails can be unsafe as there are UXOs (Unexploded Ordnance) in the region. A data dictionary for assessing the hiking trails, which included erosion conditions and trailside campsites, was created before traveling to the site. As the trails were mapped, photos were captured and stored via Terrasync. The project resulted in the creation of a new interactive map including trailside and campsite photos. The use of Terrasync as well as Pathfinder Office enhanced productivity by organizing attributes and GPS data for trails, campsites, and UXOs (West Virginia Water Research Institute 2010).

After thorough evaluation, the Terrasync software used in accordance with Trimble Pathfinder Office was chosen as the best fit tool for inspecting a coal impoundment. The software will be easier to use on the Trimble Yuma because of potential compatibility issues with software generated by other agencies. The Terrasync software will enhance the speed at which the routine coal impoundment inspection can be performed because it is skilled at creating seamless forms for data entry, and having the ability to capture photos with time-stamped location and attributes will prove essential throughout the process of an inspection. An even more vital skill possessed by Terrasync is the ability to sort and filter data imported from a GIS in chronological order, which will allow inspectors to create an inspection route from the data collected on site, thus eliminating a tedious step of the routine. The attribute data may be viewed as a list or distributed over a map with an imported aerial photo or satellite image in the 
background. Features may be edited in the Terrasync software during or after the inspection, increasing productivity and complication nonetheless. The use of Terrasync and Pathfinder Office will guarantee a better performance of inspecting a coal impoundment by eliminating painstaking steps of the coal impoundment inspection routine.

\section{Method}

\subsection{Microsoft Excel Electronic Inspection Form}

Upon the completion of an inspection form using Microsoft Excel (Appendices I \& II), it was concluded that all pertinent information could not be integrated accordingly. For the purpose of this study, it is necessary to have the ability of time stamping information/records in the field instantly and automatically. In addition to the time stamping issue, Microsoft Excel was unqualified regarding the automatic capturing of GPS coordinates. The use of hyperlinks in excel could have caused a problem as well because of the significance of the photo/video and GPS links on the form. Microsoft Excel did not have any means of confirming completion of the form before the departure by the inspector, which could pose a serious threat to the safety of the workers and the stability of the dam upon the failing to foresee imminent failures. By using a form created with Excel, the responsibility would fall on the inspector, thus requiring more time in the field to perform an inspection.

Following a meeting with York Grow of Earth Vector Systems in Charlottesville, Virginia, it was decided that a more capable technology was necessary for functioning as a coal waste impoundment inspection form. Trimble Terrasync software paired with Pathfinder Office was used for the creation of the inspection form because of its ability to record GPS coordinates, capture photos with quick links, and time stamp information automatically as well as its compatibility with the Trimble field computer. The Pathfinder software can be used in the office to generate a data dictionary with all of the required fields for an impoundment inspection. The dictionary may then be uploaded onto the Yuma and used in the field via the Terrasync software. The details of the inspection procedure using this software are explained under Section 3.4. Accordingly, the information from the excel inspection form was used to input fields into the Pathfinder Office data dictionary, and Terrasync was used for field inspection and mapping. 


\subsection{Data Dictionary Development}

Following the installation of Trimble's Pathfinder Office and Terrasync software programs, a data dictionary was created for use by the inspector in the field. The data dictionary contains all the necessary text fields for completing a routine coal impoundment inspection. A form created in Microsoft Excel (Appendices I and II) was used as a template for the electronic form later structured in Trimble Pathfinder Office software. The automated inspection process begins with the creation of a data dictionary using Pathfinder Office. The data dictionary serves as the template used with the Trimble Yuma in the field and consists of only features and attributes. Each feature in the data dictionary may serve as a portion of the coal impoundment. For example, crest, downstream toe, and piezometer could all be considered individual features because each portion of the impoundment has particular criteria to be evaluated during an inspection. Each feature may be set to record in the field as a point, line, or area. The concept of features and attributes may be viewed in Figure 1.

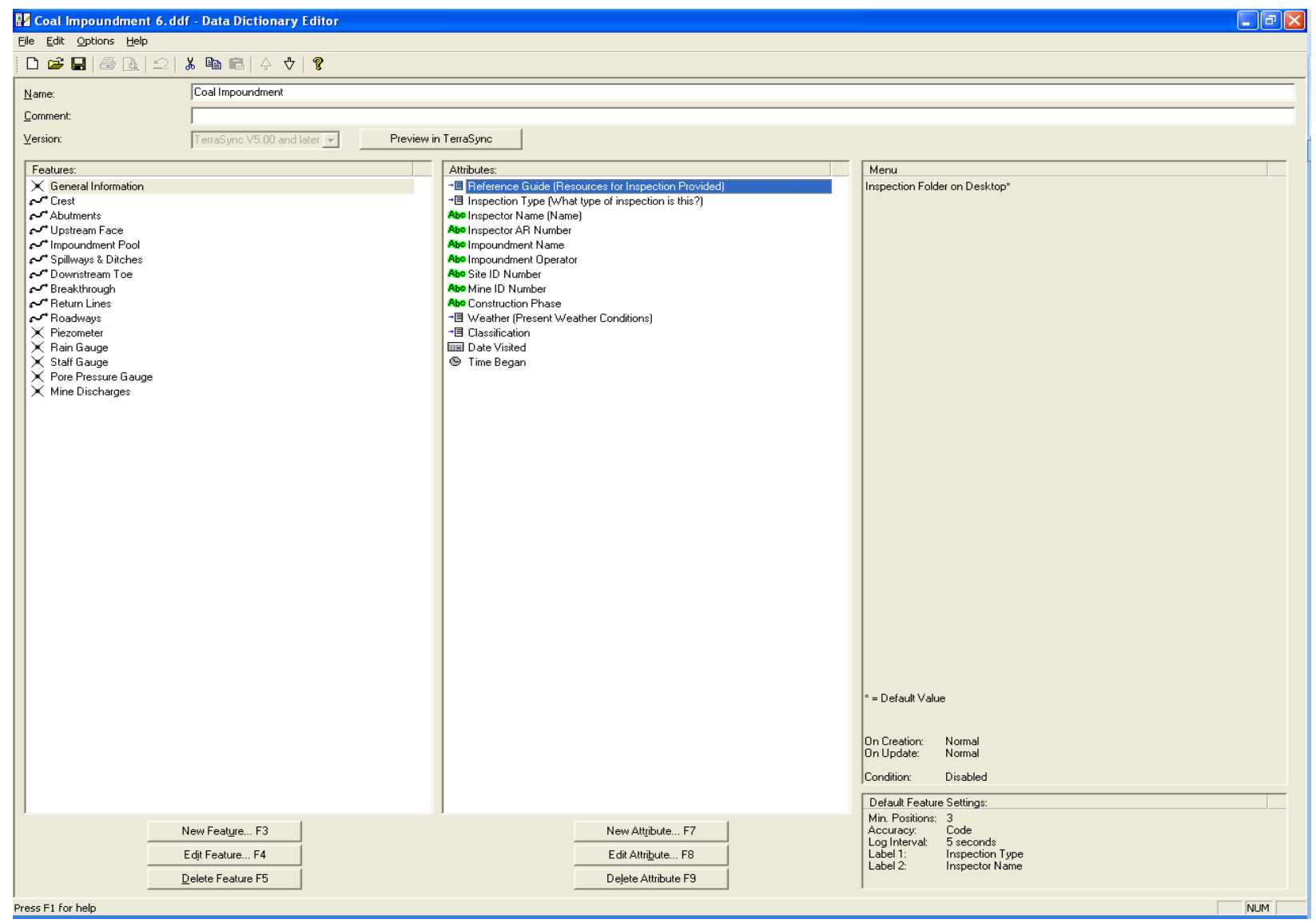

Figure 1: General Information feature and coinciding attributes. 
Point and line features were employed in the impoundment dictionary because using an area feature requires the inspector to make nearly a full loop in order to close a polygon and record an area. The use of an area feature is equally inappropriate because the main purpose of recording locations for each feature is to monitor the inspection route traveled as well as make it more efficient to locate potential hazards during maintenance. Most features were set to record as lines with a recording interval of five seconds while others, such as piezometers, pore pressure gauges, and mine discharges, were recorded as points with the same recording interval. An additional setting was enabled with point features however (Figure 2). The point features were required to contain a minimum of three recorded locations to improve accuracy by allowing Pathfinder Office to differentially correct the data back in the office. In fifteen short seconds, the three positions will be recorded; therefore, the inspection is not delayed because the inspector most definitely spends more than fifteen seconds recording the point IDs and numerical values for gauges and discharges.

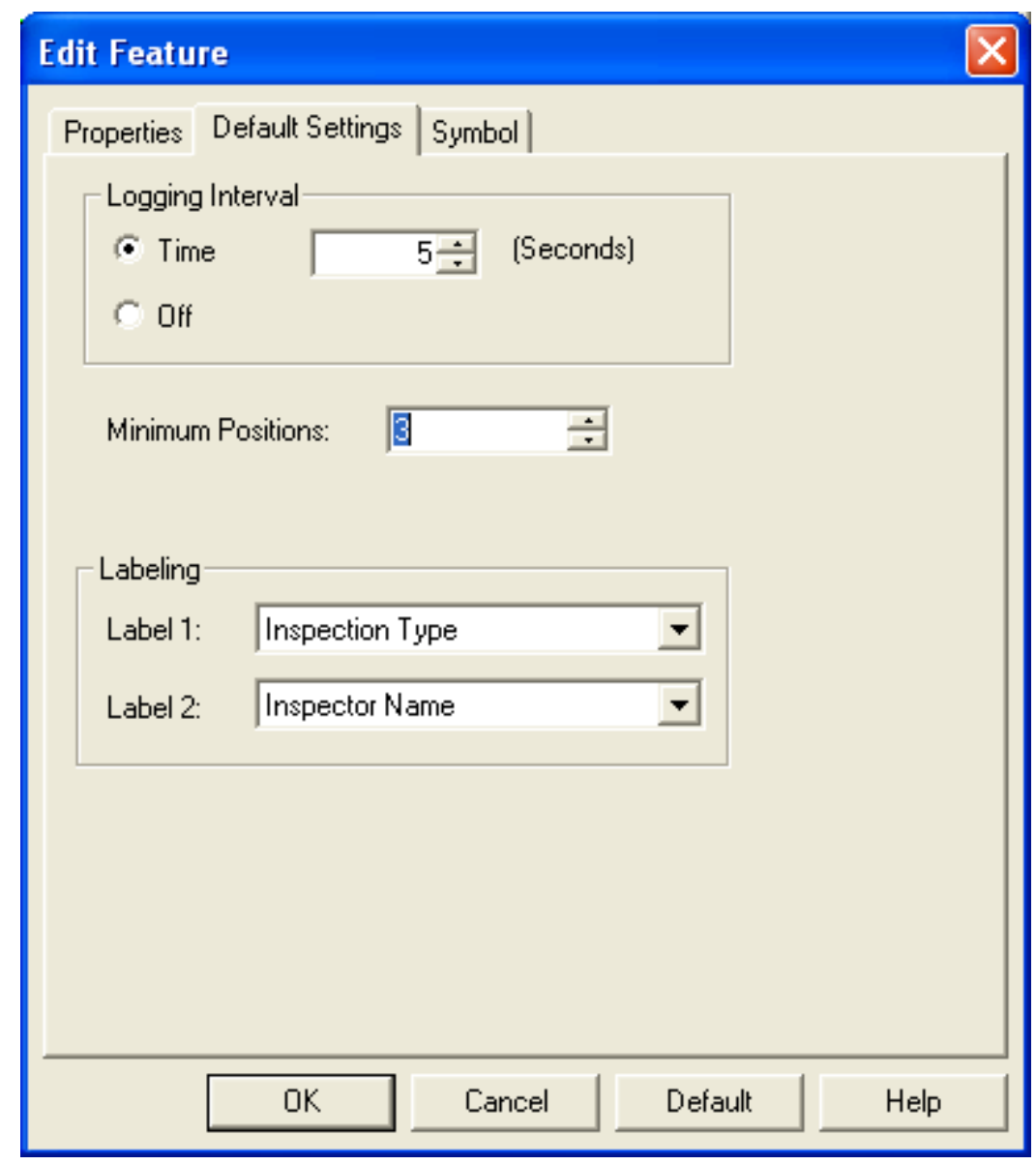

Figure 2: Minimum position setting on point feature. 
Under each feature lies a collection of attributes, which acts as the template for all questions pertaining to that feature. An attribute may appear as a dropdown menu for questions requiring a "yes" or "no" answer (Figure 3), or as a text or numerical field for questions that cannot be given a concise answer (Figure 4). For instance, a question asking to explain an observation such as erosion requires a text attribute because an explanation may not be picked from a menu. Similarly, gauge readings must be recorded as a numerical attribute because of the complexity of the values. The dropdown menus may have options created by the user, and the text and numerical fields may have a character limit set (Figure 4). The numerical fields may also have a predetermined range of values so that the inspector may not type a value outside of that range, which acts as an alert if the inspector is reading a gauge incorrectly.

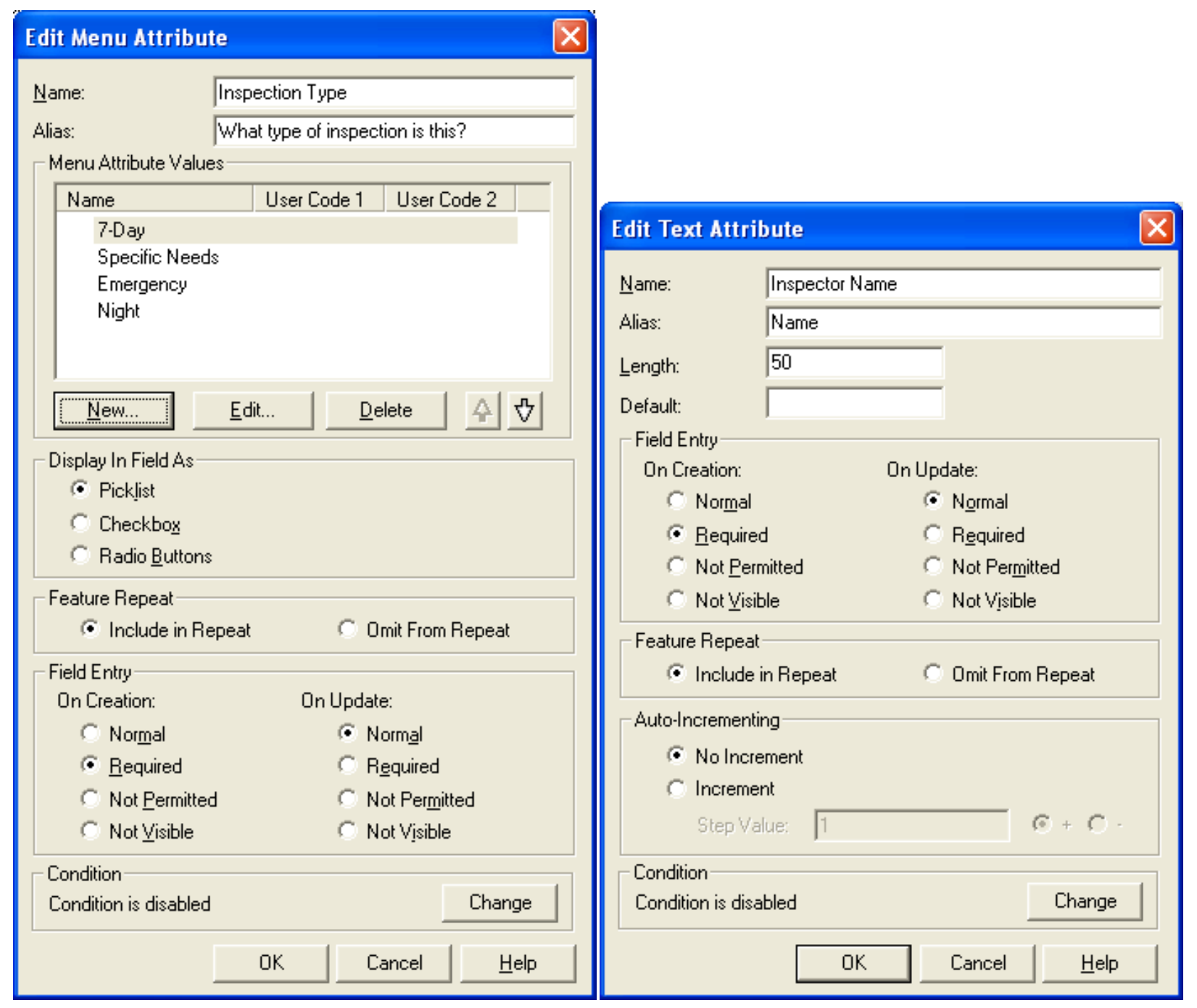

Figure 3: Data dictionary dropdown menu.

Figure 4: Text attribute with set character length. 
Photo links are part of the Pathfinder Office program for storing photographs as well as video with audio within the data file. When the links are selected in the field, the camera utility opens, allowing the user to capture a photograph. Within the camera utility, the option for capturing video is present. Taking advantage of this option allows the inspector to capture a video with an oral description of the observance or problem. Additional fields are provided as well for extra comments or additional photos (Figure 5).

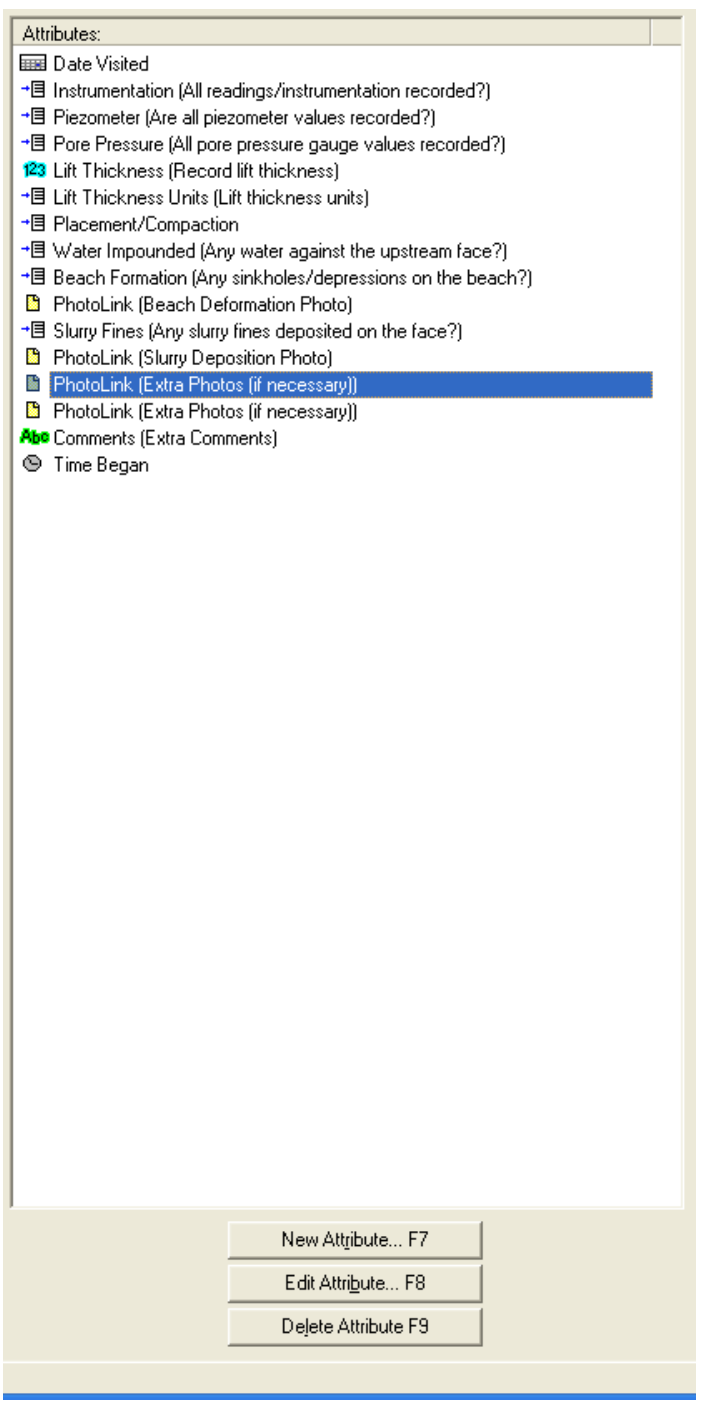

Figure 5: Attributes for additional photos/comments.

Time and date attributes may be appended to each feature for the purpose of data organization in the office and monitoring inspection practices (Figure 5). The time and date fields may be automatically generated and locked so that the inspector may not change them in the field (Figure 6). The use of 
automatic generation validates the date and time that each feature of the impoundment was inspected. Taking the difference between times allows the capability of showing how much time was spent inspecting each feature of the impoundment. Additionally, each five-second location recorded has a time affixed by the GPS unit; therefore, these data may be used for monitoring the time delay between ending one feature and beginning another to confirm the inspector is applying his time efficiently.

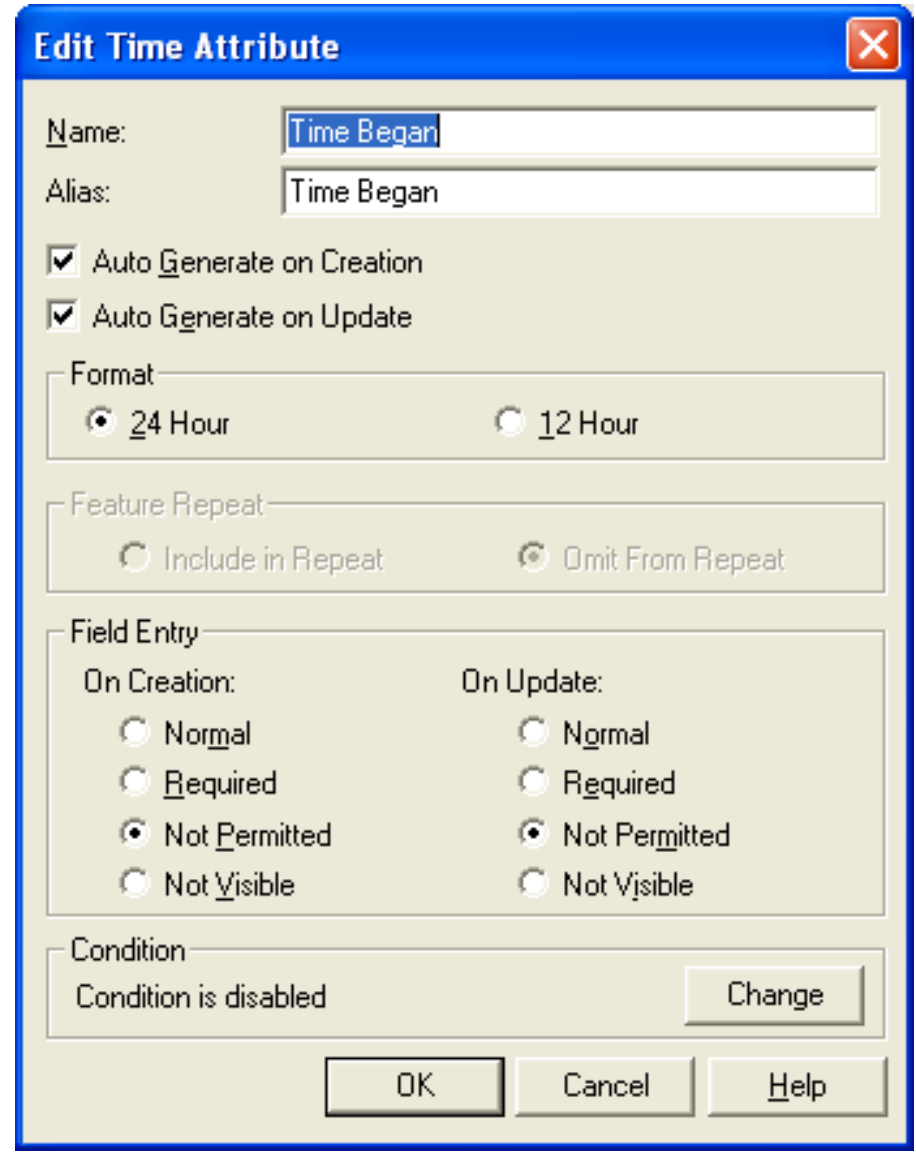

Figure 6: Auto-generated time attribute (notice field entry is not permitted).

Each feature and attribute in the data dictionary contains a field for a title as well as a description. The title is used primarily for the manipulation and organization of data in the office while the description of the feature is seen on-screen while performing an inspection. Only the description can be viewed in Trimble Terrasync, thus all pertinent information to each question must be portrayed in the description field so that it may be understood in the field. Figure 7 (below) demonstrates what the inspector sees on screen while performing a routine inspection. 


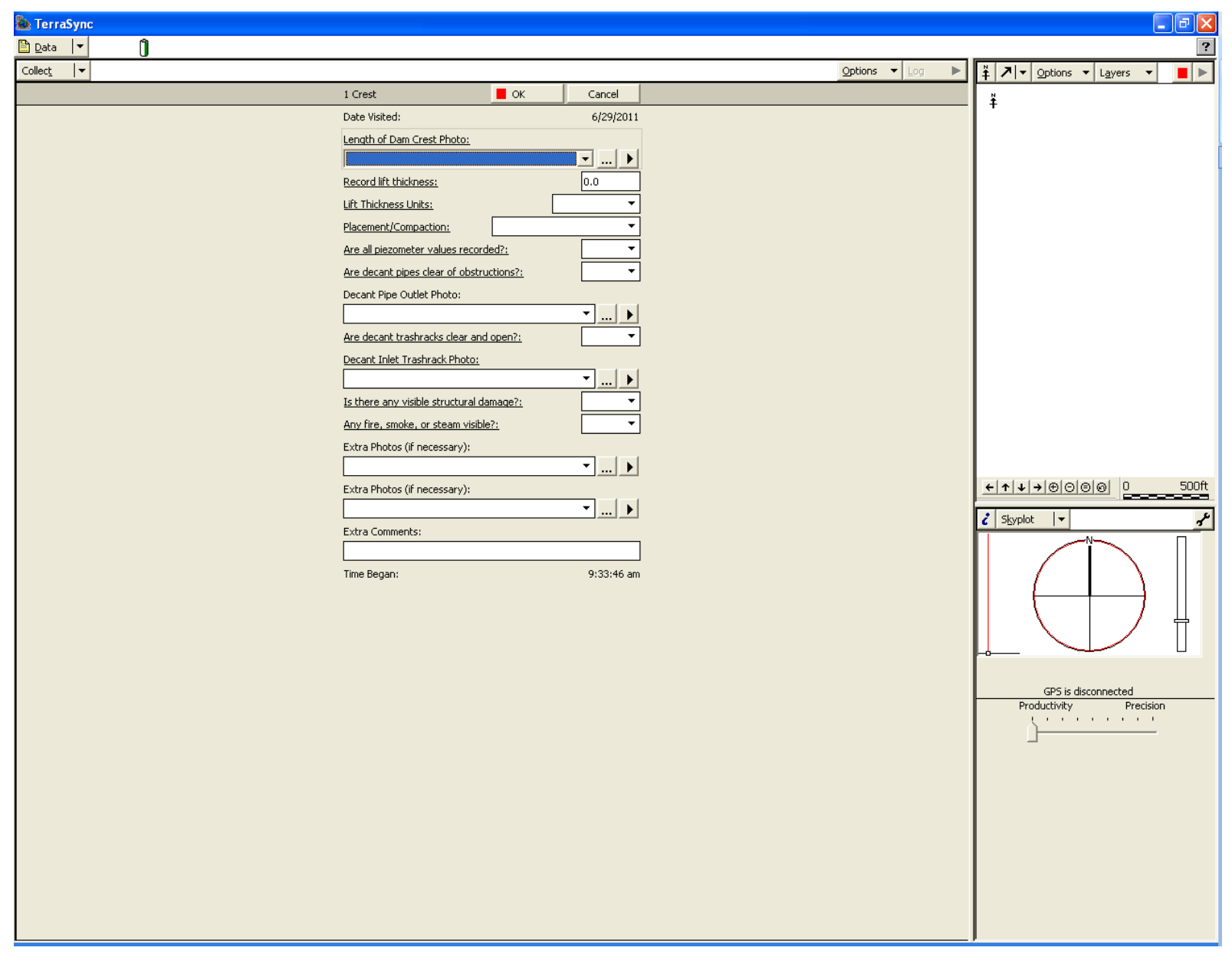

Figure 7: Screen shot of template in Trimble Terrasync.

Each attribute in the Pathfinder Office data dictionary contains settings related to security and conditional situations. Notice the field entry box in Figure 6. Attributes may be configured so that they are not permitted to receive an answer, such as the time and date stamp attributes. The time and date attributes are automatically generated; hence, the inspector does not have permission to alter them in any way. Each attribute may be set so that the inspector chooses to input an answer for the question. Attributes may be required instead, forcing the inspector to provide an answer in order to make sure he/she does not accidentally miss the question. Most attributes in the coal impoundment dictionary were created as required fields to ensure all questions are answered. There are some required attributes, however, that are not visible unless the inspector provides a particular answer to a question.

Some attributes may be set so that they are not visible unless another attribute is given a specific response. Notice the condition box in Figure 6. For example, if the inspector answers that there is erosion on a spillway of the impoundment, then he or she will be prompted to provide a description of 
where and what was observed. The inspector will also be prompted to take a photograph of the observance, which will contain matching coordinates. Conditional settings are used in the data dictionary utility to create questions that only pertain to specific situations. In the case of erosion, the description attribute contains a conditional setting, which can be selected so that the description attribute is only visible if the inspector provides that there is erosion (Figure 8). Any attribute following another may be set so that it only appears depending on the answer provided to the first.

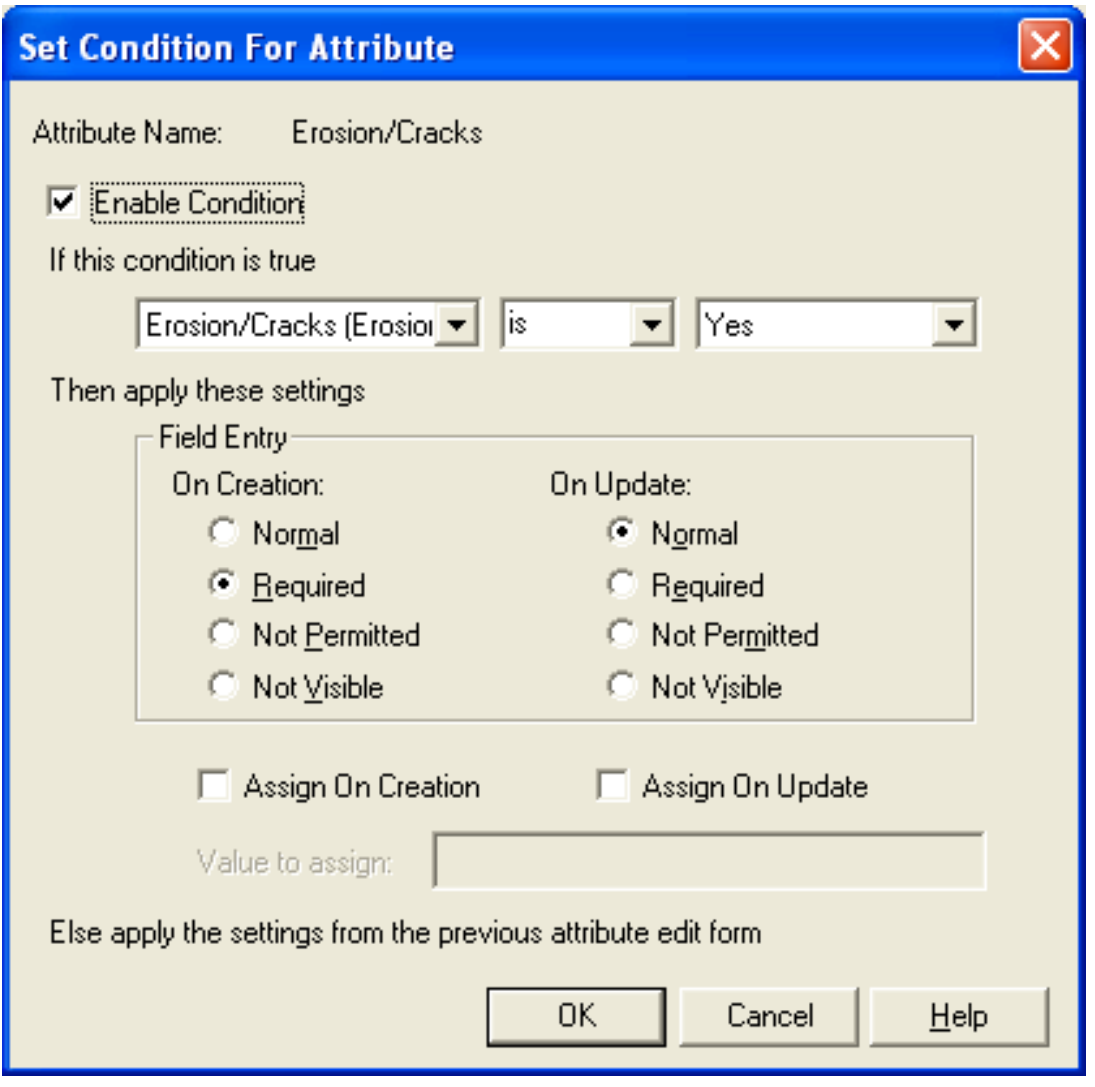

Figure 8: Conditional setting for describing erosion based on answer that erosion is present.

The second characteristic of the conditional attributes is that they may be required or optional similar to the primary attributes. This option was taken advantage off by not requiring all conditional fields because some photo links may be unnecessary. The option of taking a photo that is not required will be left at the discretion of the inspector. Most other conditional attributes not including the photo links are required nonetheless because they are important to risk assessment and reduction in error due to negligence.

All information provided on the inspection form was successfully conveyed using the Trimble Pathfinder Office software; therefore, a trial was necessary to examine the functionality of the equipment, 
especially concerning ease of use and ability to produce geotagged photos. The use of audio tags as well as GPS tagged photographs were also investigated to determine how they can be incorporated into the template.

\subsection{Beta Testing for Optimal Functionality}

A total of five field trials were performed as upset condition tests to evaluate the electronic inspection concept as well as the organization and functionality of the form. The first trial of the examination progressed into identifying a number of problems which helped to identify ways of improving the organization and method of opening/saving the data file. The data transfer utility made by Trimble was not employed for transferring the data dictionary from the desktop computer to the Trimble Yuma. Instead, the data dictionary was saved to a portable flash drive to be uploaded to the Yuma at a later point in time. The Terrasync program only recognizes the dictionary if it is placed in the designated folder for data dictionaries, which had an unknown location at the time.

When the field trial was to be conducted, the location of the designated Terrasync folder was unknown and as a result, the dictionary could not be sent to the correct location for use. This caused an issue later in the field because the data dictionary would not appear in the Terrasync program, which in turn would not allow the user to view any of the features or record any points via GPS. Without the ability to record any points or open the data dictionary to store information, the field trial was essentially terminated. The first field trial had the purpose of inspecting the ease of opening the data dictionary and ability of entering responses into generated fields. This trial was not complete, as it would be unnecessary to create an entire data dictionary if it were done incorrectly; therefore, only a few features were created with simple attributes under each feature.

Following the successful upset condition test of the first field trial, many improvements were made to the program to ensure better functionality in the field. More features were added to the data dictionary first since the opening/saving problem was identified as a failure to use the Trimble data transfer utility. For trial 2, photos were taken as well to demonstrate the Yuma's capability for taking photos and recording coordinates for each concurrently. Upon arrival in the field however, more problems arose regarding the opening/saving locations in Terrasync. A flash drive was used again, but this time the data transfer utility was used to copy the dictionary to the predetermined Terrasync folder. 
Although the dictionary was transferred correctly and showed no signs of failure, the default save location could not be used for storing a completed data file. The Terrasync program is set up with a predetermined save location on the Yuma hard drive, usually in a "GPS Projects" folder within the "My Documents" folder under the main drive on the Yuma. This folder could not be found on the Trimble Yuma during field trial 2, which did not completely cause a failure but did leave the user with a small inconvenience. Instead of using the default location on the hard drive to store the data file, the user was able to leave the flash drive plugged into the Yuma as a means of storing the data file.

Upon completion of the second field trial, more improvements were under identified with respect to the functionality of geotagging and field input aliases. While in the field, it was difficult to view the desired input fields because they were created incorrectly in Pathfinder Office. The "new attribute" window in Pathfinder Office has a field for a title as well as a field for alias. The fields were created under the impression that both fields would appear on the unit during a field trial, but this was simply not the case when trial 2 was performed. Instead of being able to view the subject and the detail under that subject, only the detail field could be seen, which caused confusion because the operator was unable to identify to which part of the dam the detail belonged. For the third field trial, these alias fields needed to be more complete so that the operator is able to fully understand what the field is requiring he/she to inspect.

The second major problem in the field dealt with taking photos that contained GPS information, an activity more commonly referred to as geotagging. When the data dictionary was designed, it was assumed that photos could simply be taken at points during the field inspection and saved automatically with corresponding GPS information. This assumption was also incorrect and was quickly noticed in the field. The Trimble Yuma has a button on its control panel that provides direct access to the camera utility, and this was employed by the operator to capture photos during the second field trial.

After transferring the data file back to the desktop via data transfer, it was noticed that the photos were not included as part of the field trial 2 file, which was suspected by the operator during the field trial. The problem was corrected by creating photolinks within the data dictionary to be used during the third field trial. The links are added as attributes and can have titles and aliases similar to the other attributes in the data dictionary, but the most effective characteristic of the photolink is that it automatically opens the camera utility when it is selected. After the photo has been captured, it is stored in a default location within the data file with its matching coordinates. The use of this attribute is a very valuable tool as he/she can take geotagged photos in seconds. 
One issue that remained unresolved after field trial 2 dealt with the default save location of the Terrasync software. After talking with representatives for the Trimble equipment, the problem continued without a solution. The Terrasync software was removed from the Trimble Yuma and reinstalled to be sure that the first install was not corrupted, but the default save folder was still missing after the second installation. Instead of focusing on the saving issue, more effort was directed toward the completion of the data dictionary. The decision was made because even though the use of a flash drive was a bit inconvenient, the problem arose as a result of the equipment and not the operator, and the data dictionary was still functional.

After the advancements were made from the second field trial, the data dictionary was expected to function in the field much more smoothly. The third field trial was performed soon after the improvements were finished, yielding a better collection of data including geotagged photos as well as complete field entry descriptions to serve as questions. The operator was easily capable of geotagging imitation problem areas on the mock impoundment site. Additionally, the operator was able to view the new aliases, which were reformed into more complete questions to be better understood. Overall, the field trial was a success, as many goals were met regarding the functionality of the automated inspection program.

The completion of the third field trial was followed by a series of improvements that were not construed from problems in the field but from the advanced capability of the data dictionary editor in Pathfinder Office. Through the previous work with the editor, a few new features were found which made the automated inspection form appear more organized and function better overall. The conditional attribute aspect in the editor, allowing fields to only appear if the operator provides a particular answer to an attribute, was utilized. The use of this feature allows for a much nicer appearance on-screen as unnecessary fields are not visible until they are required. The condition feature can even be utilized for photolinks, which will not prompt the operator to take a photo unless it is required.

A second feature of the editor includes the use of the "field entry" utility, which allows the programmer to require that the inspector visits each attribute and enters data. As a means of guaranteeing the inspector performs each part of the inspection, the data dictionary was created so that each feature will not save until all attributes have been visited and the field entry has been completed for each. The addition of this aspect will serve as a sure way to check the inspection practice because the coordinates of each feature will be stored as well, showing the inspection path traveled over the duration that each feature was open in Terrasync. 
The fourth field trial was executed at a mine impoundment so that the full functionality of the data dictionary in addition to its organization could be examined. The ordering of the attributes was checked so that the operator may inspect the dam without scanning through the dictionary continuously looking for the attributes to be completed for each area. A precise ordering of the attributes under each feature was necessary to guarantee that the inspector will not waste his/her time with the equipment. The most important part of using this automated form with the Trimble Yuma mobile computer is that it should provide more capability than the paper form with a minimal amount of problems resulting in wasted time.

This field trial brought about a few more ideas about the general information settings and the security of the inspection form. After using the data transfer to upload the data file onto the desktop computer, it was detected that the general information was difficult to find because no GPS information was recorded. After the data file was exported to ArcGIS, the general information could not be found at all because no layer existed for the feature. A decision was made to modify the general information feature so that it records points as the inspector fills out the information. This will ensure that the information is not lost back in the office as it is very important to the inspection. The second modification made to the data dictionary after trial 4 was the addition of automatic locked time stamping, which was added to each feature so that it records the time each feature was completed. The feature may not be modified in the field, so it provides as a good verification that the inspector is spending the correct amount of time on each part of the inspection and not skipping over that area instead.

\subsection{Final Data Dictionary Template}

For the fifth and final unofficial field trial, all amendments were made and worked successfully. It was decided that instead of trying to add direct links for PDF files into the data dictionary, a folder was created on the desktop of the Yuma with all the necessary documents needed for inspection. A reference to the destination of the folder was added onto the general information feature so that the inspector can be made aware at the beginning of the inspection. The time stamps, which automatically generate a locked time stamp when each feature is opened in Terrasync, were added to each feature as well.

Another decision made for this field trial involved the inclusion of probability statistics for decant trash rack attributes as well as spillway clog attributes. The probability attributes were based on a study 
presented at a technical seminar (Dise 2009). These additional attributes required conditional elements, which only prompt the inspector to inspect if another attribute is given a particular answer. For example, if the inspector answers that the decant trash rack is not clear and open, then he/she is prompted to answer a question asking to predict the clogging of the trash rack as a percentage. The clogging attribute is categorized into ranges of percentages, and any category chosen above 50 percent alerts the inspector to contact the mine manager immediately.

In addition to including the clog percentage of the trash rack, an attribute regarding likelihood of causing pool level rises was incorporated into the template. An attribute for pool level rise likelihood follows the inspector providing an answer to the clog percentage attribute. The attribute is shown as a dropdown menu with five possible answers, all having a designated probability as presented by Dise (Dise 2009). Once the inspector provides an answer from the dropdown menu, a new attribute follows with an assigned probability value. Lastly, the inspector is required to take a photo of the decant trash rack to solidify the clog percentage estimation provided.

Another innovative attribute added to the data dictionary includes a reference guide, which provides a location on the Trimble Yuma desktop for finding pertinent information to the inspection, such as an Emergency Action Plan and MSHA Inspection Handbook. One more new attribute deals with an input area for weather conditions, which are important to the pool level and structural stability of a newly constructed impoundment without vegetation. A torrential rain on a newly constructed impoundment without vegetation can cause rills and trenching quickly, resulting in a weakened structure. Extra photos/comments attributes were added to each feature to simply leave an area for the inspector to comment on additional observations on-site. An attribute was included in the Spillways/Ditches feature involving the spillway type. The inspector must choose what type of spillway/ditch he or she is inspecting. A dropdown menu is provided, which includes left groin ditch (from crest), right groin ditch (from crest), spillway, and auxiliary spillway. The use of this attribute will help support the GPS data recorded for each spillway/ditch feature as well.

The audio/video capture problems were resolved within the software by using the video utility on the Trimble Yuma. When the inspector is prompted to capture a photo for a particular attribute, he/she must click the photo icon within the data dictionary. Within just a few seconds, the camera utility opens on the Yuma, and the inspector may capture a photo. After a photo has been taken, the inspector simply exits the camera utility, and the picture is automatically saved in its designated location within the data file. For a video or audio attribute, the procedure is the same for triggering the camera. While 
the camera utility is open, the inspector must select the video option from the top menu. An audio-only file cannot be recorded easily by using the data dictionary capability, so an alternative method was found to make the process more efficient for the inspector. In order to record audio files, the inspector is able to open the camera utility and choose video. Instead of using the rear camera, which faces away from the inspector, he/she may switch to the forward facing camera by choosing the option from the menu bar at the bottom of the camera screen. The inspector is then able to record him/herself speaking about the necessary observations. The rear camera may also be utilized for taking a video of the observation and providing a verbal description simultaneously.

The capability of the final inspection form is not limited to the geotagging of photographs and capturing of videos. All numerical values for piezometers, mine discharges, and staff, pore pressure, and rain gauges may be stored within the inspection file as well. The capability of storing all the information within the file improves organization and allows the information to be imported into a historical database for easy storage. All gauges will have coordinates linked to the numerical values and identification numbers, which helps to ensure the gauges are marked correctly on-site. The ability to map these features is an improvement to the inspection process as well because it saves time when locating potential hazards for maintenance.

\subsection{Risk Assessment Attributes}

Poor risk assessment and negligence are equally important to the improvement of inspection procedures as both have caused catastrophic failures recently. Involving features to assist in risk assessment and including these fields in the output report are both essential to the improvement of inspection practice. Additional attributes were included involving decant trash rack clogging and spillway/groin ditch obstructions. One attribute prompts the inspector to provide an estimate of the likelihood of each instance causing a pool level rise, while another requires an estimate of the clog as a percentage if the inspector claims that the trash rack or spillway is obstructed in some way. Both of these attributes are conditional in that they only appear if the inspector answers that the decant trash rack is not clear and open (Figure 9). Once the inspector answers that the trash rack is not clear, the additional questions appear regarding clogging percentage and likelihood. If the inspector answers that the rack is over 50 percent clogged, then a third conditional attribute will appear directing the inspector to notify the mine manager immediately. These three attributes function in the final report as a risk assessment tool for determining what level of risk the feature has on the impoundment. 

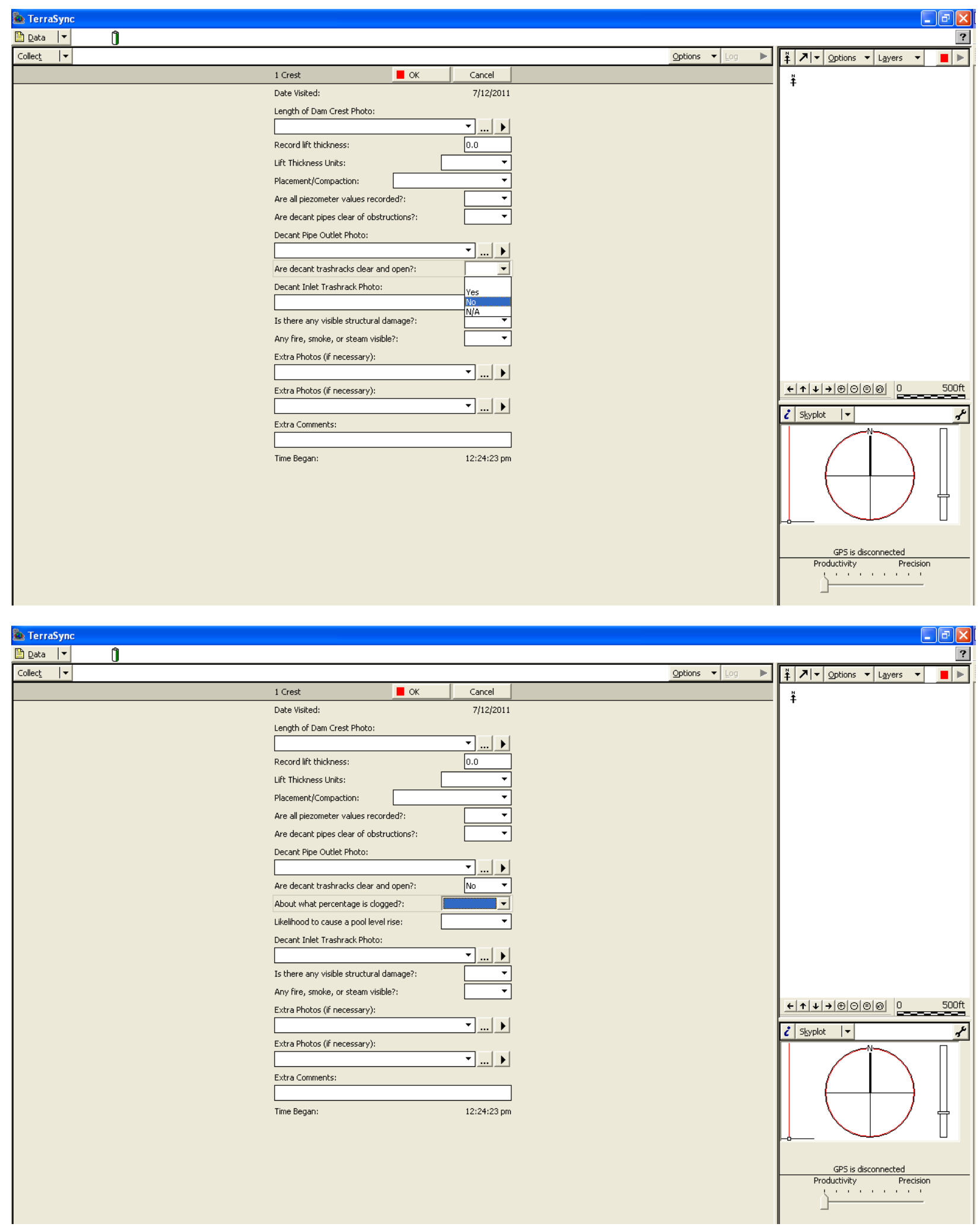

Figure 9: Illustration of conditional attributes appearing after answer was provided that trash racks are not clear and open. 
Another form of risk assessment involves the employment of frequency of occurrence histograms to describe the rate of recurrence of specific answers provided by the inspector. Over time, the populated histograms may be used to illustrate how often a decant trash rack or emergency spillway was clogged or somehow impeded. The graphs appear on the final output report after each inspection with the latest information provided. The results shown in these figures may suggest that an impoundment either needs better maintenance practice or has the potential to fail. Utilizing this method may efficiently improve impoundment maintenance and reduce failures resulting from negligence.

\subsection{Using the Yuma in the Field/Uploading in the Office}

Once the data dictionary is created, it may be saved onto the Trimble Yuma for use on an impoundment field inspection. This may be done more than one way because the Trimble Yuma has its own Window system. On older Trimble equipment, the data transfer utility has to be employed, which uses a link between a default folder in Pathfinder Office and another default folder in Terrasync. The Trimble equipment has to be linked to the desktop PC with a special cable, usually provided by Trimble. The transfer only takes seconds to send the data dictionary file from the desktop to the predetermined folder on the Yuma. The Trimble Yuma is different however because it is a computer on its own. The cable method cannot be used because two computers may not be connected via USB ports. A SD card or portable flash drive may be used instead to transfer dictionary files to the Yuma. The files may simply be located on the desktop and copied to the portable memory. Next, the data transfer utility may be opened on the Yuma to create the link between the Terrasync program and the portable memory. The link takes only seconds to create and is only required once. After the link is created, Terrasync will recognize the portable drive when it is plugged in; therefore, the location of the data dictionary templates will accessible from Terrasync without making a new link every time. Another method for transferring the template is to locate the Terrasync default folder on the Yuma and copy the file to that location.

The inspector can simply open the Terrasync program and access the correct data dictionary to begin the inspection. The template is completed during the inspection by answering the questions provided. The inspection file saves to the default location on the Yuma unless otherwise specified. After the inspection, the data file on the Yuma may be saved on a portable storage device (flash drive, SD card, etc.) if it was not already configured to do so and sent to a desktop PC using the Trimble Data Transfer program. If the data transfer link was previously made to the storage device, the data transfer may be 
performed similarly to the data dictionary. The eight files created during the inspection will be sent to the desktop PC as one compressed file for viewing in Pathfinder Office. Following the data transfer, the data may be opened in Pathfinder Office, which is primarily used for mapping the inspection route and exporting to other software programs. The complete process is illustrated in Figure 10.

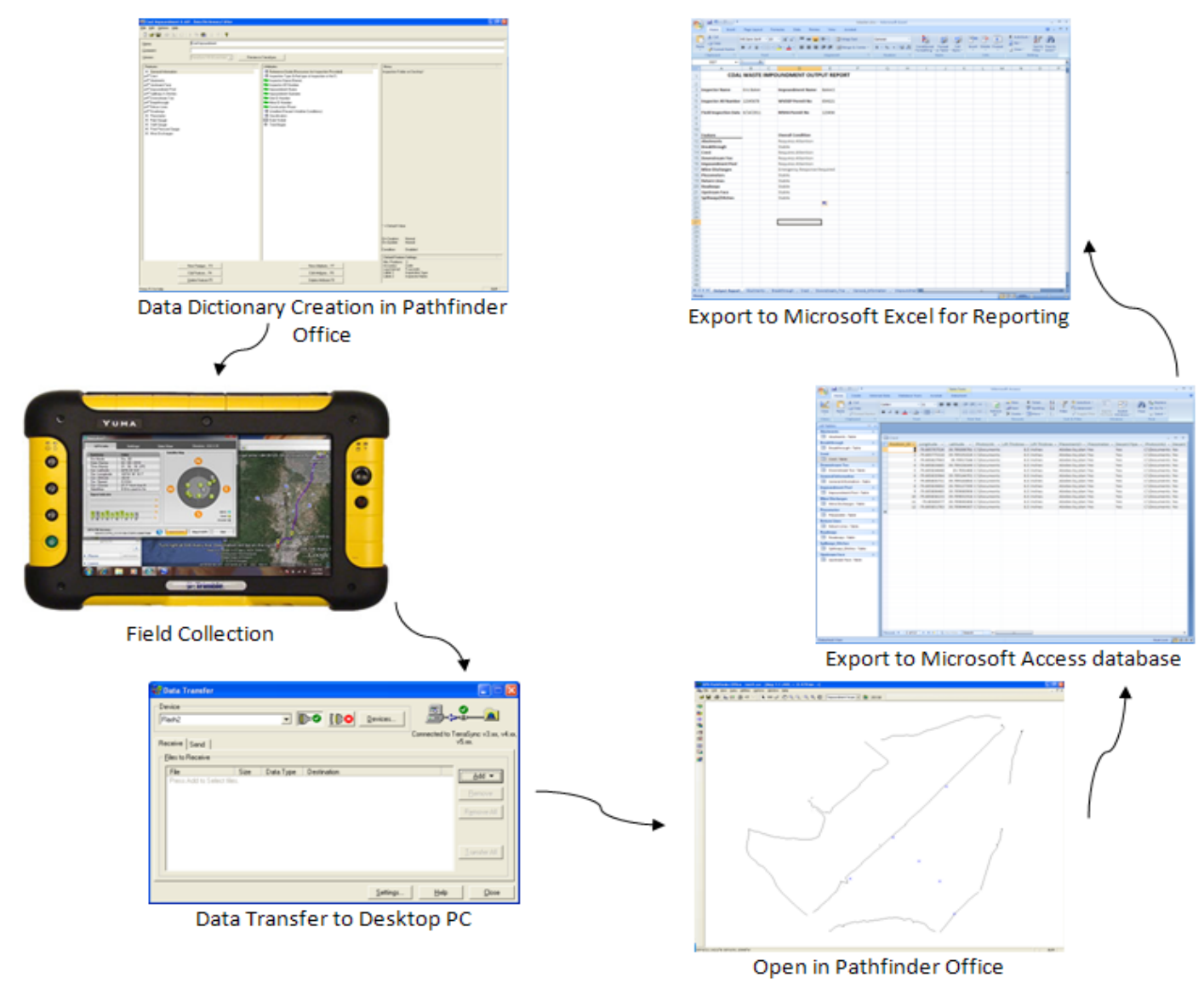

Figure 10: Flow chart showing basic electronic data collection process.

In a few easy steps, the data file may be exported to a Microsoft Access database, which includes all inspection fields and coordinates. Access stores the file as individual tables for each feature of the impoundment (crest, abutment, etc.). This database may be updated in Access as more inspections are performed or sent to Microsoft Excel for data manipulation and report generation. Sending the data to Excel stores each feature as a new worksheet tab, and a master report worksheet may be made which automatically populates from the data for each feature. The report includes the general information for the impoundment as well as a risk assessment of each feature based on particular fields from the inspection. For each new inspection, the output report tab may be brought in as a new tab and should automatically populate with new inspection information upon doing so. 
A historical database may be formed by adding new data to the master tables in Access using an append utility in the program. The updated master sheet may be exported to Excel along with the output report template, and the risk assessment frequency of occurrence graphs, which are histograms containing information pertaining to the number of times the inspector selected particular trash rack clog values, will update with the new information. Upon completion of exporting and formatting, the output report may be printed with risk assessment recommendations. The report will contain general information on the impoundment as well as a risk assessment value for each feature inspected. The final portion of the report will illustrate the frequency of which some answers, particularly those pertaining to clogging and probability, were provided by the inspector.

\section{Results \& Analysis}

For the purpose of testing the functionality of the template, a series of mock field inspections were conducted at two different sites. Both sites are former slurry impoundments reclaimed by the West Virginia Division of Natural Resources as wildlife management areas (WMA) for fishing and other recreation, such as boating, kayaking, and wildlife observation. The purpose for performing the inspections was to ensure recording sufficient data for building the historical database. Performing inspections on different dates would allow the data to be sorted more easily and the possibility of changes to be seen. After performing multiple inspections, the template becomes more user-friendly as well because the user develops a familiarity with locations of attributes.

The Pedlar WMA was the first impoundment used to test the functionality of the custom template for inspection. Located in Core, WV, the impoundment now retains the structure of Mason Lake and is maintained by the WV DNR. A series of three inspections were performed over a five day period in order to change observation methods and test functionality of conditional attributes. Throughout the course of the three inspections, observations were changed intentionally to simulate problems with the structure and test the alerting capabilities of the template. During the series of inspections, no problems were encountered regarding the usability of the template; however, the GPS utility on the Yuma failed to work correctly at the beginning of the second inspection. The Yuma was restarted and the problem resolved itself. The data from the three inspections are located in Section 4.1.

After assessing the collection of data from the Pedlar inspections, it was observed that a few minor changes could be made to the template. Some attributes were not properly organized for the 
inspection process. For example, the decant pipe outlet photolink was placed in the crest feature, and in most cases, a photo of the decant outlet may not be taken from the crest of the impoundment because of the distance to the structure as well as the vegetative cover that may exist on the downstream face of the impoundment. Another attribute not located conveniently was the question asking if the water exiting the decant outlet was clear. The attribute was located under the impoundment pool feature, making it impossible to answer the question without travelling from one face of the impoundment to the other. Leaving the attribute under the impoundment pool feature would result in time lost or omission because the inspector would not want to make the trip over the downstream face of the impoundment more than once. Both of these misplaced attributes were relocated for the second series of inspections for increased usability in the field.

The second series of inspections was performed at the Hibbs Run impoundment outside of Mannington, WV. The Hibbs Run site is an area within the Dents Run WMA for fishing and other recreation. A series of three inspections was performed over a period of seven days. Over the seven days, no significant changes were observed, and the inspection template was fully functional. Photos were stored as part of the template and comments were added primarily to capture more information for the database. The data from the three inspections are located in Section 4.2. One inspection yielded problems similar to that of the Pedlar inspection with the Trimble GPS utility; however, the Yuma resolved the problems after a system restart.

\section{Data Reduction}

After the three inspections were completed for each series, the data was returned to the office for uploading and report generation. The portable flash drive used for the inspection data save location was inserted into the desktop PC, and the Trimble data transfer utility was employed for uploading the data files into their respective locations. Once all three files were uploaded onto the desktop PC, each file was opened separately within Trimble Pathfinder Office. Each file was opened first for viewing, and differential correction was used to enhance the accuracy of the GPS locations collected during the inspection. A base station located in Uniontown, PA was used for differentially correcting the series of inspections (Figure 11). At least $67 \%$ of the recorded positions for Pedlar and $80 \%$ for Hibbs Run were corrected within two to five meters, which is the best accuracy the Trimble Yuma can accomplish. The correction reports are in Sections 4.1.2 and 4.2.2. The differential correction utility can create a new file for each inspection with the same file name and a new file extension, or it can overwrite the original 
shape file depending on what option is chosen. For all inspections, the option was chosen to create a new file so the original data was kept unmodified.

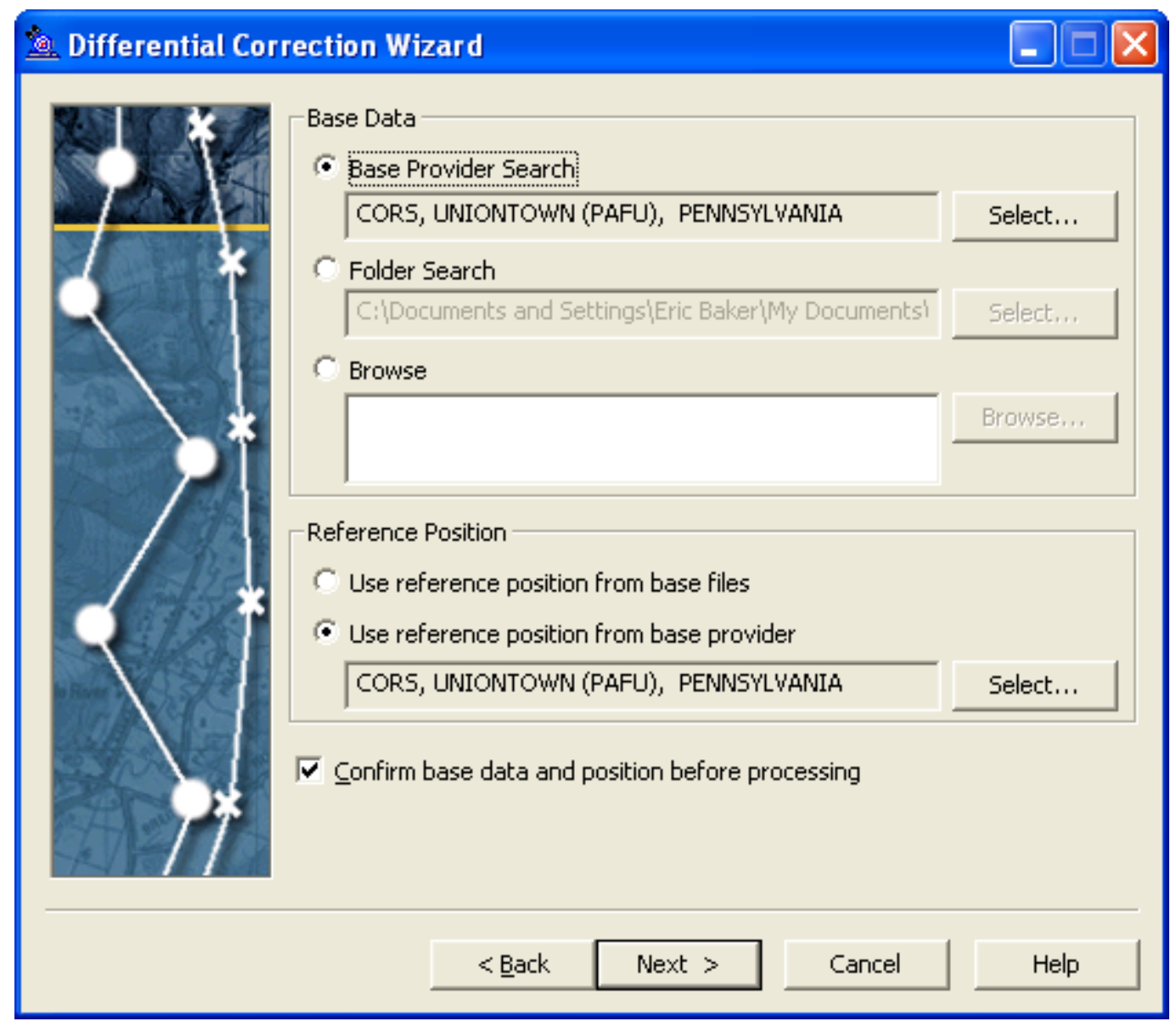

Figure 11: Differential Correction Wizard showing Uniontown, PA CORS station.

Following the differential correction, the original shape file was closed and the corrected file was opened. Only minor changes exist between the original and corrected shape files, most of which cannot be seen by the user unless one file is placed over the other, which demonstrates the high precision GPS feature of the Yuma. For the purpose of impoundment inspection, the differences are insignificant because the mapping is mostly for monitoring inspection routes. Background files were then added into the inspection file using aerial images provided by the Environmental Systems Research Institute (ESRI). A world imagery layer was first uploaded into ArcGIS 9.3 from the ESRI website. The impoundment was located next and zoomed to so that the impoundment was visible and all the data recorded would be displayed on the map. 
Before using the imagery file in the Trimble software, the coordinate system was checked to ensure that it was displayed in the NAD83 coordinate system, and it indeed was not after a quick assessment. The coordinate system was transformed from WGS1984 to NAD83 (Figure 12) because all inspection data files were recorded in the NAD83 coordinate system and using two different coordinate systems is not allowed by Pathfinder Office. The transform utility in ArcGIS was found within the coordinate systems section of the data frame properties. The export utility within ArcGIS was used to save the imagery as a .tiff file so that it could be opened by Trimble Pathfinder Office. A world file was also required for opening in Pathfinder Office so that imagery pixels were matched correctly to geographical coordinates (Figure 13). The world file was easily created by ArcGIS by indicating that a world file was necessary. ArcGIS created the .tiff file of the GIS map window display with an attached world file.

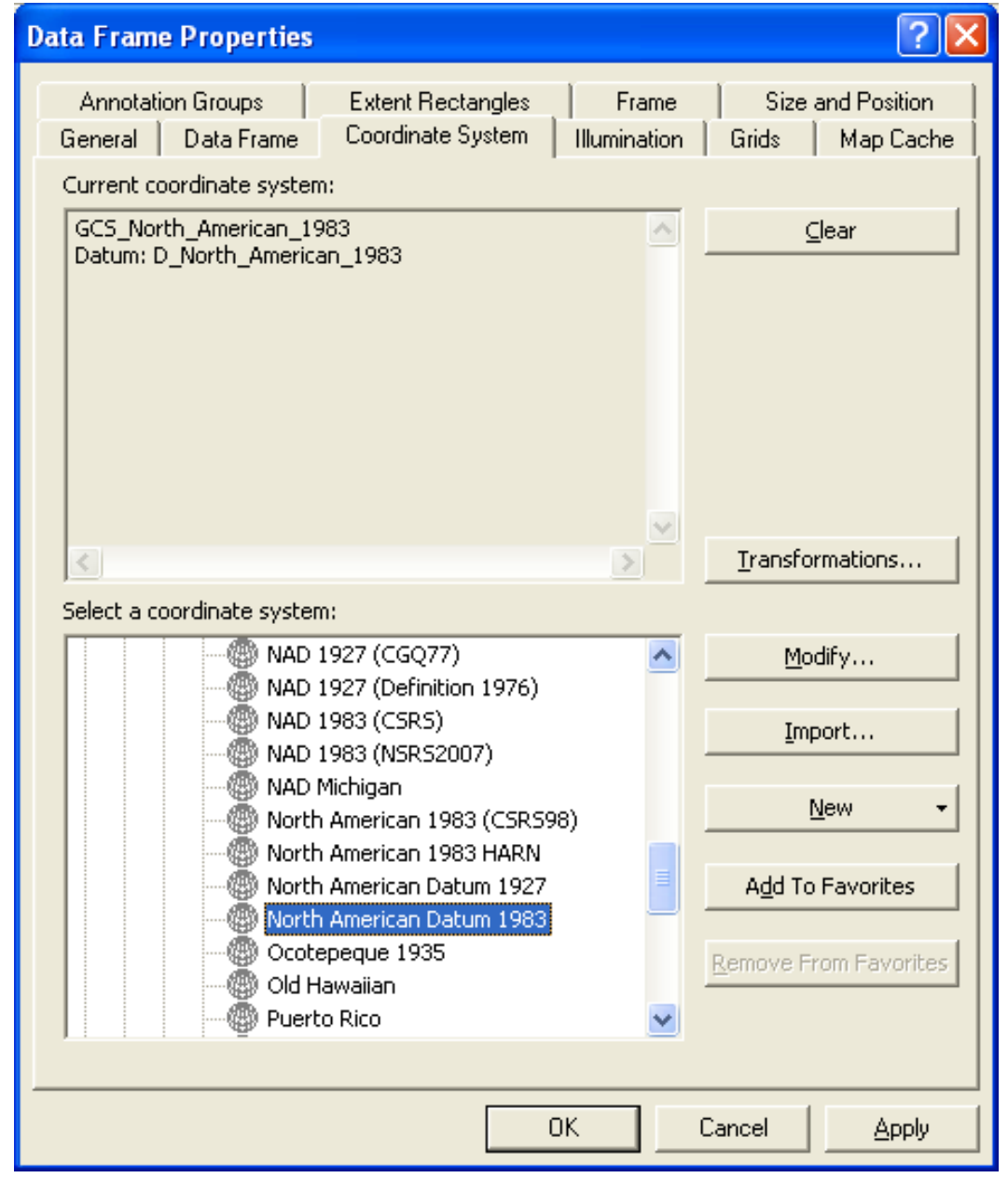

Figure 12: Changing of world imagery coordinate system in ArcGIS to match recorded inspection routes. 


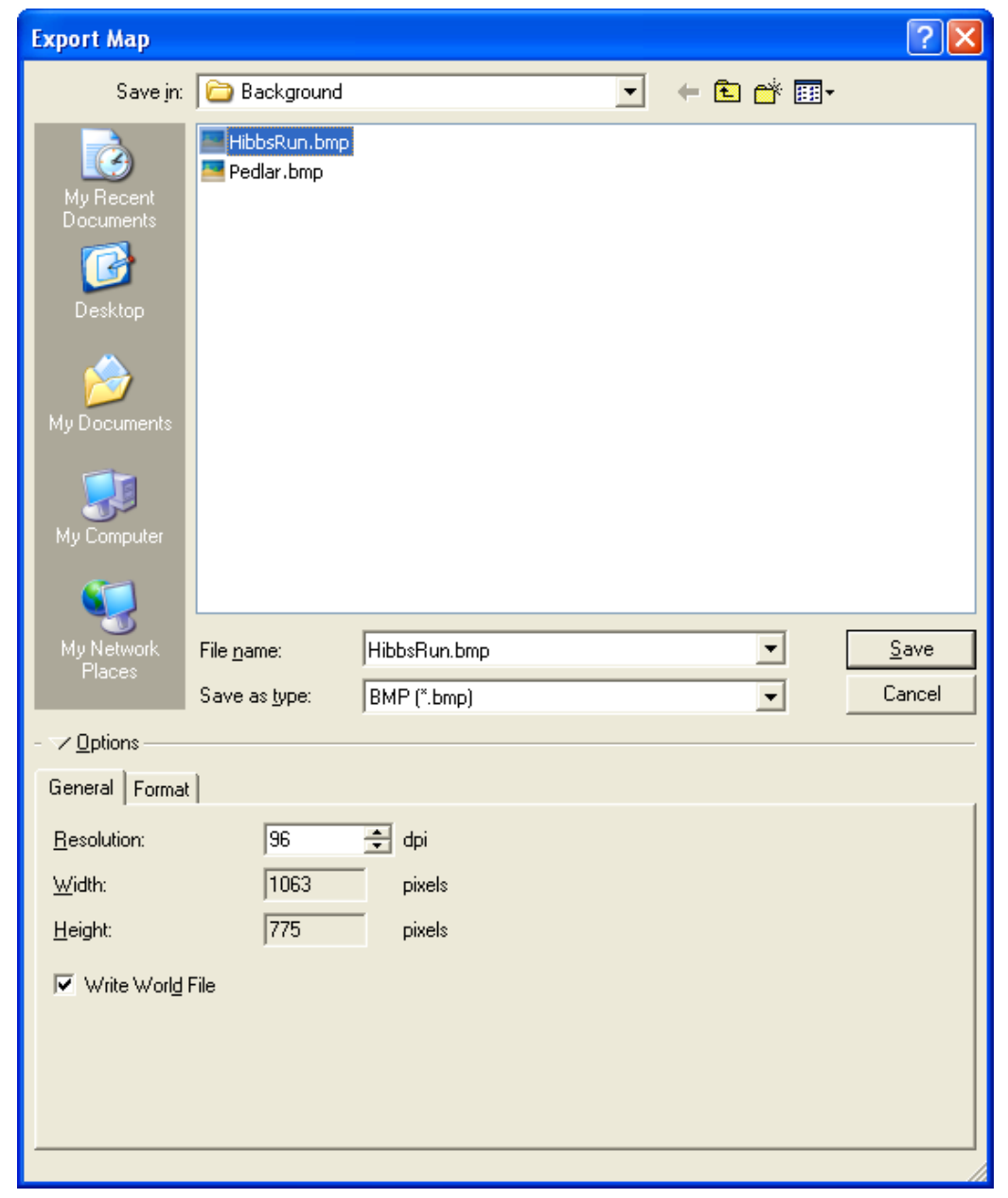

Figure 13: Export of imagery map from ArcGIS with world file for use in Pathfinder Office.

The imagery file was opened in Pathfinder Office by locating it through the background option in the software (Figure 14). The aerial image was uploaded correctly and all data was displayed over an image of the impoundment. Without these imagery files, the route mapping is virtually irrelevant because it is impossible to see where the mapped routes fall on the impoundment. Using the imagery file ensures that the mapped routes were in fact on the impoundment site and the inspector inspected each required portion of the impoundment. 


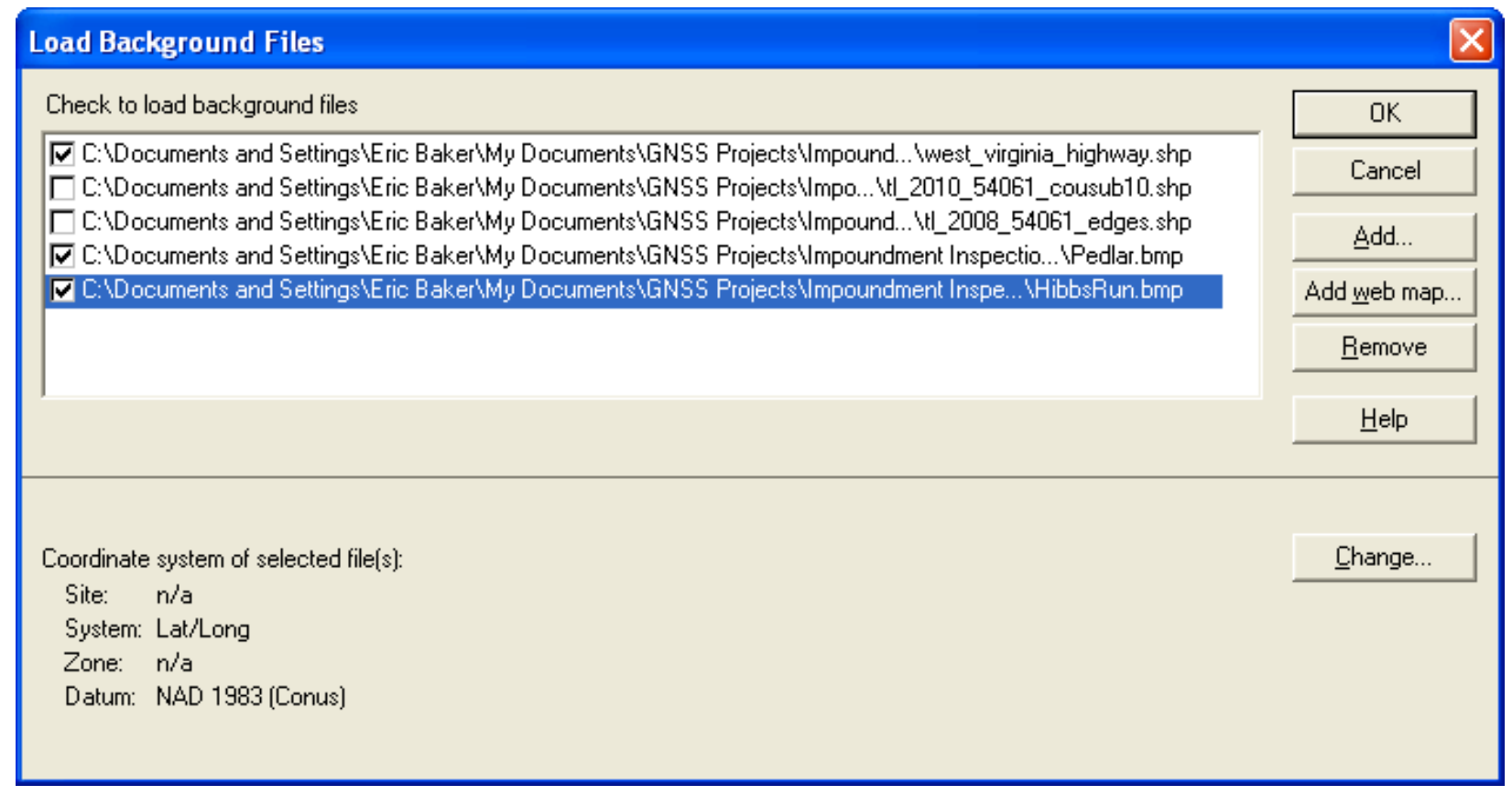

Figure 14: Adding imagery map into Pathfinder Office as background file.

Once the data file was combined with a background file, the attribute information was exported into a Microsoft Access database. The Trimble export utility was used to perform this task efficiently (Figure 15). After creating the Access database composed of all the necessary attributes, the file itself was opened and reviewed. The Access database was used primarily for organizing the information to be stored as a historical archive. In Access, the data is all present; however, it is not displayed for rapid assessment and for obtaining signatures from mine officials (see Sections 4.1.3 and 4.2.3).

In order to meet these requirements, the data was exported from Access to Excel (Figure 16). In Excel (Version 2007), individual worksheets may be linked to a master report template for rapid printing. A master report template was created in Excel with links to each worksheet tab (see Sections 4.1.4 and 4.2.4). All the necessary questions on the MSHA inspection form, portrayed on the Excel inspection form located in Section 8.1, were appended to the master form and linked to answers provided during the inspection. The output report was completed in Excel for printing so that it could be signed by an official for the impoundment, which is a federal regulation dealing with impoundment inspection practice. 


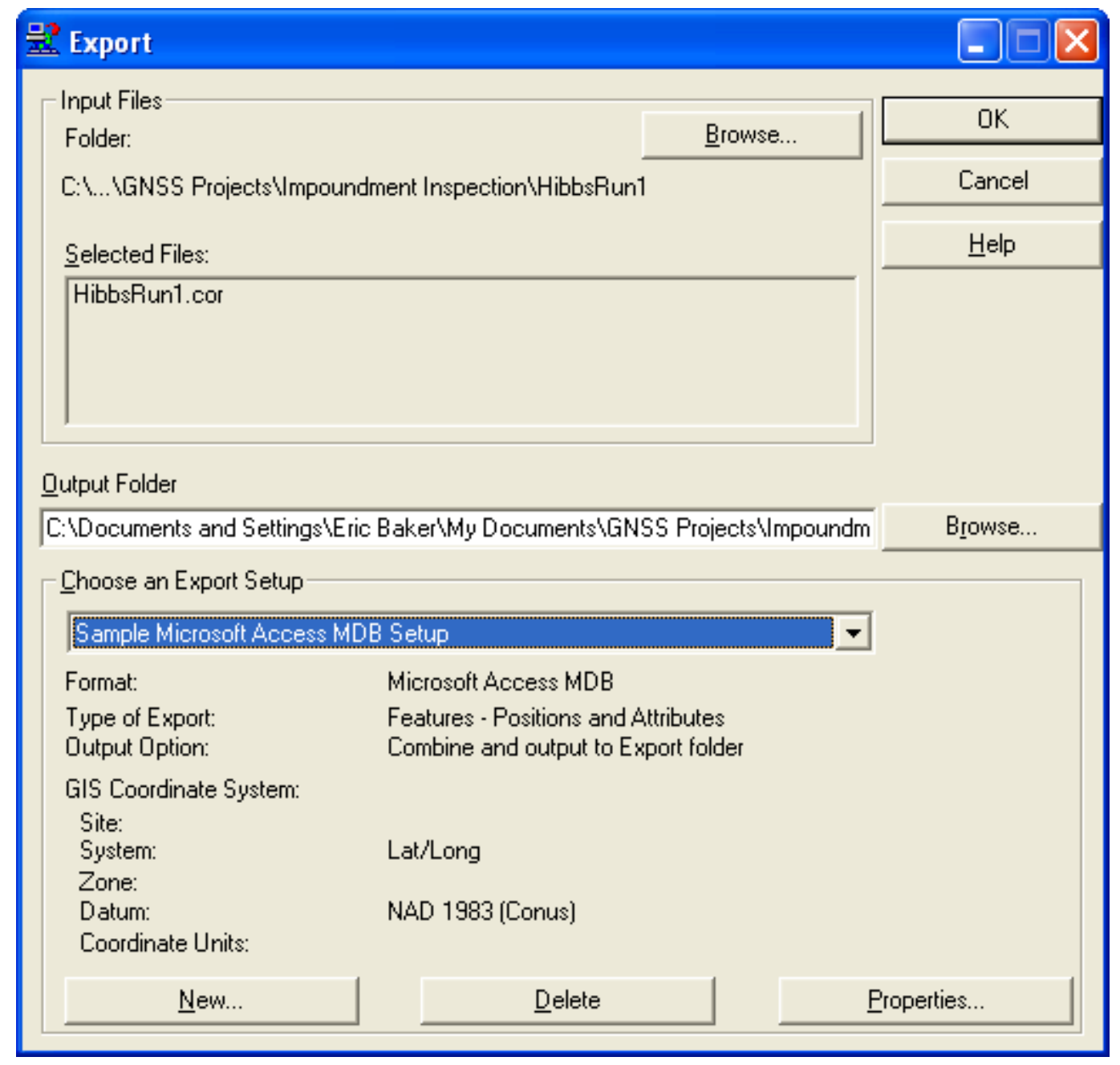

Figure 15: Use of Pathfinder Office export utility to create Access database for inspection. 
Select the destination for the data you want to export

Specify the destination file name and format.

File name: $\quad$ C: |Documents and Settings IEric Baker Wy Documents IGNSS Projects IImpoundment Inspection Vedla

File format: $\quad$ Excel Workbook $(*, x \mid s x)$

Specify export options.

$\square$ Export data with formatting and layout.

Select this option to preserve most formatting and layout information when exporting a table, query, form, or report.

Open the destination file after the export operation is complete.

Select this option to view the results of the export operation. This option is available only when you export formatted data.

Export only the selected records.

Select this option to export only the selected records. This option is only available when you export formatted data and have records selected.

Figure 16: Use of Access export utility to create Excel file for inspection.

There are several problems that exist with this method of reporting however. The first is that the time elapsed during this process is a factor in determining its overall functionality in the industry may be too long. Many inspectors need to have a paper form of the form for signatures readily available following the inspection. The process illustrated takes time that many inspectors do not have and may not be the most efficient means for obtaining a hard copy of the inspection. The form in Excel is also difficult to populate correctly because of the complexity of the information being provided each time. Features are repeated often during inspections because of how the dam is traveled, and different answers may be provided to certain questions the second time around. For example, at least two crest features were created during each Pedlar inspection. This occurred because a piezometer was located at the center of the dam crest, so the crest feature was closed upon arriving at the piezometer in the center. After the piezometer value was recorded, a second crest feature was opened to record the route traveled across the remaining half of the impoundment crest. The first crest feature contained some responses while the second feature contained the remaining responses (Figure 17). 


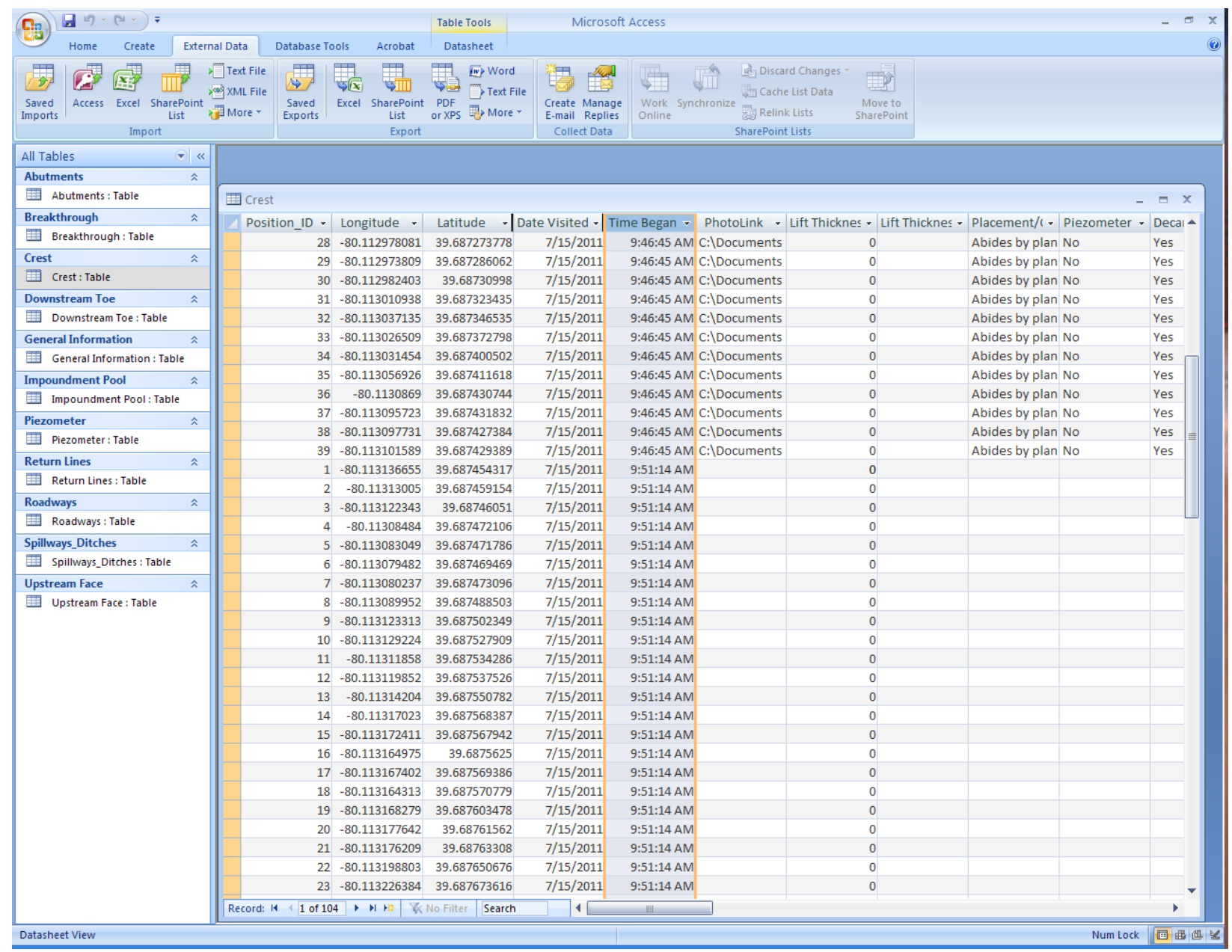

Figure 17: Complexity of inspection information used for output report. Notice that repeated questions were not answered for the second crest feature to reduce wasted time.

When the attribute information was exported to Excel and the output report template was attached (Figure 18), it was difficult to link the report information to particular cells on the worksheet containing the crest information because the first part of the feature included only some of the answers. The information was not the same throughout multiple inspections; therefore, it was impossible to know which cells would contain the correct information to be viewed on the final output report. Without the ability to automatically populate the output report, the Excel form is not useful for obtaining a hard copy for rapid assessment and official signatures.

Microsoft Access has the capability of reporting, but due to time constraints and the complexity of the Access report wizard, research was limited. Alas, completing the task was not within the scope of this phase of the project. The task of creating a report template may be difficult at first; however, the templates may be saved in Access and updated rapidly for efficient reporting. A benefit of using 
Microsoft Access for reporting is that many organizations have the Microsoft Office Suite containing Access. A simple export from Pathfinder Office to Access in the field would result in a report to be signed by the officials on site. The wireless internet connection on the mine site may be employed to send the file to the official for printing, or a portable printer may be an option as well. The simplicity of only using two programs is desirable, and many already have Access but are not very familiar with its flexibility.

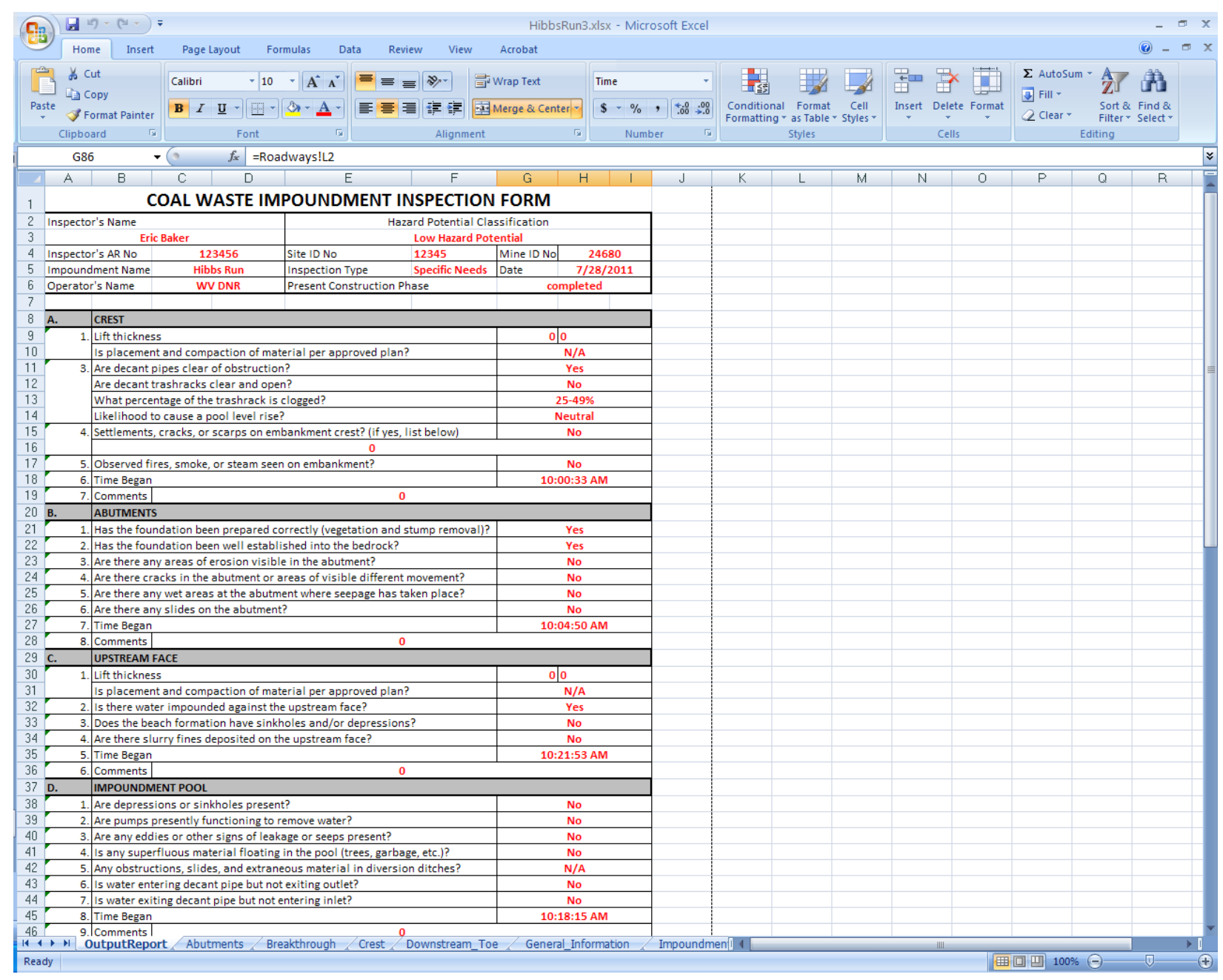

Figure 18: Output report template tab inserted into inspection excel file.

ArcGIS also has a report wizard, which may or may not be an effective method for reporting. ArcGIS may be capable of creating a template which could populate with all the pertinent inspection data. The template could be saved and reused for each individual inspection. Once again, by employing this method of reporting, only two software programs are being used. Not all organizations have ArcGIS however, and reporting with the software requires a good working knowledge of the program. ArcGIS 
may be installed on the Trimble Yuma with a license for use, but its use in the field would require training. Providing training may be undesirable to some and there are annual fees for keeping the ArcGIS program licenses active.

Another procedure performed involved a compilation within Pathfinder Office of all three inspections for each impoundment. All three individual corrected files were combined using a feature provided by the Trimble software. All three inspections routes were located on the same background aerial map (Section 4.3), which is a good illustration of the consistency of inspection practice. Using this feature in the software is effective for showing a portion of the dam continuously missed by the inspector during a routine assessment of the impoundment. The features for the multiple inspections were also combined, which may allow for an easier assessment of the continuity of provided answers. Viewing multiple inspections within the same window in a single software program can allow the inspector to identify radical changes quickly, which can help to improve the safety of impoundments by increasing the ability to identify potential failure modes.

\subsection{Pedlar Inspection Results}

Section 4.1.1 discusses each inspection performed at the Pedlar WMA, particularly the order that the features were recorded in to demonstrate the discrepancy amongst the inspections. The inspections were performed in alternating orders to show that the template may be used in a manner that best suits the inspector. The results show up identically on a map regardless of the order of which they were recorded. The following aerial images illustrate the inspector learning curve throughout the series as well. Notice how the traveled routes for the second and third inspections do not overlap or cover the same area more than once. 


\subsubsection{Pedlar Inspections over Aerial Imagery}

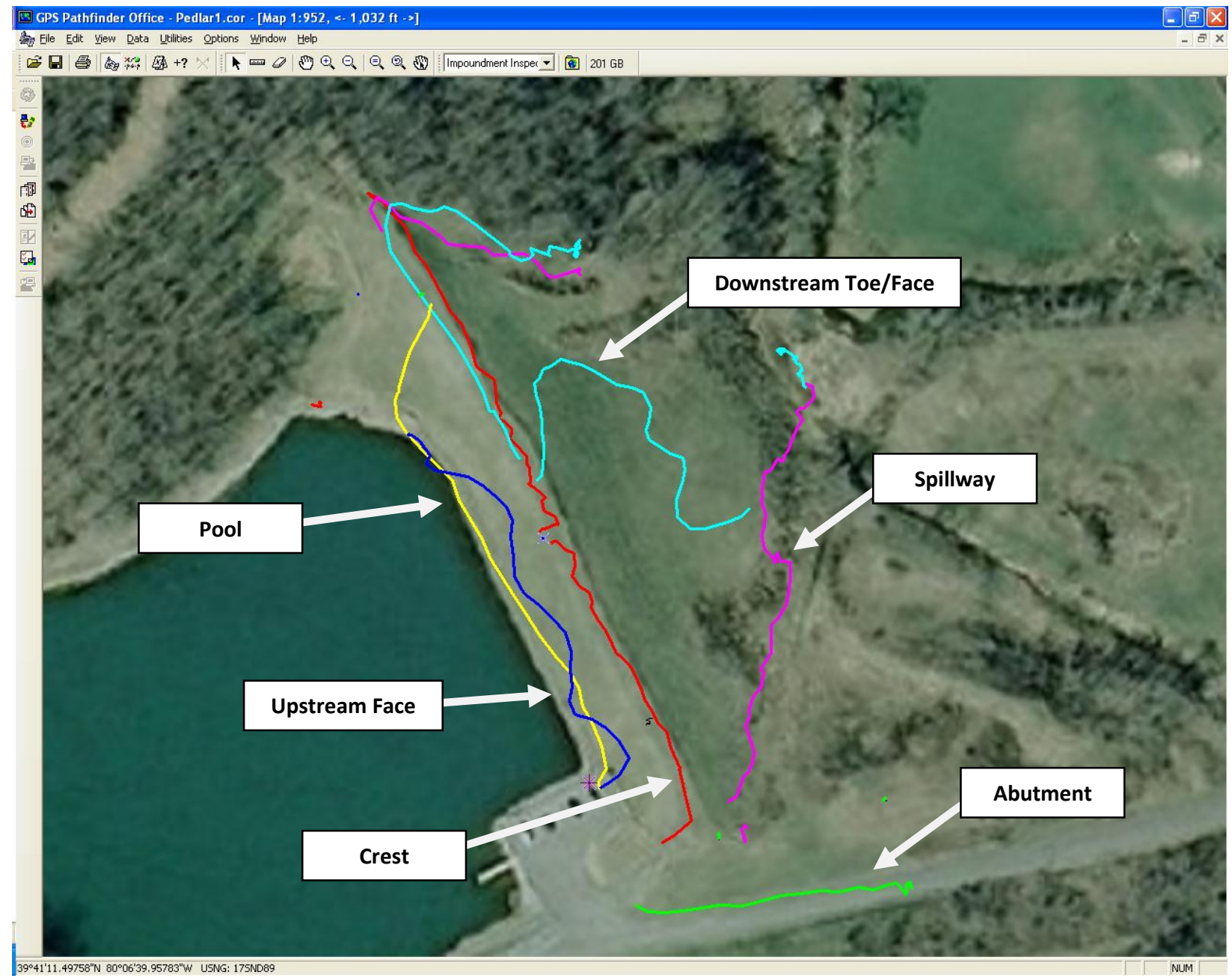

Figure 19: Pedlar1 inspection mapped over aerial imagery.

The first Pedlar inspection (Figure 19) began with an examination of the crest (red). At the midpoint of the crest, a piezometer was in place; therefore, the crest feature was ended and a piezometer feature was created. Following the piezometer recording, a second crest feature was opened in order to record the remaining crest. The left abutment (green), upstream face (dark blue), and impoundment pool (yellow) features were recorded next, completing the upstream face of the impoundment. After completing the breakthrough, return lines, and roadway features, the right abutment was inspected, followed by the left groin ditch (magenta). The downstream toe and face (cyan) was examined as well, and the right groin ditch inspection concluded the full inspection routine. 


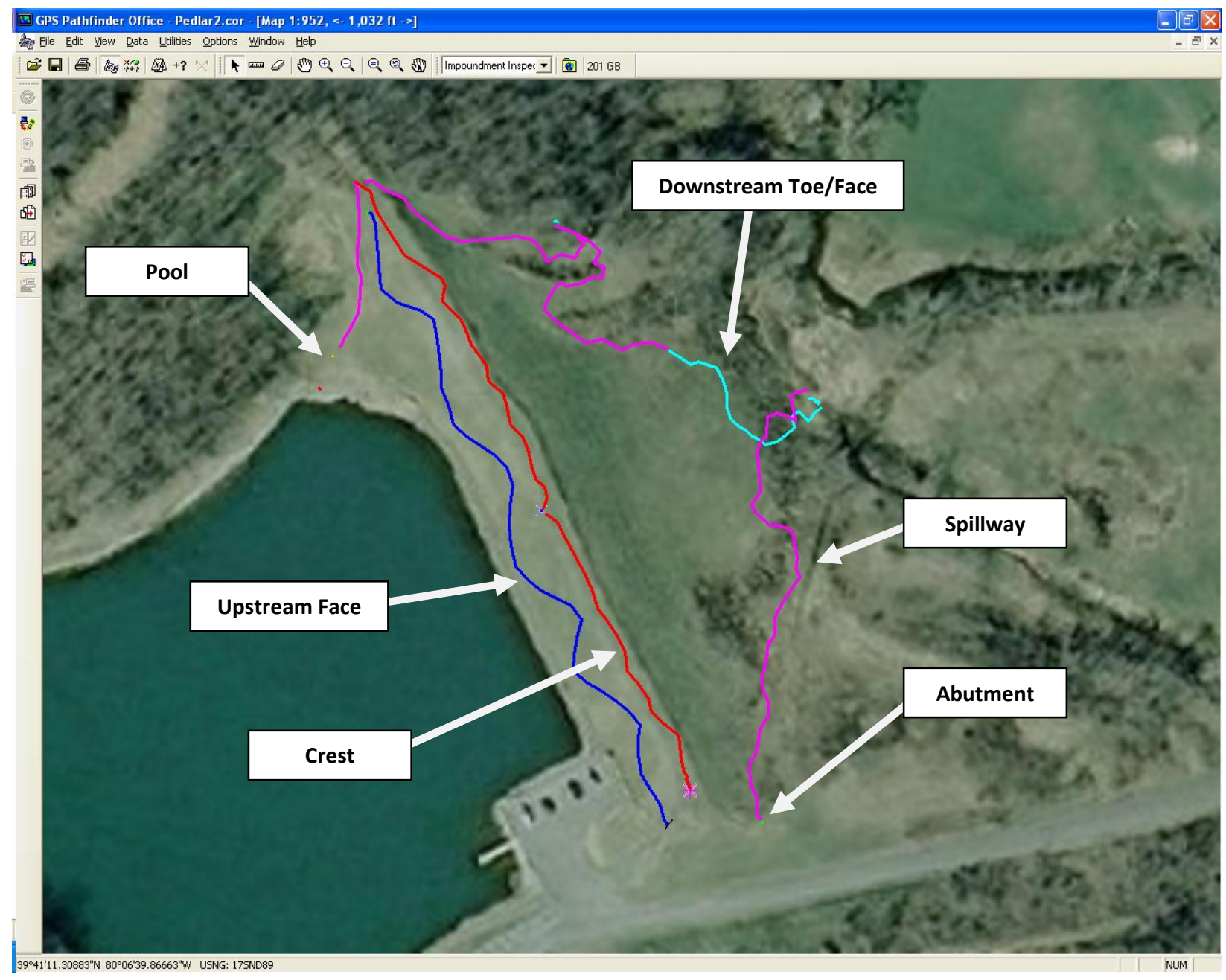

Figure 20: Pedlar2 inspection mapped over aerial imagery.

Similar to the first inspection, the second inspection (Figure 20) began with a crest examination. The piezometer was recorded at the midpoint of the crest feature as it was during the first inspection. On the second inspection, however, a spillway on the north side of the upstream face was encountered. The vegetation was overgrown near the abutments; therefore, the spillway went unnoticed during the first inspection. A quick inspection of the impoundment pool was performed from the north end of the upstream face because it reduced overall time by not traveling across the upstream face twice. Next, the left abutment and upstream face of the impoundment was checked for potential hazards. The questions involving breakthrough, return lines, and roadways were responded to before performing an inspection of the right abutment, and the groin ditches and downstream toe/face completed the second inspection. The second inspection resulted in less time and less distance was traveled due to the increased familiarity of the impoundment. 


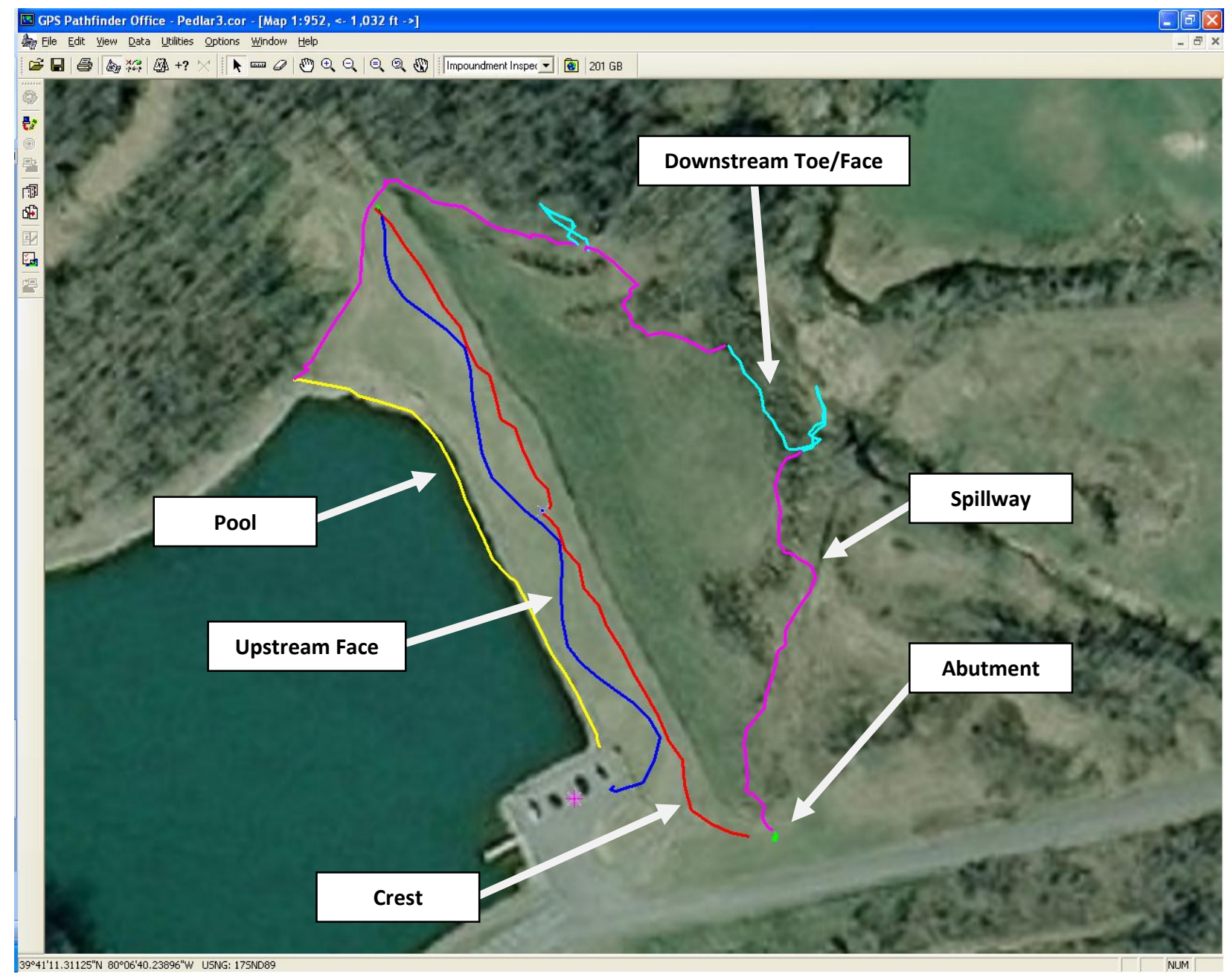

Figure 21: Pedlar3 inspection mapped over aerial imagery.

After the general information was completed for the third inspection (Figure 21), the impoundment pool was examined for any hazards. The spillway at the north end of the upstream face was examined next, followed by the left groin ditch. This ditch could not easily be followed because of the exceptionally overgrown vegetation covering the downstream face of the impoundment. The downstream toe/face was inspected after the left groin ditch, and the right groin ditch was navigated in order to reach the top of the impoundment again. The right abutment was inspected from the top of the right groin ditch, and the crest was examined after along with the piezometer at the midpoint. The inspection continued with the examination of the left abutment and the recording of the breakthrough, return lines, and roadway features. The latter three features are not so important to this impoundment as there are no return lines or mines adjacent to the impoundment, and the roadways are paved and well maintained. The inspection was completed with the assessment of the upstream face. The total time to inspect the 
impoundment was roughly $30 \mathrm{~min}$ compared to about $72 \mathrm{~min}$ for the first inspection, which clearly demonstrates the quick ability to become familiar with the template as it pertains to a particular impoundment.

\subsubsection{Differential Correction Report}

The data below is the result of the differential correction wizard for Pedlar in Trimble Pathfinder Office. The distribution of corrected positions is displayed on Page 47.

Searching for base files...

File C: \Documents and Settings\Eric Baker\My Documents\GNSS Projects\Impoundment Inspection\Base\CORS, UNIONTOWN (PAFU), PENNSYLVANIA\pafu19511133.zip downloaded. File C:\Documents and Settings\Eric Baker\My Documents\GNSS Projects\Impoundment Inspection\Base\CORS, UNIONTOWN (PAFU), PENNSYLVANIA\pafu19611122.zip downloaded. File C: \Documents and Settings\Eric Baker\My Documents\GNSS Projects \Impoundment Inspection\Base\CORS, UNIONTOWN (PAFU), PENNSYLVANIA\pafu19911112.zip downloaded. Successfully found or downloaded 3 of 3 files.

Search complete.

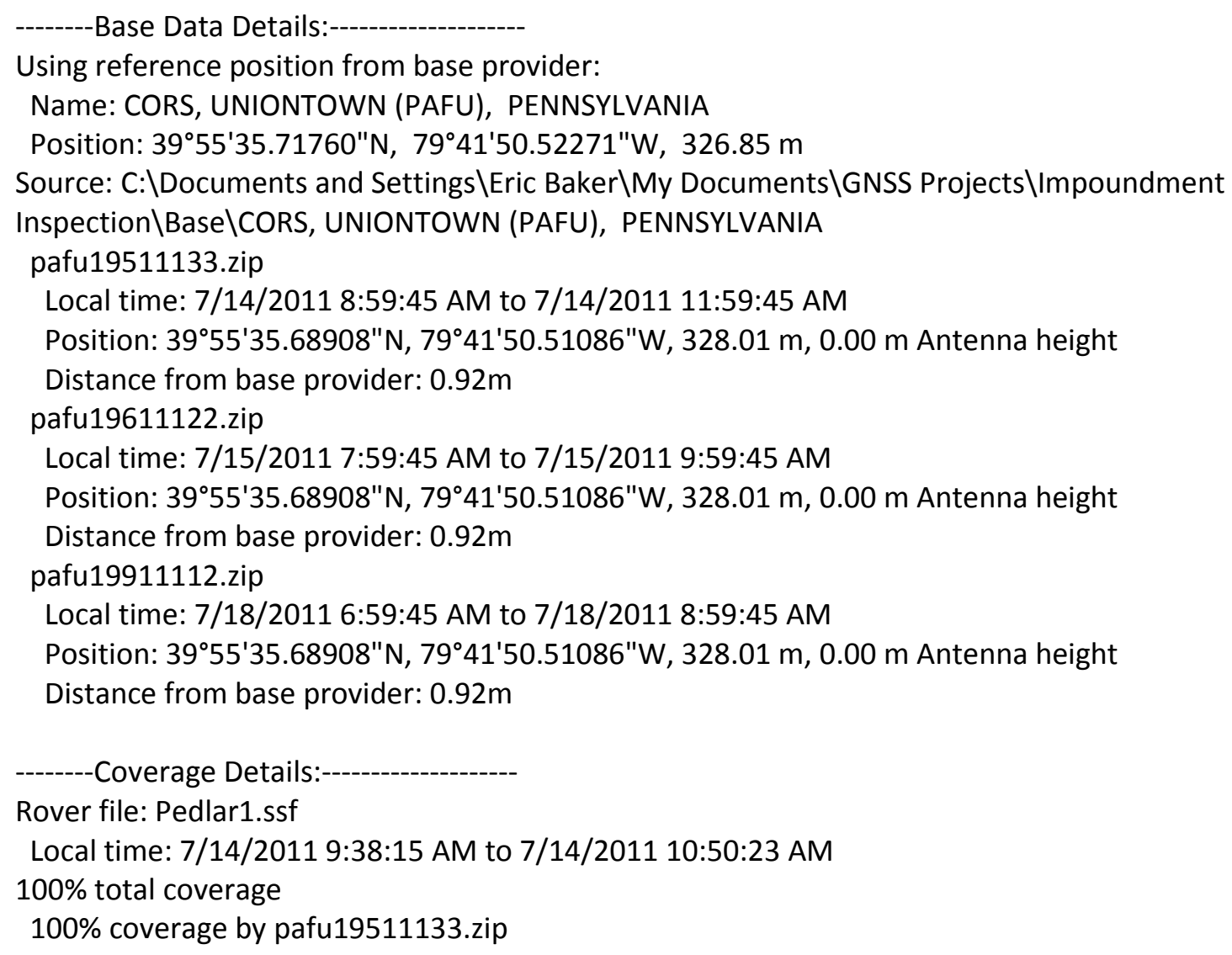


Rover file: Pedlar2.ssf

Local time: 7/15/2011 8:32:43 AM to 7/15/2011 9:10:56 AM

$100 \%$ total coverage

$100 \%$ coverage by pafu19611122.zip

Rover file: Pedlar3.ssf

Local time: 7/18/2011 7:37:33 AM to 7/18/2011 8:10:29 AM

$100 \%$ total coverage

100\% coverage by pafu19911112.zip

Differentially correcting...

Differential correction settings:

Use smart automatic filtering: On

Re-correct real-time positions: On

Output positions: Corrected only

Processing rover file, Pedlar1.ssf ...

...to output file, C:\Documents and Settings \Eric Baker\My Documents \GNSS Projects \Impoundment Inspection \Pedlar1\Pedlar1.cor

Carrier processing...

No carrier processing performed as file has no carrier data

Corrected 0 positions

Code processing...

Selected 492 positions for post-processing

Corrected 492 positions

Processing rover file, Pedlar2.ssf ...

...to output file, C:\Documents and Settings \Eric Baker\My Documents \GNSS Projects \Impoundment Inspection\Pedlar2\Pedlar2.cor

Carrier processing...

No carrier processing performed as file has no carrier data

Corrected 0 positions

Code processing...

Selected 335 positions for post-processing

Corrected 335 positions

Processing rover file, Pedlar3.ssf ...

...to output file, C:\Documents and Settings \Eric Baker\My Documents \GNSS Projects \Impoundment Inspection\Pedlar3\Pedlar3.cor

Carrier processing...

No carrier processing performed as file has no carrier data

Corrected 0 positions

Code processing...

Selected 333 positions for post-processing 
Corrected 333 positions

Differential Correction Summary:

3 files processed. In these files:

$1160(100.0 \%)$ of 1160 selected positions were code corrected by post-processing

$0(0.0 \%)$ of 0 selected positions were carrier corrected by post-processing

Estimated accuracies for 1160 corrected positions are as follows:

\begin{tabular}{cc} 
Range & Percentage \\
\hdashline $0-15 \mathrm{~cm}$ & - \\
$15-30 \mathrm{~cm}$ & - \\
$30-50 \mathrm{~cm}$ & - \\
$0.5-1 \mathrm{~m}$ & - \\
$1-2 \mathrm{~m}$ & - \\
$2-5 \mathrm{~m}$ & $67.8 \%$ \\
$>5 \mathrm{~m}$ & $32.2 \%$
\end{tabular}

Differential correction complete.

\subsubsection{Example Final Report}

Figures 22 and 23 show the final results from one of the Pedlar inspections performed. The data displayed below is similar to what is shown on the traditional paper form, as required by MSHA, and is automatically populated to an extent onto this sheet when the data is exported into Excel. The complexity of the GPS data and attributes limits the ability of the program to automatically fill out the output report in full. 


\begin{tabular}{|c|c|c|c|c|}
\hline \multicolumn{2}{|c|}{$\begin{array}{|ll|}\text { Inspector's Name } & \\
& \text { Eric Baker } \\
\end{array}$} & \multicolumn{3}{|c|}{$\begin{array}{c}\text { Hazard Potential Classification } \\
\text { High Haza rd Potentia }\end{array}$} \\
\hline \multicolumn{2}{|c|}{ Inspector's AR No } & Site ID No & Mine ID No & NA \\
\hline \multicolumn{2}{|c|}{ Impoundment Name } & Inspection Type & \multirow{2}{*}{\multicolumn{2}{|c|}{$\frac{7 / 16 / 2011}{\text { completed }}$}} \\
\hline \multicolumn{2}{|c|}{ Operator's Name } & \multicolumn{2}{|l|}{ Present Construction Phase } & \\
\hline A. & \multicolumn{4}{|l|}{ CREST } \\
\hline \multirow[t]{2}{*}{1.} & \multicolumn{2}{|l|}{ Lift thickness } & \multicolumn{2}{|c|}{$0 \mid 0$} \\
\hline & \multicolumn{2}{|c|}{ Is placement and compaction of material per approved plan? } & \multicolumn{2}{|c|}{$\mathrm{N} / \mathrm{A}$} \\
\hline \multirow[t]{4}{*}{3.} & \multicolumn{2}{|c|}{ Are decant pipes clear of obstruction? } & \multicolumn{2}{|c|}{0} \\
\hline & \multicolumn{2}{|c|}{ Are decant trashracks clear and open? } & \multicolumn{2}{|c|}{ No } \\
\hline & \multicolumn{2}{|c|}{ What percentage of the trashrack is clogged? } & \multicolumn{2}{|c|}{$25-49 \%$} \\
\hline & \multicolumn{2}{|c|}{ Likel ihood to cause a pool level rise? } & & utral \\
\hline 4. & Settlements, cracks, or scarps o & ankment crest? (if yes, list below) & & lo \\
\hline & & 0 & & \\
\hline 5. & Observed fires, smoke, or stear & on embankment? & & lo \\
\hline 6. & Time Began & & $8: 3$ & D9 AM \\
\hline 7. & Comments & 0 & & \\
\hline B. & ABUTMENTS & & & \\
\hline 1. & Has the foundation been prepa & rectly (vegetation and stump removal)? & & es \\
\hline 2. & Has the foundation been well e & ed into the bedrock? & & es \\
\hline 3. & Are there any areas of erosion & the abutment? & & o \\
\hline 4. & Are there cracks in the abutme & eas of visible different movement? & & o \\
\hline 5. & Are there any wet areas at the & nt where seepage has taken place? & & o \\
\hline 6. & Are there any slides on the abu & & & $\mathbf{l o}$ \\
\hline 7. & Time Began & & $8: 5$ & D2AM \\
\hline 8. & Comments & 0 & & \\
\hline C. & UPSTREAMFACE & & & \\
\hline 1. & Lift thickness & & 0 & \\
\hline & Is placement and compaction o & ial per approved plan? & & $\not A$ \\
\hline 2. & Is there water impounded agai & upstreamf ace? & & es \\
\hline 3. & Does the beach formation have & les and/or depressions? & & lo \\
\hline 4. & Are there slumy fines deposited & upstream face? & & lo \\
\hline 5. & Time Began & & $8: 5$ & $33 \mathrm{AM}$ \\
\hline 6. & Comments & 0 & & \\
\hline D. & IMPOUNDMENT POOL & & & \\
\hline 1. & Are depressions or sinkholes pr & & & o \\
\hline 2. & Are pumps presently functionir & move water? & & $\mathbf{l o}$ \\
\hline 3. & Are any eddies or other signs o & e or seeps present? & & o \\
\hline 4. & Is any superfluous materialfloa & he pool (trees, garbage, etc.)? & & es \\
\hline 5. & Any obstructions, slides, and ex & us material in diversion ditches? & & lo \\
\hline 6. & Is water entering decant pipe b & xiting outlet? & & lo \\
\hline 7. & Is water exiting decant pipe but & tering inlet? & & o \\
\hline 8. & Is water exiting decant outlet fl & lear and without debris? & & es \\
\hline 9. & Time Began & & $8: 4$ & $56 \mathrm{AM}$ \\
\hline 10. & Comments & trees growing up in water & & \\
\hline E. & DOWNSTREAM FACE \& TOE & & & \\
\hline 1. & Are the decant pipe/underdrai & s deteriorated? & & o \\
\hline & Is the pipe bedding deteriorate & & & o \\
\hline & Any signs of seepage around th & t pipes/underdrains? & & lo \\
\hline 2. & Is the color of the water unifor & ree of unusually colored areas? & & es \\
\hline & Does the water contain sedime & & & lo \\
\hline
\end{tabular}

Figure 22: Page 1 of example populated output report for Pedlar inspection. 


\begin{tabular}{|c|c|c|c|c|c|}
\hline 3. & \multicolumn{3}{|c|}{ Iswater impounded against the downstream toe? } & \multicolumn{2}{|r|}{ Yes } \\
\hline \multirow[t]{2}{*}{4.} & \multicolumn{3}{|c|}{ Boils, discoloring, sloughing, backcutting, or obstructions? (if yes, list below) } & & No \\
\hline & \multicolumn{5}{|c|}{\begin{tabular}{|c|c|} 
& 0 \\
\end{tabular}} \\
\hline 5. & \multicolumn{3}{|l|}{ Time Began } & \multicolumn{2}{|c|}{ 9:05:04 AM } \\
\hline 6. & \multirow{2}{*}{\multicolumn{5}{|c|}{$\begin{array}{l}\text { |Comments | } \\
\text { SPILWAYS, DIVERSION DITCHES, AND GROIN TRENCHES }\end{array}$}} \\
\hline F. & & & & & \\
\hline 1. & Erosion, slid & & ging, or sloughing? (if yes, list below) & & No \\
\hline & \multicolumn{5}{|c|}{0} \\
\hline 2. & \multicolumn{3}{|c|}{ Are there any visible restrictions/obstructions (trees, garbage, etc.)? } & \multicolumn{2}{|r|}{ Yes } \\
\hline & \multicolumn{3}{|c|}{ What percentage of the spillway is blocked? } & \multicolumn{2}{|r|}{$50-74 \%$} \\
\hline & \multicolumn{3}{|c|}{ Likelihood to cause a pool level rise? } & \multicolumn{2}{|r|}{ Likely } \\
\hline 3. & \multicolumn{3}{|c|}{ Are there any tears in the lining? } & \multicolumn{2}{|r|}{$\mathrm{N} / \mathrm{A}$} \\
\hline 4. & \multicolumn{3}{|c|}{ Any signs of deterioration or erosion in the lining? } & \multicolumn{2}{|r|}{$\mathrm{N} / \mathrm{A}$} \\
\hline 5. & \multicolumn{3}{|c|}{ Time Began } & \multicolumn{2}{|c|}{$8: 43: 59 \mathrm{AM}$} \\
\hline 6. & Comments & & 0 & & \\
\hline G. & \multicolumn{5}{|c|}{ BREAKTHROUGH } \\
\hline 1. & \multicolumn{3}{|c|}{ Are any underground mines beneath or adjacent to the pool or embankment? } & \multicolumn{2}{|r|}{ No } \\
\hline 2. & Any signs of & & to the embankment? & & No \\
\hline & Have mine & & gged since the last measurement? & & $\mathrm{N} / \mathrm{A}$ \\
\hline 3. & Time Began & & & & 55:22 AM \\
\hline 4. & Comments & & 0 & & \\
\hline $\mathrm{H}$. & SLURRY/RE & & & & \\
\hline 1. & Abnormaliti & & cked joints, etc.)? & & $\mathrm{N} / \mathrm{A}$ \\
\hline 2. & Are slurry lir & & ind clear of moving equipment? & & $\mathrm{N} / \mathrm{A}$ \\
\hline 3. & Are the pipe & $t a$ & eventing significant sagging in the line? & & $\mathrm{N} / \mathrm{A}$ \\
\hline 4. & Time Began & & & & 55:57 AM \\
\hline 5. & Comments & & 0 & & \\
\hline I. & ROADWAYS & $\mathrm{MB}$ & AENT & & \\
\hline 1. & Are roadwa & an & for travel? & & Yes \\
\hline 2. & Are berms i & & ere necessary? & & Yes \\
\hline 3. & Are there ar & ont & & & $\mathrm{N} / \mathrm{A}$ \\
\hline 4. & Are dump ld & & ined? & & $\mathrm{N} / \mathrm{A}$ \\
\hline 4. & Time Began & & & & 56:31 AM \\
\hline 5. & Comments & & 0 & & \\
\hline Piezomet & terID & 1 & & 125 & Inches \\
\hline Piezomet & terID & 0 & & 0 & 0 \\
\hline Piezomet & terID & 0 & & 0 & 0 \\
\hline Piezomet & terID & 0 & & 0 & 0 \\
\hline Signature & & & & Date & \\
\hline Counters & signature & & & Date & \\
\hline
\end{tabular}

Figure 23: Page 2 of example populated output report for Pedlar inspection. 


\subsection{Hibbs Run Inspection Results}

Section 4.2.1 discusses each inspection performed at the Hibbs Run facility. Like the Pedlar series, these inspections were performed in alternating orders to show that the template may be used in a manner that best suits the inspector. Again, the results show up identically on a map regardless of the order of which they were recorded. The template worked better yet with this impoundment because of the locations of certain impoundment features such as the piezometer and emergency spillway. The inspections were easily performed without overlapping routes or alternating features multiple times.

\subsubsection{Hibbs Run Inspections over Aerial Imagery}

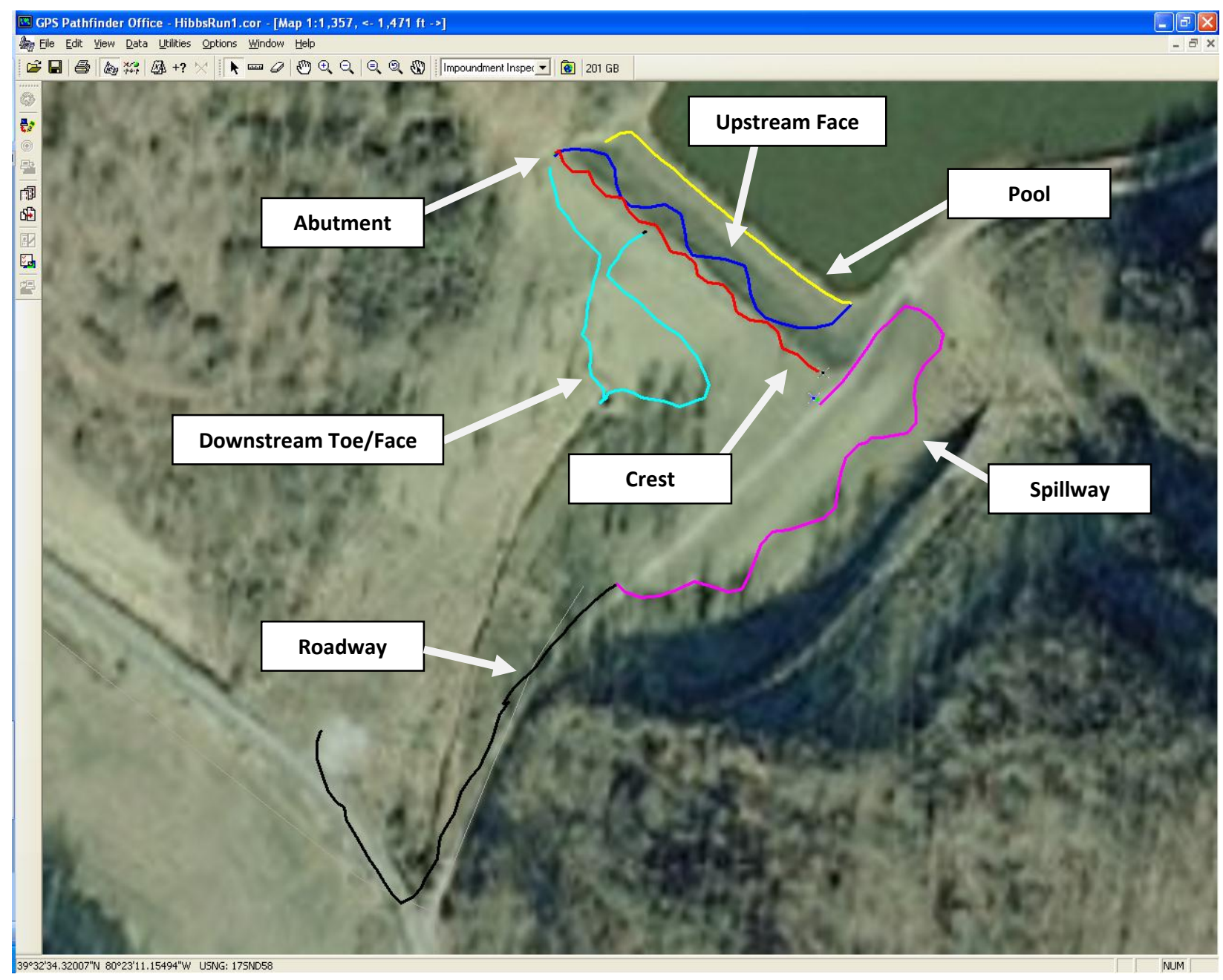

Figure 24: HibbsRun1 inspection mapped over aerial imagery.

The first inspection at Hibbs Run began with completion of the general information. The first feature in Figure 24 recorded for the impoundment was the crest (red), which unlike the Pedlar site, could be 
entirely recorded at once. This reduced the number of features to work with back in the office. After the crest was examined, the left abutment (green) followed. From the left side of the impoundment, the upstream face (dark blue) was recorded. The waterfront was inspected after under the impoundment pool (yellow) feature. The downstream toe (cyan) and face was assessed next by traveling over the downstream face to the outlet and back. The breakthrough and return line features were recorded next, which posed no significance because there are no mines or return lines adjacent to the site. The only piezometer on site was recorded at the left side of the crest, as was the left abutment. The walk from the impoundment consisted of recording the left spillway (magenta) and the roadway (black) leading out of the site.

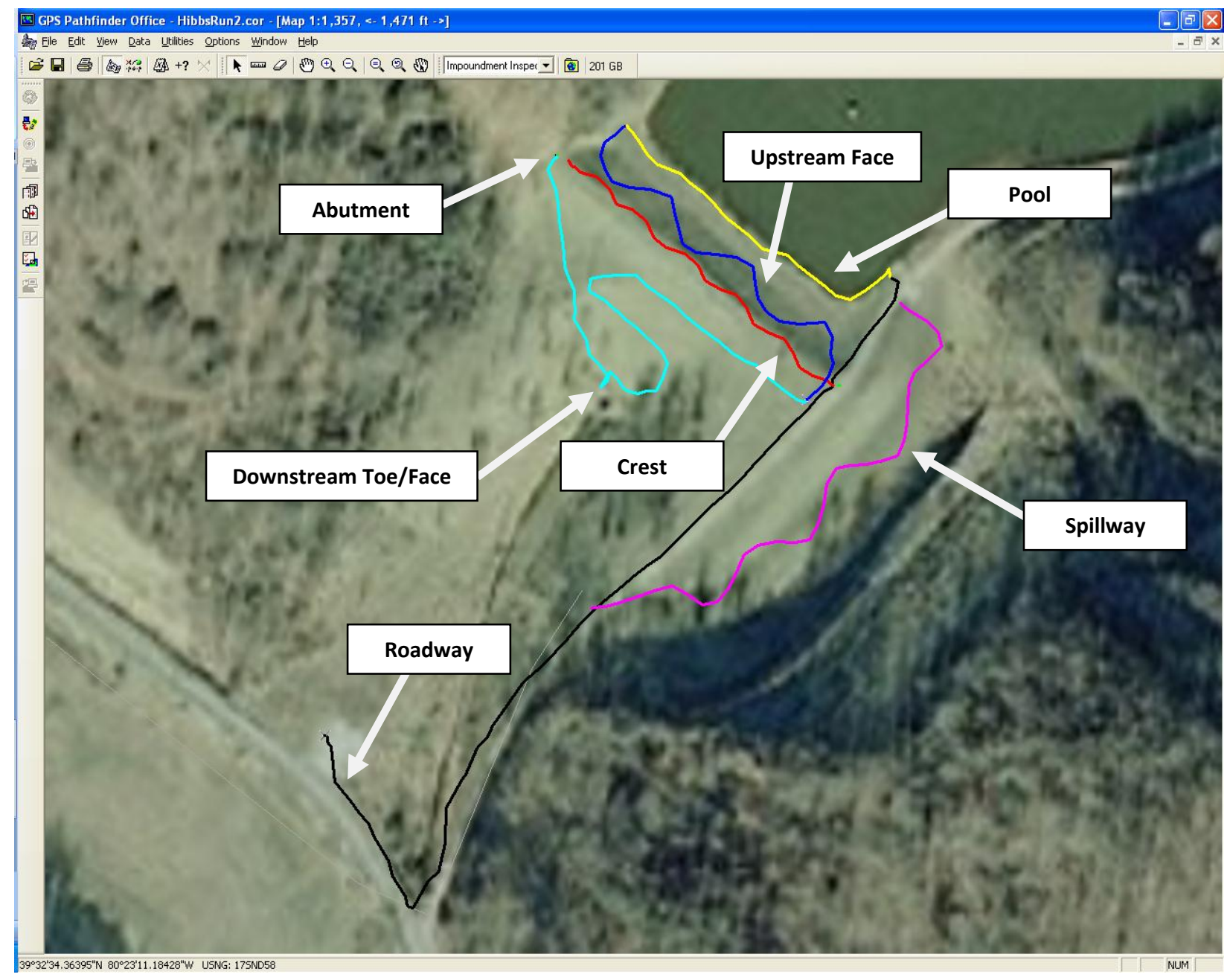

Figure 25: HibbsRun2 inspection mapped over aerial imagery.

The second inspection (Figure 25) consisted of recording the roadway feature on the way into the impoundment, which differed from the order of the first inspection. The roadway was traveled down to 
the impoundment pool, which was recorded next. From the right side of the impoundment, the upstream face was navigated and inspected, followed by the piezometer and then the downstream toe/face, which was traveled differently than before. Breakthrough and return line features were recorded after the downstream toe area. Then, the right abutment was inspected and the crest was navigated in the opposite direction from before. The left abutment and spillway were examined to complete the inspection, which only totaled about 28 minutes.

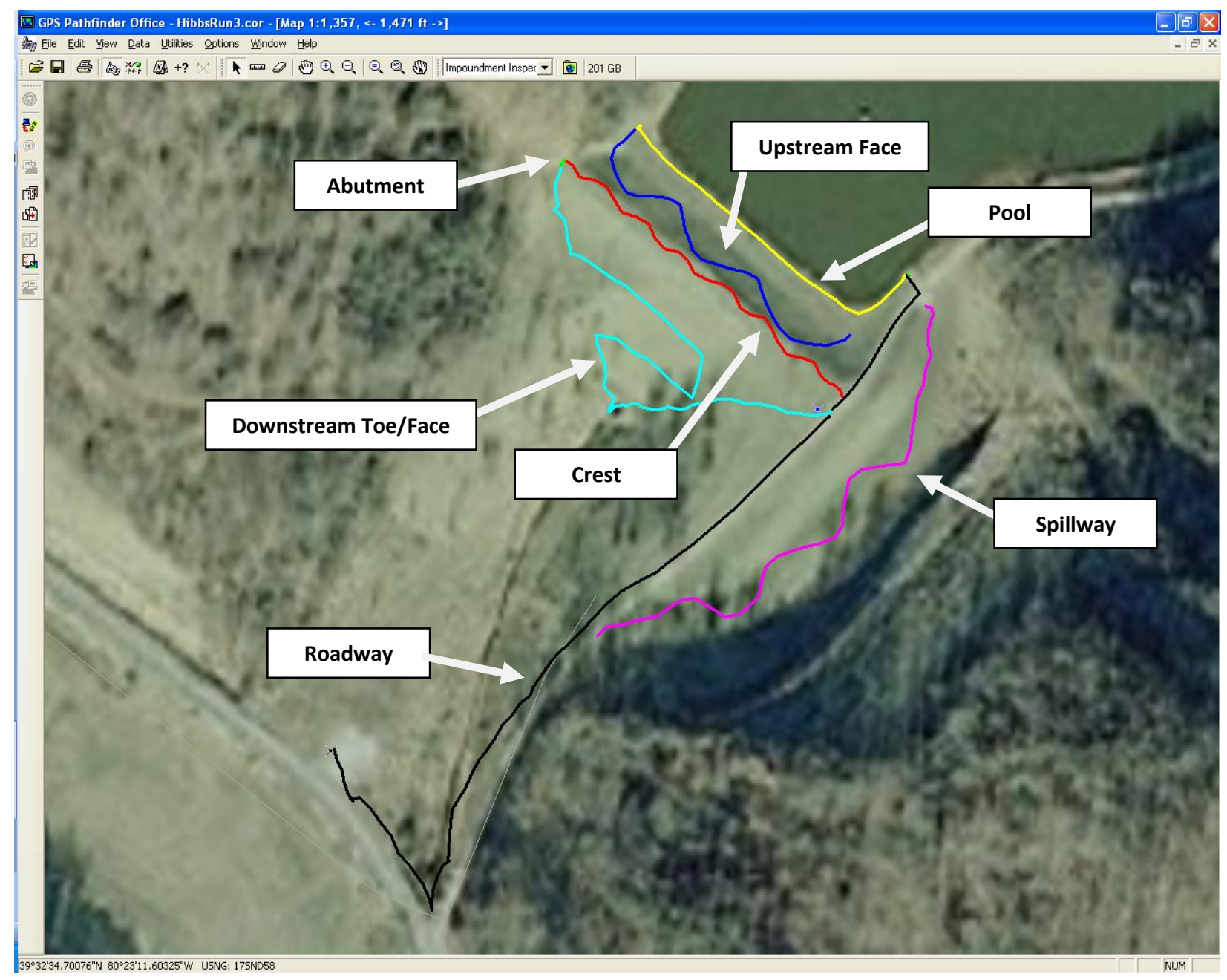

Figure 26: HibbsRun3 inspection mapped over aerial imagery.

The third inspection (Figure 26) of Hibbs Run began with the roadway inspection once again, which followed completion of the general information feature. The piezometer was recorded next, and the crest followed. The right abutment was assessed for hazards preceding the navigation over the downstream face of the structure. The downstream face was traveled differently again, making sure that all area was covered between the three inspections. After arriving at the crest of the impoundment 
again, the section of roadway from the crest to the impoundment pool was examined. From this point, the left abutment was recorded and the breakthrough/return lines questions were completed. From this same location, the impoundment pool was inspected, and on the way back from the right side, the upstream face was checked. The spillway feature concluded the third inspection performed at the Hibbs Run area.

\subsubsection{Differential Correction Report}

The data below is the result of the differential correction wizard for Hibbs Run in Trimble Pathfinder Office. The distribution of corrected positions is displayed on Page 55.

Searching for base files...

File C: \Documents and Settings \Eric Baker \My Documents \GNSS Projects \Impoundment Inspection\Base\CORS, UNIONTOWN (PAFU), PENNSYLVANIA\pafu20111161.zip (1 of 3) found locally. File C: :Documents and Settings\Eric Baker\My Documents\GNSS Projects \Impoundment Inspection\Base\CORS, UNIONTOWN (PAFU), PENNSYLVANIA\pafu20711162.zip (2 of 3) found locally. File C: \Documents and Settings\Eric Baker\My Documents\GNSS Projects\Impoundment Inspection\Base\CORS, UNIONTOWN (PAFU), PENNSYLVANIA\pafu20811132.zip (3 of 3) found locally. Successfully found or downloaded 3 of 3 files.

Search complete.

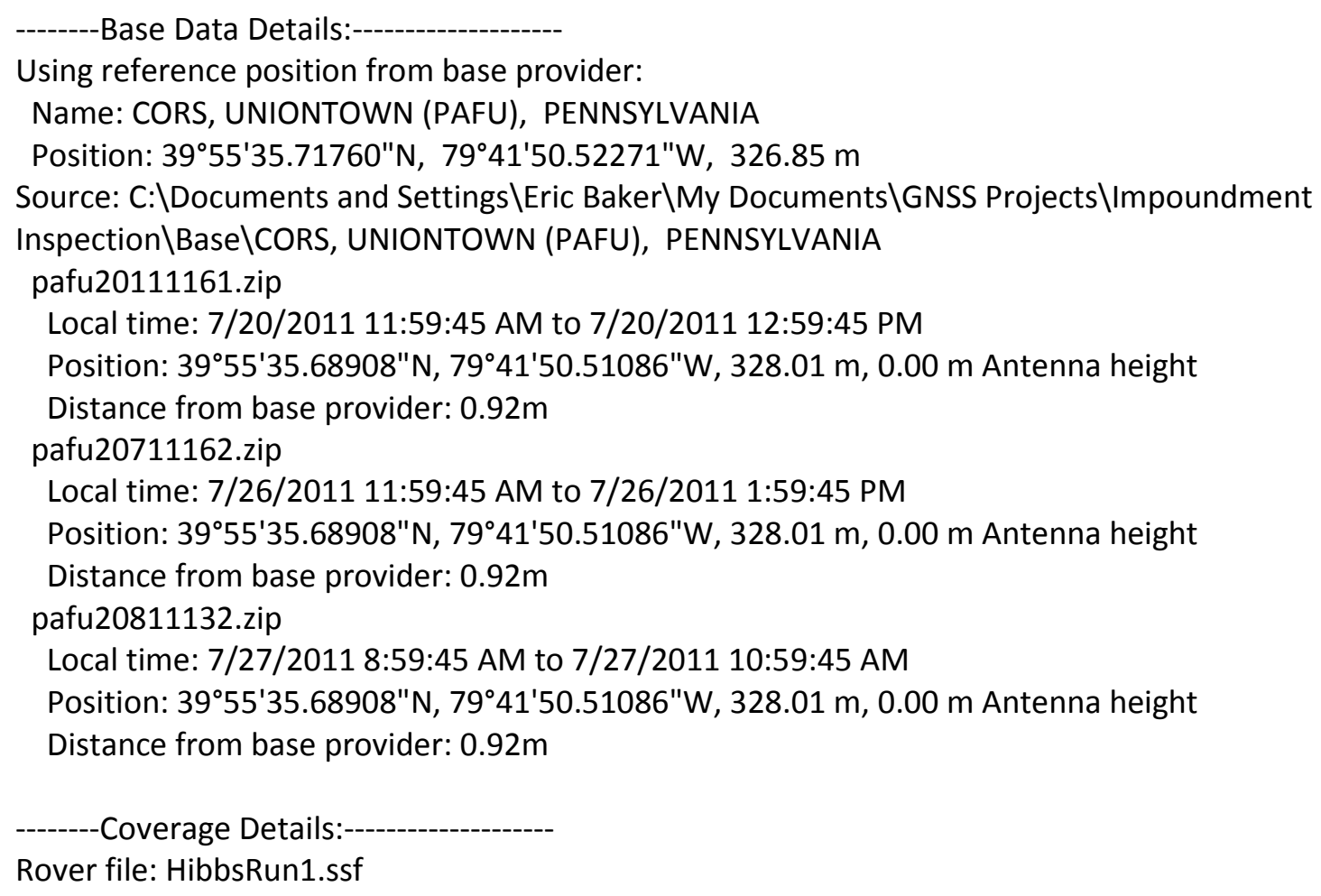


Local time: 7/20/2011 12:27:24 PM to 7/20/2011 12:58:15 PM

$100 \%$ total coverage

100\% coverage by pafu20111161.zip

Rover file: HibbsRun2.ssf

Local time: 7/26/2011 12:49:27 PM to 7/26/2011 1:17:44 PM

$100 \%$ total coverage

$100 \%$ coverage by pafu20711162.zip

Rover file: HibbsRun3.ssf

Local time: 7/27/2011 9:48:53 AM to 7/27/2011 10:25:00 AM

$100 \%$ total coverage

$100 \%$ coverage by pafu20811132.zip

Differentially correcting...

Differential correction settings:

Use smart automatic filtering: On

Re-correct real-time positions: On

Output positions: Corrected only

Processing rover file, HibbsRun1.ssf ...

...to output file, C:\Documents and Settings \Eric Baker\My Documents\GNSS Projects \Impoundment Inspection\HibbsRun1.cor

Carrier processing...

No carrier processing performed as file has no carrier data

Corrected 0 positions

Code processing...

Selected 320 positions for post-processing

Corrected 320 positions

Processing rover file, HibbsRun2.ssf ...

...to output file, C:\Documents and Settings \Eric Baker\My Documents\GNSS Projects \Impoundment Inspection\HibbsRun2.cor

Carrier processing...

No carrier processing performed as file has no carrier data

Corrected 0 positions

Code processing...

Selected 286 positions for post-processing

Corrected 286 positions

Processing rover file, HibbsRun3.ssf ...

...to output file, C: \Documents and Settings \Eric Baker\My Documents $\backslash$ GNSS Projects $\backslash I m p o u n d m e n t$ Inspection\HibbsRun3.cor

Carrier processing... 
No carrier processing performed as file has no carrier data

Corrected 0 positions

Code processing...

Selected 385 positions for post-processing

Corrected 384 positions

Failed to correct 1 positions

Filtered out 1 uncorrected positions

(only "Corrected" positions selected for output)

Differential Correction Summary:

3 files processed. In these files:

990 (99.9\%) of 991 selected positions were code corrected by post-processing

$0(0.0 \%)$ of 0 selected positions were carrier corrected by post-processing

Estimated accuracies for 990 corrected positions are as follows:

Range Percentage

$\begin{array}{cc}-------- & -------- \\ 0-15 \mathrm{~cm} & - \\ 15-30 \mathrm{~cm} & - \\ 30-50 \mathrm{~cm} & - \\ 0.5-1 \mathrm{~m} & - \\ 1-2 \mathrm{~m} & - \\ 2-5 \mathrm{~m} & 80.0 \% \\ >5 \mathrm{~m} & 20.0 \%\end{array}$

Differential correction complete.

\subsubsection{Example Final Report}

Figures 27 and 28 show the final results from one of the Hibbs Run inspections performed. The data displayed below is similar to what is shown on the traditional paper form, as required by MSHA, and is automatically populated to an extent onto this sheet when the data is exported into Excel. The complexity of the GPS data and attributes limits the ability of the program to automatically fill out the output report in full. 


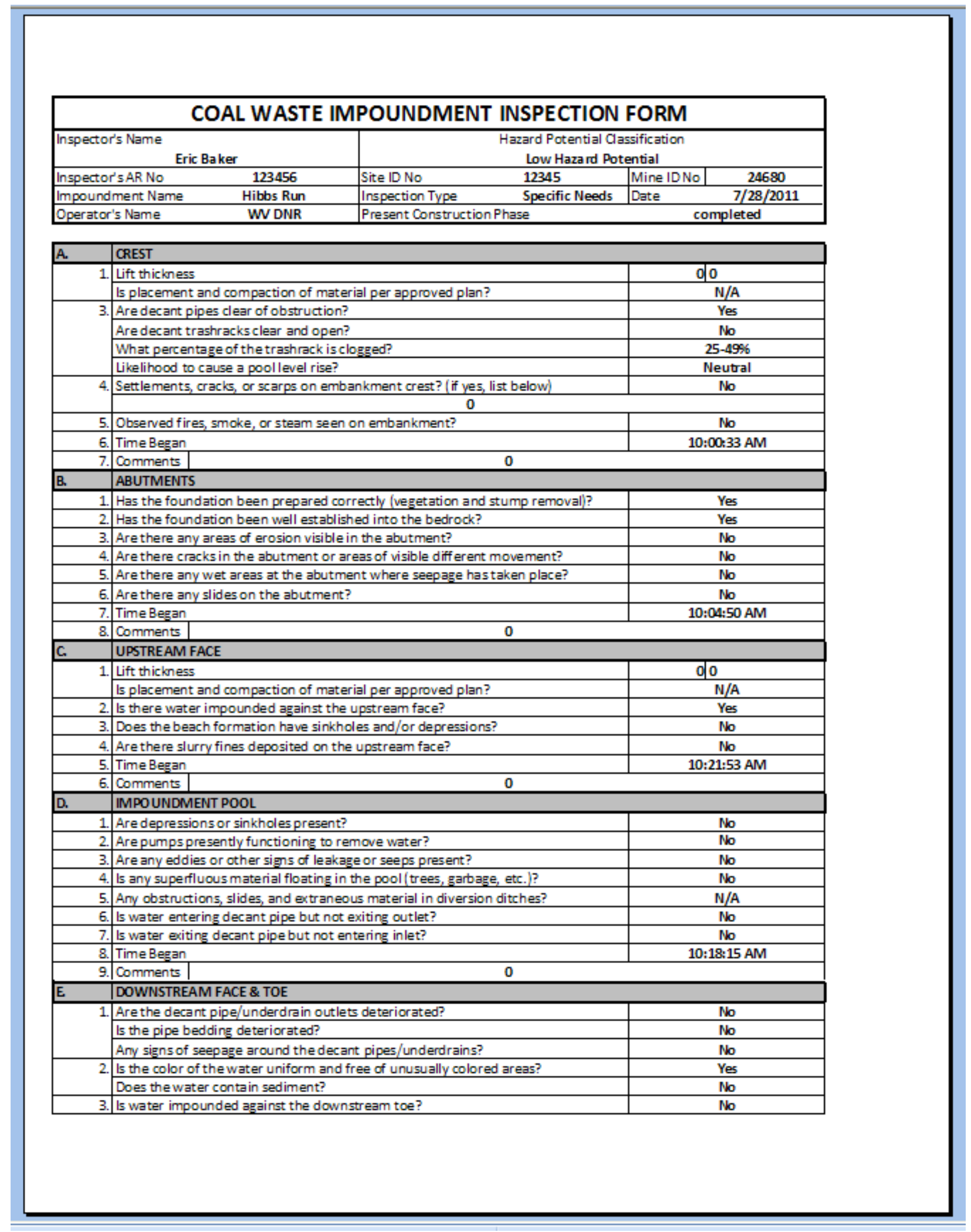

Figure 27: Page 1 of example populated output report for Hibbs Run inspection. 


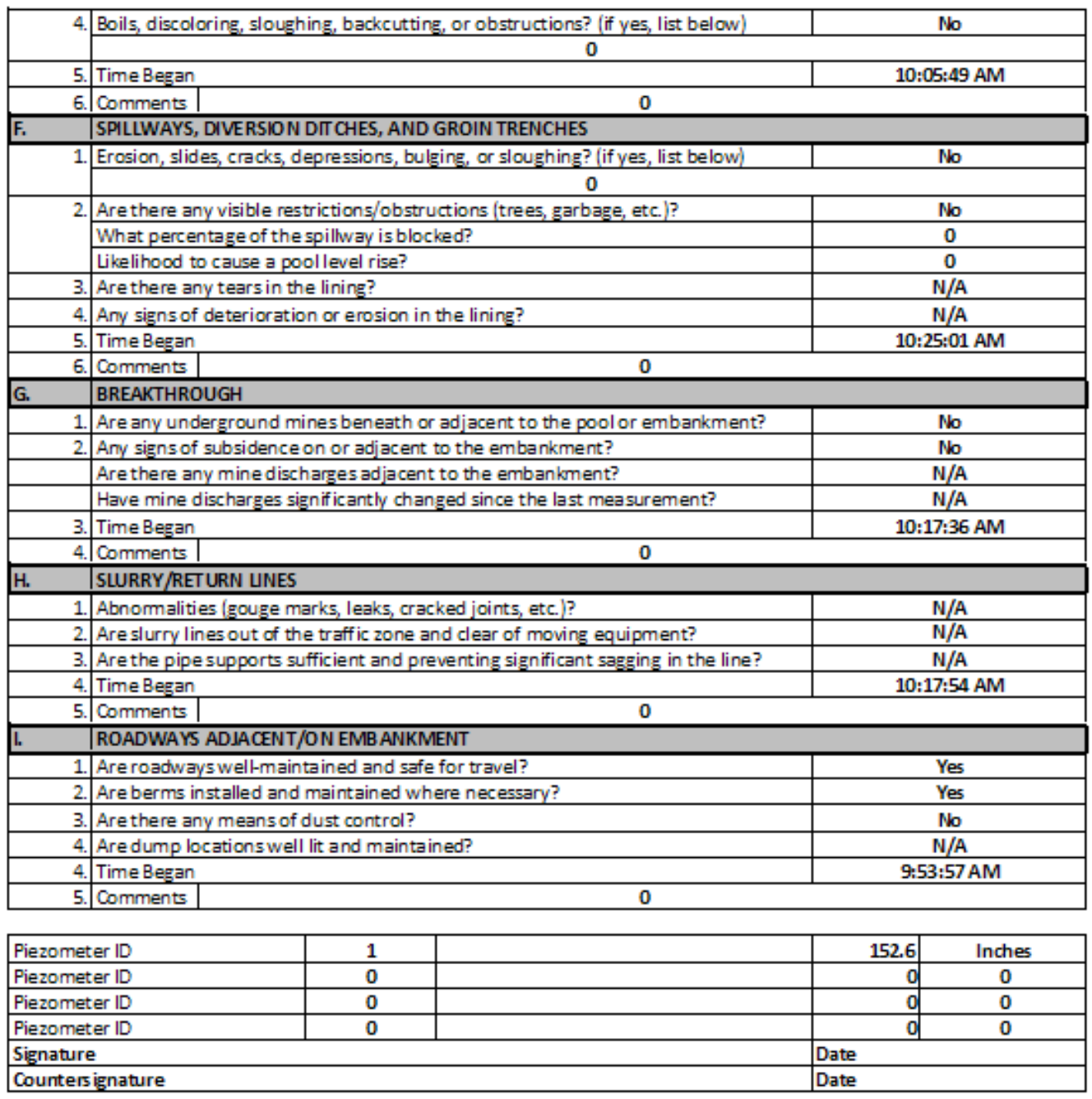

Figure 28: Page 2 of example populated output report for Hibbs Run inspection. 


\subsection{Combined Inspection Mapping}

Combining inspection files may be beneficial to the industry because of its ability to show the multiple routes traveled over time. The maps are proficient at demonstrating either the consistency or the randomness of the routes walked over the retention structure. Figure 29 shows the series of three inspections performed at Pedlar WMA while the second is of the series performed at Hibbs Run impoundment. Notice how the downstream face of the Pedlar impoundment was only traveled one of the three times, while the downstream face of the Hibbs Run impoundment was covered in a different manner each time. These types of features are essential to proper inspection, and using a combined map of inspection routes will identify missed or skipped areas on any impoundment inspection.

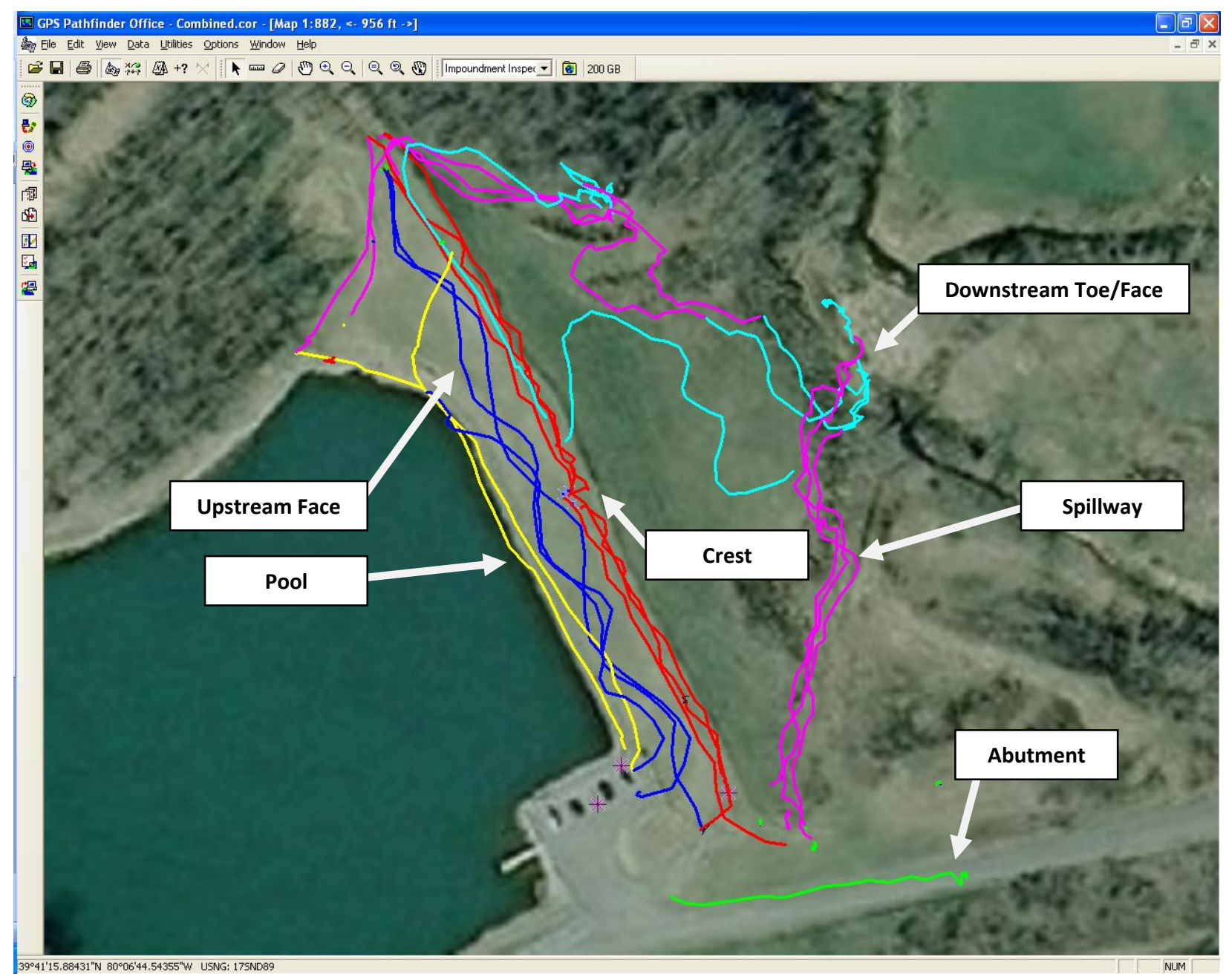

Figure 29: Combined map of Pedlar inspections over aerial imagery. 


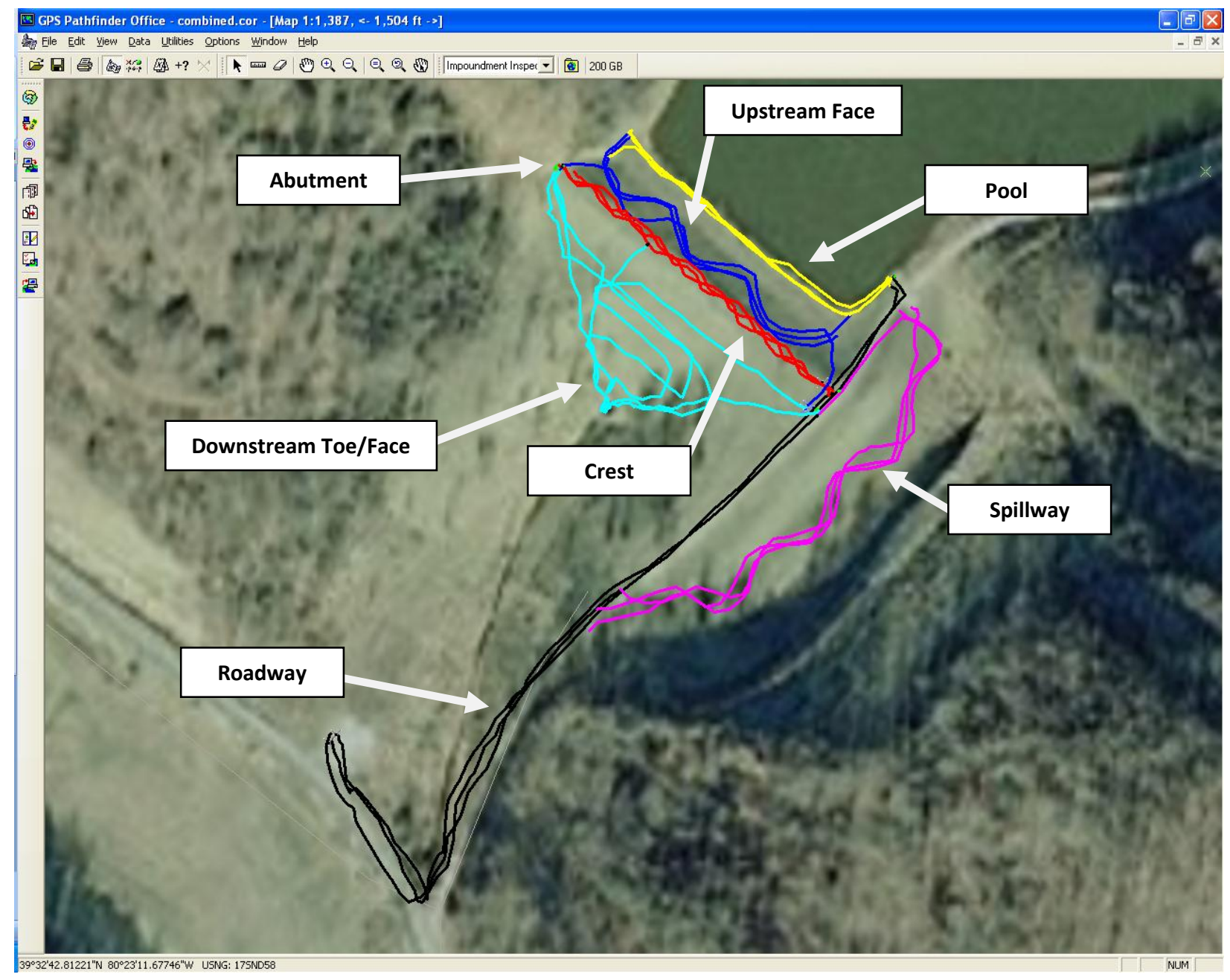

Figure 30: Combined map of Hibbs Run inspections over aerial imagery.

\subsection{Technology Evaluation}

Before the Mannington inspection series, a meeting was scheduled with members of Consol Energy in Monongah, WV. One employee was a project engineer and the other a professional surveyor. The purpose of the meeting was to give to the employees a presentation and receive feedback on the functionality of the instrument and inspection template in the coal industry. A short presentation was given on the Trimble Yuma and the inspection template created in Pathfinder Office, and a discussion pursued. The employees also filled out a questionnaire following the discussion to assess their overall feelings on the electronic inspection process. The forms were collected and are illustrated in Figures 31 and 32 . 
The employees had many questions regarding the capability of the Terrasync program, particularly about calculating values within the program automatically for output in the final report. The employees were especially interested in the ability of the Trimble software to automatically calculate the difference between the piezometer values of the current and previous inspections. Each Consol representative stated that as the photos are innovative and helpful to locating and identifying problems, they may require too much space on the computer hard drive as well. The surveyor present also suggested that for constant logging of travel routes, a logging interval of more than five seconds would suffice. Fifteen seconds was recommended as an appropriate interval for logging walking paths.

They had concerns about the turnaround time for getting a hard copy of the final report because MSHA requires that the inspection be reviewed and signed by a mine official within a reasonable amount of time of inspecting the impoundment. Ultimately, their question asked if a final report could be saved as a Microsoft Word or PDF file following the inspection so that a mine official may receive a readerfriendly copy of the information soon after the inspection.

All of the questions posed by Consol were discussed the meeting and addressed with potential solutions. As far as the Trimble software is equipped, it does not calculate values within the Terrasync program. Terrasync is equipped primarily for capturing GPS coordinates and does not have the capability to locate values from previous inspections and perform simple math in order to provide discrepancies in piezometer values. The surveyor at the meeting recommended that in the case the project is continued, using other software in order to achieve these results may be a more efficient method instead of modifying Trimble software to do so. The photo sizes were discussed in addition to the logging interval, and the Consol employees were notified that the photos do not need to be required unless problem areas are encountered. The logging interval can be changed to suit the project or employer as well.

The primary concern involved the output report deals with the signature requirement of the report as required by federal regulation. A few potential solutions were examined in order to achieve an output report on paper nearly immediately after the inspection. Ignoring the potential problems with the template used in Excel, the inspection can be exported to Access and then to Excel in only a few minutes. The output report template automatically populates the inspection information, and a copy of the file may be sent to the mine manager via the wireless internet on site or a portable flash drive. Another solution is to cut out the use of Access and Excel and turn to ArcGIS instead. Pathfinder Office export may be used to send all the selected inspection information to an ArcGIS shape file, which then 
may be formatted into an output report. Limited investigation of ArcGIS reporting was performed, but custom templates may be made to include particular information as desired; however, the output report file may only be saved in particular file formats. Utilities may exist for saving the ArcGIS reports in Microsoft Word or PDF formats, but none were examined. This approach would require ownership of the ESRI program, but could reduce the time to achieve a hardcopy of the inspection report immensely. The procedure would be shortened drastically as well once the custom template has been created for the output report because ArcGIS has a more organized method for storing collected attributes.

Overall, the Consol staff found a use for the Trimble equipment and associated template for inspecting coal impoundments. Each employee claimed that the automated template would be at least somewhat more useful than the paper form used now. They also thought that the electronic template may be helpful in improving impoundment safety. The employees thought that it may be difficult to incorporate the inspection tool into their inspection operations, considering training and the technical level of understanding involved. The employees both implied that the inspection tool could be beneficial to impoundment inspection, but some improvements could be made to enhance the functionality, especially within their own organization. Each employee made valuable claims that helped to identify potential difficulties involved with the electronic inspection procedure, many of which may be mended or approached differently in order to make the tool more functional in the coal industry. 


\section{IMPOUNDMENT INSPECTION TOOL REVIEWER EVALUATION FORM}

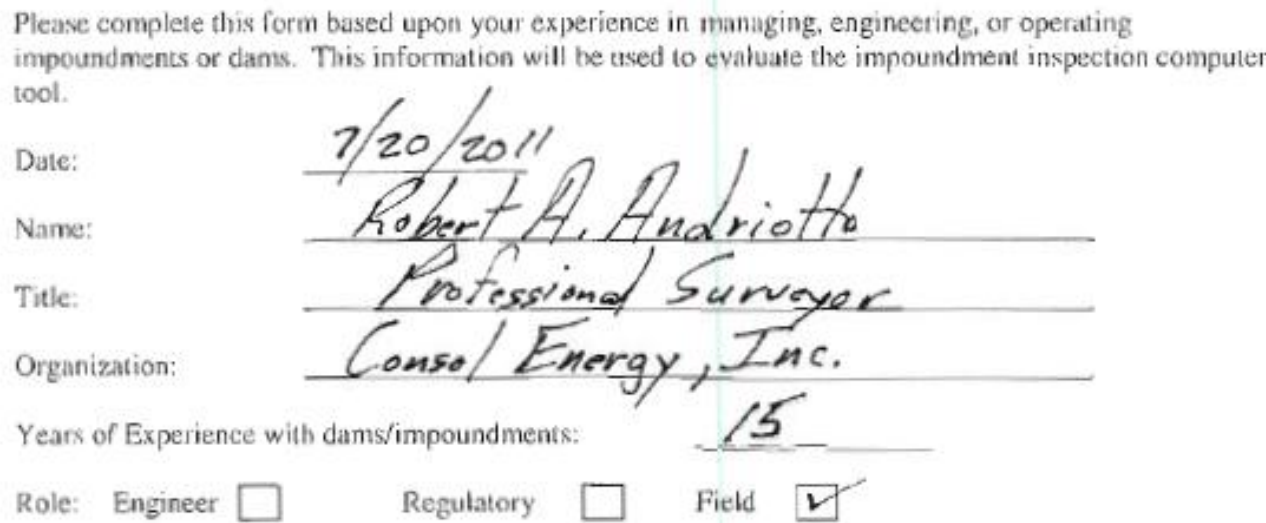

1. On the basis of your experience and role, how uscful do you consider the tool for improving the quality and detail of an inspection over a paper inspection form? Very useful

2 Somewhat useful Noc very useful

2. How applicable do you consider this tool for improving impoundment safety?

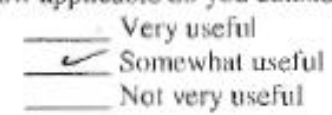

3. To what level do you consider the GIS tracking features, time/date stamping, photographic, and audio recording features of the tool specificaliy for reducing liability for your organization?

$$
\begin{aligned}
& \text { Very useful } \\
& \text { Somewhat useful } \\
& \text { Not very useful }
\end{aligned}
$$

4. How applicable would this tool function in your company's operations, considering technical operation and software Iraining requirements? Very difficult

$\angle$ Difficult Nor difficult

5. How applicable would you consider this tool is for reducing the risk to your impoundment/dam? Very useful

$\checkmark$ Somewhat useful Not very useful

6. Please list features of the tool you found important or features you consider are desrimental to its use or implementation:

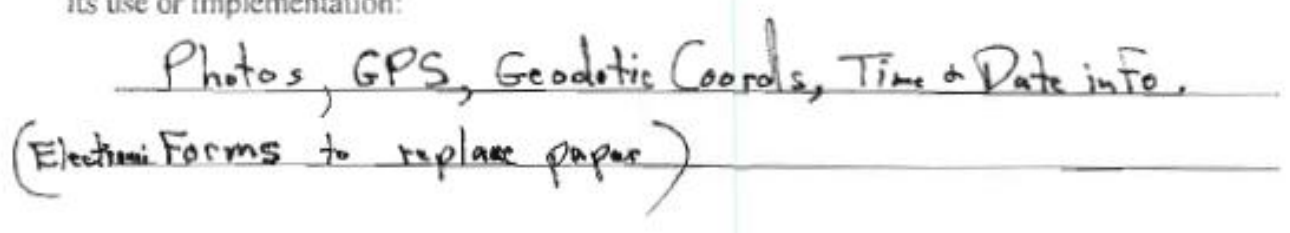

Figure 31: Evaluation form regarding technology and inspection process. 


\section{IMPOUNDMENT INSPECTION TOOL REVIEWER EVALUATION FORM}

Please complete this form based upon your experience in managing, engineering, or operating impoundments or dams. This information will be used to evaluate the impoundment inspection compuier lool.

Date:

Name:

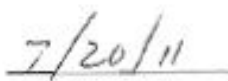

Name

Title:

Organization:

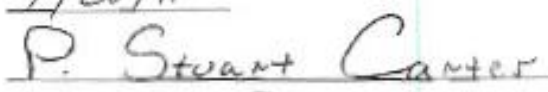

Years of Experience with damvimpoundments:

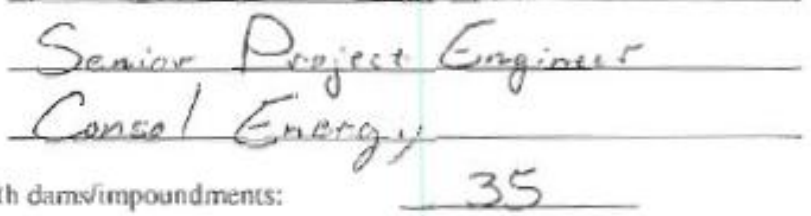

Role: Engineer $\mathrm{X}$

Regulatory

Field

1. On the basis of your experience and role, how useful do you consider the tool for improving the quality and detail of an inspection over a paper inspection form?

$\checkmark \quad$ Very useful
Somewhat useful
Not very useful

2. How applicabie do you consider this tool for improving impoundment safety?

Very useful

$\checkmark$ Somewhat useful

Not very useful

3. To what level do you consider the GIS tracking features, time/date stamping, photographic, and audio recording features of the tool specifically for reducing liability for your organization?

Very useful

Somewhat useful

$\checkmark$ Not very useful

4. How applicable would this tool function in your company's operations, considering lechnical operation and software training requirements?

$$
\text { Very difficutt }
$$

$\checkmark$ Difficult ( our not imporible)

Not difficult

5. How applicable would you consider this tool is for reducing the fisk to your impoundment/dan?

Very usefut

$\checkmark$ Somewhat useful

__ Not very useful

6. Please list features of the tool you found important or features you consider are detrimental to its use or implementation:

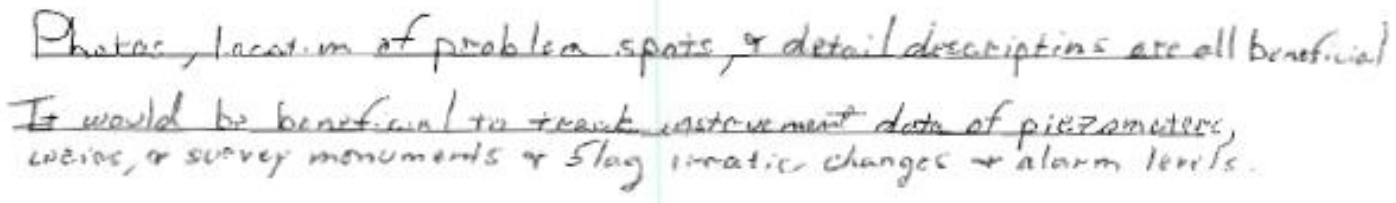

Figure 32: Evaluation form regarding technology and inspection process. 


\section{Conclusions}

The purpose of this investigation focused on coal impoundment safety and early hazard potential awareness. Development of a technology to achieve a higher degree of safety was proposed as a solution; and accordingly, a mobile field computer and supplemental software were chosen in order to assess their ability to achieve that higher degree. The objectives of this investigation were previously identified as the following:

- Electronic based check-listing software with a standard or custom template that must be completed during routine field dam inspections

- GPS for precise georeferencing field observations and geotagging photographs

- Tracking multiple inspections over time with time stamped data to guarantee the time of inspection

- Ability to record inspection path with GPS and store map of routine route traveled

- Input areas for data storage and graphing so field data may be compared over time to evaluate impoundment performance

- Ability to upload data to office computer for storage and printing

- Ability to email alerts or text message MSHA District Engineer or Tech Support for assessment of information more rapidly

- Ability to upload and store MSHA Inspection Manual and Emergency Action Plan (EAP) for ease of access

- Ability of software program to mark fields and alarm the inspector of missing information (equipment should be equipped with speaker for audible alert)

All requirements of the technology were met by creating an inspection template to be used with the selected mobile field computer which has all the necessary features. The use of this mobile field computer was successful with storage of more information for a field inspection including geotagged photos and expediting the inspection process by providing a resource for email and automated data storage. The benefits of the inspection template was shown by accomplishing the following:

- Time \& date stamping for assurance that inspector is performing inspections promptly

- Stored GPS coordinates for all inspections as a liability for inspection quality

- Tracking of field observations over time to assess progressive potential hazards 
- Ability to create historical database in Microsoft Access for later use

- Ability to use electronic data to perform risk management statistics and create frequency of occurrence graphs

- Ability to export data to ArcGIS for interactive mapping

- Accessibility of EAP and MSHA manual in the field for assistance in performing inspection

The creation of a technology to perform such a complicated task as generating databases as well as meeting MSHA requirements simultaneously was not perfected at the conclusion of this investigation and will call for improvements to ready the process for commercialization. The learning process throughout this exploration also grew upon the functionality of the technology in the industry partially due to the rapid file sharing and output report generation. After the technology was evaluated by representatives of the coal industry, the protocol of the entire procedure was reexamined. The following problems and improvements were encountered during the time of the assessment.

- Deletion of a decant pipe outlet photo and exiting water attribute under the impoundment pool feature because of inconvenient placement

- Inclusion of aerial imagery files into the Pathfinder Office software for overlaying the inspection routes because routes were essentially useless without aerial images (this step documents the inspector's presence at the impoundment)

- The overall process appeared complicated to the individuals and thus did not emerge as useful without the rapid ability to generate an output report to obtain signatures from mine officials on site, which is problem in regard to legal compliance. The time elapsed from the beginning of the inspection until the generation of a hardcopy output report is essential to the coal industry, and the acceptance of this technology rests upon the ability to do so more rapidly.

Employing Microsoft Access could provide a solution to the expedited time requirement as it may have the ability to create a satisfactory report template to be signed by mine officials. Access is readily accessible by most of the industry because it is included in the Microsoft Office suite, and it would reduce the number of steps in the inspection process by cutting the export into Excel and addition of the report template; however, more research is critical to assessing the capability of the software to perform these tasks.

The automated inspection form process shows potential to improve the coal impoundment inspection practice and the overall safety of coal impoundments because of its improved ability to document data 
and report data relevant to potential hazards. Using the automated process could decrease the number of problems resulting from negligence and provide risk assessment information of problems not being corrected. The automated process may provide the opportunity to create a low maintenance historical database with ease of access. Output reports containing risk management suggestions will be readily accessible within a short time of inspection, although the time must be reduced to commercialize the technology.

\section{Future Research}

\subsection{Risk Assessment Using Palisade Software}

A software program made by Palisade was examined to test its validity for performing a routine coal impoundment inspection with the help of a mobile field computer. The Palisade software contains many entities intended for different principles, but for the purpose of inspecting a coal impoundment the two desirable programs are @RISK and PrecisionTree. These two programs can be used together in Microsoft Excel, making calculations much easier and saving storage space on the field computer. Upon purchasing, the Palisade software is sent via download and placed into Excel as an add-on tab. Palisade software has the ability to create event trees and financial models as well as perform Monte Carlo simulations, all of which will prove to be beneficial to an automated impoundment inspection.

Using a Monte Carlo simulation allows the qualified personnel to see all the possible outcomes and assess the level of risk for each given outcome. The Monte Carlo simulation works by creating a probability distribution and calculating results repeatedly by using a different set of values from the distribution every time (Palisade Corp. 2010). The Monte Carlo simulation has been used by the Bureau of Reclamation for finding flow values in aquifers (Leake 2010) in addition to the Census Bureau for estimating total lifetime risk from radon loaded drinking water based on different maximum contaminant levels (Raucher 2004).

Considering the required features for the software program, the Palisade software meets every need and is compatible with the Trimble Yuma, the recommended mobile field computer to be used for the impoundment inspection. The software must be capable of having a check-listing template to be completed during routine inspections. Since @RISK and PrecisionTree both work through Microsoft Excel, there should be no problem creating such a model. Excel is also very gifted at having the space to 
log field observations indefinitely so that the data may be graphed over time. Furthermore, the files will not take up much disk space and be easy to store on the field computer.

The time stamping of information during a routine inspection is critical as well; thus, the Excel software has the ability to input a time stamp on a particular cell. Moreover, the Excel file itself will have a time stamp revealing when it was last modified; in essence, Microsoft Excel saves the last date and time that anything in the document was altered. Additionally, the completed inspection files may be sent to the district office with ease because they will be saved as a simple .xlsx Excel file.

After checking over the Palisade software for a feature that marks fields of interest or fields that were not filled out, the search for such a set-up was inconclusive. The PrecisionTree portion of the software will design an event tree and evaluate the probability of any occurrence. If key values are not entered into the system, then the event tree will more than likely not be able to output any results, alerting the inspector that he or she has missed important data input. Excel does, however, have the ability to highlight cells and flag certain cells.

The Palisade software has seen much use in the field lately that is strongly related to the risk assessment of an impoundment. When a Chilean mine collapsed and trapped 33 miners over 200 feet underground, it was Palisade software that helped Metaproject, an engineering consultant, rescue the miners as quickly as possible. There were many options explored involving a rescue operation that used many different drill rigs and tunnels. After using the PrecisionTree modeling software, Metaproject used three different drill rigs to all work simultaneously, and as the PrecisionTree model predicted, Drill B was the first to reach the miners (Palisade Corp. 2010).

In another risk related incident, the @RISK software is helping to prepare for a volcanic explosion on the Caribbean island of Montserrat. The Soufriere Hills volcano erupted once in 1997, killing twenty individuals on the island. Since then, the @RISK software combined with the PrecisionTree analysis has been used to simulate risk under a variety of situations. The software is also used to calculate the probabilities of assorted eruptions based on past volcanic activity (Palisade Corp. 2010).

Overall, the Palisade software should accomplish the necessary tasks for performing risk assessment of an automated coal impoundment inspection. Mostly because of its simplicity to use and store files in Microsoft Excel, the Palisade software is the recommended selection for assessing risk to particular attributes of a coal impoundment. The software has demonstrated its worth in the field with its use by government agencies and is being suggested as the most viable resource for risk assessment and 
creating an event tree. The use of this software will help to ensure safer coal impoundments, which in turn will create safer working conditions for mine personnel and increase worker productivity.

This software could serve as an entirely new branch to impoundment inspection because of its expedited use in Microsoft Excel. Foremost, this software integrated with the Trimble Yuma could make available the ability to perform risk assessment procedures in the field. The process would involve performing a field inspection and opening the data file in Pathfinder Office for export to Microsoft Access. Once the file has been exported to Access, it may be exported from Access to Excel. Once the file is in Excel, the output report as well as Palisade evaluation may be performed. It may be possible to create a template in Palisade so that the information provided from the inspection file will automatically populate an event tree. This feature would offer the ability to perform a detailed risk assessment in a short amount of time on site, seriously expediting the risk management process involved with impoundment inspection. The assessment may not be completed in fill on site; however, the findings may provide enough information to locate a potential hazard before it has progressed enough to result in failure.

\subsection{ArcGIS Mapping of Inspection}

ArcGIS may be integrated into the automated coal impoundment inspection process to utilize interactive mapping and FTP uploads. ArcGIS may be used to overlay multiple inspection routes on a topography map or aerial image and upload the information to a private or public website. The information presented may be passcode protected or available to the general public depending on the situation. A running interactive map and corresponding database may be created with an online version GIS for easier collaboration between companies for viewing inspection records, including risk assessment conclusions. Users will not necessarily need to have the background knowledge of ArcGIS but can utilize the user-friendly online version. Increasing communications and providing documentable accounts of current and historical conditions are essential to ensuring the successful longevity of these impoundments.

ArcGIS may also serve as a better means of creating the final output report to be signed on site by a mine official. The use of ArcGIS in place of Access and Excel may serve as an easier process for producing a hard copy of a detailed inspection report. The final inspection file can easily be opened on the Yuma in Pathfinder Office and exported to ArcGIS. From ArcGIS, the user may create a customized output report based on the necessary attributes, primarily those pertaining to information required by 
MSHA. The template may be generated in seconds and emailed to the mine official using the wireless internet connection on the impoundment site. If a wireless connection is not present, an express card from a cell phone may be employed. The mine official can print out the form, sign it, and return it to the inspector for his/her records within a very short time frame. The process would most likely take up to an additional fifteen minutes after the inspection; however, a signed hard copy would supplement the stored electronic information.

\section{References}

Bilefsky, D. (2010). Hungarian Arrested in Sludge Spill is Freed. New York Times. New York City: A15.

Binder, D. (2002). "Emergency Action Plans: A Legal and Practical Blueprint "Failing to Plan Is Planning to Fail”."

Dise, K. (2009). Subjective Probability and Expert Elicitation. 2010 NDSP Dam Safety Technical Seminar No. 17 Version 3: 11.

Intermec Technologies Corp. (2009). "CN3e Mobile Computer." Retrieved November 18, 2010, from http://www.intermec.com/public-files/product-profiles/en/CN3e spec web.pdf.

Intermec Technologies Corp. (2010). "CS40 Mobile Computer." Retrieved November 18, 2010, from http://www.intermec.com/public-files/product-profiles/en/CS40-spec-web.pdf.

Leake, S. A., J.P. Hoffman, and Jesse E. Dickinson (2010). Numerical Ground-Water Change Model of the C Aquifer and Effects of Ground-Water Withdrawals on Stream Depletion in Selected Reaches of Clear Creek, Chevelon Creek, and the Little Colorado River, Northeastern Arizona: 39.

Motion Computing Inc. (2010). "Motion F5v Product Specifications." Retrieved November 17, 2010, from http://www.motioncomputing.com/resources/F5/F5 Product Specs en.pdf.

National Research Council (2002). Coal Waste Impoundments - Risks, Responses, and Alternatives. Washington D.C.

Palisade Corp. (2010). "Metaproject Determines Safest Way to Rescue Chilean Miners Using Palisade's PrecisionTree Analysis Tool." Retrieved December 15, 2010, from http://www.palisade.com/cases/metaproject.asp.

Palisade Corp. (2010). "Monte Carlo Simulation." Retrieved December 16, 2010, from http://www.palisade.com/risk/monte carlo simulation.asp.

Palisade Corp. (2010). "@RISK, PrecisionTree Critical in Preparing for Volcano Eruption." Retrieved December 15, 2010, from http://www.palisade.com/cases/volcano.asp. 
Panasonic Corp. (2010). "The Toughbook U1 Ultra." Retrieved November 18, 2010, from

ftp://ftp.panasonic.com/pub/panasonic/toughbook/specsheets/TB-U1-Ultra ss.pdf.

Raucher, B., and Megan Harrod. (2004). "Estimating Lifetime Excess Cancer Risks for Potential MCLs for Radon in Drinking Water: A Monte Carlo Simulation and Results to Reflect Residential Mobility."

Retrieved December 16, 2010, from

http://www.nrwa.org/whitepapers/conserve/conserve03/appendixb/appendixb.doc.

Trimble Navigation Limited 2005. (2005-2009). "Trimble Ranger handheld." Retrieved November 22, 2010, from http://trl.trimble.com/docushare/dsweb/Get/Document-241754/022501-

061D Trimble\%20Ranger DS 0109 Ir.pdf.

Trimble Navigation Limited 2009. (2009-2010). "Trimble Yuma Rugged Tablet Computer." Retrieved November 18, 2010, from http://trl.trimble.com/docushare/dsweb/Get/Document-452035/NZ022490068C MCSTrimble Yuma DS 0210 LR.pdf.

Trimble Navigation Limited. (2010). "GPS and GIS Technologies Speed Assessment of Historic Sites in Post-Katrina New Orleans." Retrieved February 11, 2011, from http://trl.trimble.com/docushare/dsweb/Get/Document-495003/022501-

230 Assessment\%20of\%20Historic\%20Sites\%20 CS MGIS 0510 LR.pdf.

Trimble Navigation Limited. (2011). "Powerful and easy to use GNSS data processing software." Retrieved February 11, 2011, from http://www.trimble.com/pathfinderoffice.shtml.

Trimble Navigation Limited. (2011). "Software for Highly Productive Field GIS Data Collection and Maintenance." Retrieved February 14, 2011, from http://www.trimble.com/terrasync.shtml.

U.S. Department of Labor (2007). MSHA Coal Mine Impoundment Inspection and Plan Review Handbook.

U.S. Department of the Interior (2010). RECLAMATION - Managing Water in the West. FEMA National Dam Safety Seminar: 222.

United States Department of Labor (1977). Federal Mine Safety \& Health Act of 1977.

West Virginia Division of Culture and History. (2010). "Buffalo Creek." Retrieved January 14, 2011, from http://www.wvculture.org/history/buffcreek/intro.html.

West Virginia Water Research Institute (2010). Geoenvironmental Assessment of Dolly Sods Trail Network for CERCLA Review: 93. 


\section{Appendices}

\subsection{Inspection Template Created Using Microsoft Excel}

COAL WASTE IMPOUNDMENT INSPECTION FORM

\begin{tabular}{|l|l|l|}
\hline Inspector's Name & \multicolumn{1}{|c|}{ Hazard Potential Classification } \\
\cline { 2 - 3 } & \multicolumn{1}{|c|}{ Low } & \multicolumn{1}{|c|}{ Significant } \\
\hline Inspector's AR No & Site ID No & Mine ID No \\
\hline Name of Impoundment & Name of Mine Site \\
\hline Operator's Name & Present Construction Phase \\
\hline
\end{tabular}

\begin{tabular}{|c|c|c|c|c|}
\hline A. & CREST & YES & NO & N/A \\
\hline 1. & \multicolumn{4}{|l|}{ Record lift thickness and collect compaction information } \\
\hline & Is placement and compaction of material per approved plan? & & & \\
\hline 2. & \multicolumn{4}{|l|}{ Record readings from piezometers and rain gauges } \\
\hline \multirow[t]{2}{*}{3.} & Are decant pipes clear of obstruction? & & & \\
\hline & Are decant trashracks clear and open? & & & \\
\hline 4. & Settl ements, cracks, or scarps on embankment crest? (if yes, list below) & & & \\
\hline 5. & Observed fires, smoke, or steam seen on embankment? & & & \\
\hline B. & ABUTMENTS & YES & NO & N/A \\
\hline 1. & \multicolumn{4}{|l|}{ Record readings from piezometers and rain gauges } \\
\hline 2. & Has the foundation been prepared correctly (vegetation and stump removal)? & & & \\
\hline 3. & Has the foundation been well established into the bedrock? & & & \\
\hline 4. & Are there any areas of erosion visible in the abutment? & & & \\
\hline 5. & Are there cracks in the abutment or areas of visible different movement? & & & \\
\hline 6. & Are there any wet areas at the abutment where seepage has taken place? & & & \\
\hline 7. & Are there any slides on the abutment? & & & \\
\hline C. & UPSTREAM FACE & YES & NO & N/A \\
\hline 1. & \multicolumn{4}{|l|}{ Check instrumentation and record any readings available } \\
\hline & \multicolumn{4}{|l|}{ Record any piezometer and pore pressure gauge readings available } \\
\hline 2. & \multicolumn{4}{|l|}{ Record pushout-lift thickness and compaction information } \\
\hline & Is placement and compaction of material per approved plan? & & & \\
\hline 3. & Is there water impounded against the upstream face? & & & \\
\hline 4. & Is the beach formation uniform and free of sinkholes and/or depressions? & & & \\
\hline 5. & Are there slurry fines deposited on the upstream face? & & & \\
\hline D. & IMPOUNDMENT POOL & YES & NO & N/A \\
\hline 1. & \multicolumn{4}{|l|}{ Record staff gauge readings for pool el evation } \\
\hline 2. & Are depressions or sinkholes present? & & & \\
\hline 3. & Are pumps presently functioning to remove water? & & & \\
\hline 4. & Are any eddies or other signs of leakage or seeps present? & & & \\
\hline 5. & Is any superfluous material floating in the pool (trees, garbage, etc.)? & & & \\
\hline 6. & Are diversion ditches clear of obstructions, slides, and extraneous material? & & & \\
\hline 7. & Is water entering decant pipe but not exiting outlet? & & & \\
\hline 8. & Is water exiting decant pipe but not entering inlet? & & & \\
\hline 9. & Is water exiting decant outlet flowing clear and without debris? & & & \\
\hline
\end{tabular}




\begin{tabular}{|c|c|c|c|c|}
\hline E. & DOWNSTREAM FACE & YES & NO & N/A \\
\hline 1. & \multicolumn{4}{|l|}{ Record lift thickness and collect compaction information } \\
\hline & Is placement and compaction of material per approved plan? & & & \\
\hline 2. & Erosion, slides, cracks, depressions, bulging, or sloughing? (if yes, list below) & & & \\
\hline 3. & Are there any seeps present? (if yes, describe location and flow below) & & & \\
\hline F. & SPILLWAYS, DIVERSION DITCHES, AND GROIN TRENCHES & YES & NO & N/A \\
\hline 1. & Erosion, slides, cracks, depressions, bulging, or sloughing? (if yes, list below) & & & \\
\hline 2. & Are there any visible restrictions/obstructions (trees, garbage, etc.)? & & & \\
\hline 3. & Are there any tears in the lining? & & & \\
\hline 4. & Any signs of deterioration or erosion in the lining? & & & \\
\hline \multirow[t]{5}{*}{ G. } & DOWNSTREAM TOE & YES & NO & N/A \\
\hline & \multicolumn{4}{|l|}{ Check the outlets of decant pipes and underdrains } \\
\hline & Are the decant pipe/underdrain outlets deteriorated? & & & \\
\hline & Is the pipe bedding deteriorated? & & & \\
\hline & Any signs of seepage around the decant pipes/underdrains? & & & \\
\hline 2. & \multicolumn{4}{|l|}{ Examine the water discharge } \\
\hline & Is the color of the water uniform and free of unusually colored areas? & & & \\
\hline & Does the water contain sediment? & & & \\
\hline 3. & Is water impounded against the downstream toe? & & & \\
\hline 4. & Boils, discoloring, sloughing, backcutting, or obstructions? (if yes, list below) & & & \\
\hline 5. & Are the settling ponds functioning per design requirements? & & & \\
\hline H. & BREAKTHROUGH & YES & NO & N/A \\
\hline 1. & Are any underground mines beneath or adjacent to the pool or embankment? & & & \\
\hline 2. & Any signs of subsidence on or adjacent to the embankment? & & & \\
\hline 3. & Measure any water flow from mine openings on adjacent or underlying mines & & & \\
\hline & Has the flow significantly changed since the most previous measurement? & & & \\
\hline I. & SLURRY/RETURN LINES & YES & NO & N/A \\
\hline 1. & Examine pipes for abnormalities (gouge marks, leaks, cracked joints, etc.) & & & \\
\hline 2. & Are slurry lines out of the traffic zone and clear of moving equipment? & & & \\
\hline 3. & Are the pipe supports sufficient and preventing significant sagging in the line? & & & \\
\hline J. & ROADWAYS ADJACENT/ON EMBANKMENT & YES & NO & N/A \\
\hline 1. & Are roadways well-maintained and safe for travel? & & & \\
\hline 2. & Are berms installed and maintained where necessary? & & & \\
\hline 3. & Are there any means of dust control? & & & \\
\hline 4. & Are dump locations well lit and maintained? & & & \\
\hline Signature & & Date & & \\
\hline Counters & signature & Date & & \\
\hline
\end{tabular}




\subsection{Hyperlinked Form Created with Microsoft Excel}

\section{COAL WASTE IMPOUNDMENT INSPECTION FORM}

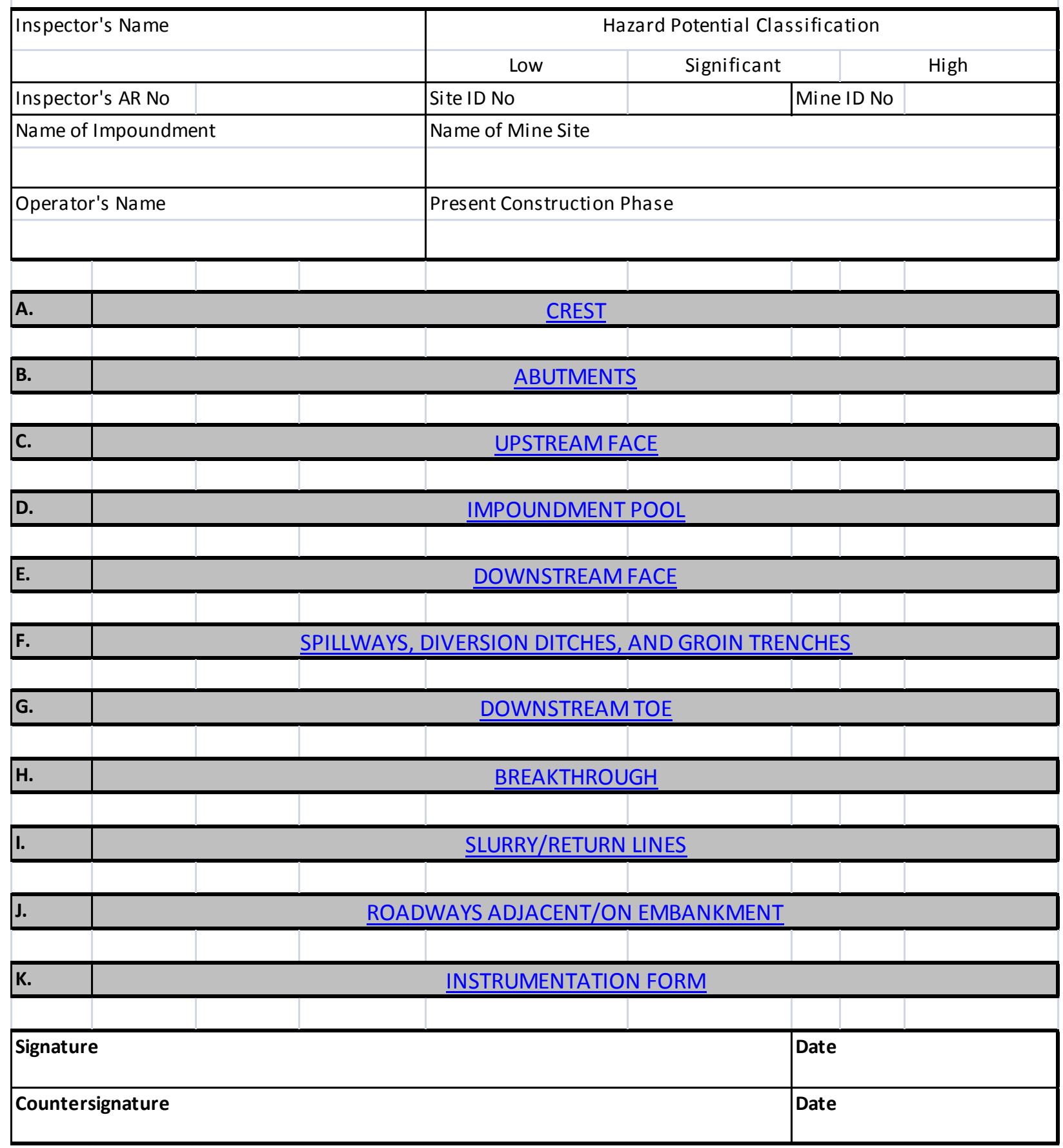




\begin{tabular}{|c|c|c|c|c|}
\hline A. & CREST & YES & NO & N/A \\
\hline \multirow[t]{2}{*}{1.} & \multicolumn{4}{|l|}{ Record lift thickness and collect compaction information } \\
\hline & Is placement and compaction of material per approved plan? & & & \\
\hline 2. & \multicolumn{4}{|l|}{ Record readings from piezometers and rain gauges } \\
\hline \multirow[t]{2}{*}{3.} & Are decant pipes clear of obstruction? & & & \\
\hline & Are decant trashracks clear and open? & & & \\
\hline 4. & Settlements, cracks, or scarps on embankment crest? (if yes, list below) & & & \\
\hline \multirow[t]{2}{*}{5.} & Observed fires, smoke, or steam seen on embankment? & & & \\
\hline & & \multicolumn{3}{|c|}{ BACK TO MENU } \\
\hline
\end{tabular}

\begin{tabular}{|c|c|c|c|c|}
\hline B. & ABUTMENTS & YES & NO & N/A \\
\hline 1. & \multicolumn{4}{|l|}{ Record readings from piezometers and rain gauges } \\
\hline 2. & Has the foundation been prepared correctly (vegetation and stump removal)? & & & \\
\hline 3. & Has the foundation been well established into the bedrock? & & & \\
\hline 4. & Are there any areas of erosion visible in the abutment? & & & \\
\hline 5. & Are there cracks in the abutment or areas of visible different movement? & & & \\
\hline 6. & Are there any wet areas at the abutment where seepage has taken place? & & & \\
\hline 7. & Are there any slides on the abutment? & & & \\
\hline & & \multicolumn{3}{|c|}{ BACK TO MENU } \\
\hline
\end{tabular}

\begin{tabular}{|c|c|c|c|c|}
\hline C. & UPSTREAM FACE & YES & NO & N/A \\
\hline 1. & \multicolumn{4}{|l|}{ Check instrumentation and record any readings available } \\
\hline & \multicolumn{4}{|l|}{ Record any piezometer and pore pressure gauge readings available } \\
\hline 2. & \multicolumn{4}{|l|}{ Record pushout-lift thickness and compaction information } \\
\hline & Is placement and compaction of material per approved plan? & & & \\
\hline 3. & Is there water impounded against the upstream face? & & & \\
\hline 4. & Is the beach formation uniform and free of sinkholes and/or depressions? & & & \\
\hline 5. & . Are there slurry fines deposited on the upstream face? & & & \\
\hline & & \multicolumn{3}{|c|}{ BACK TO MENU } \\
\hline
\end{tabular}

\begin{tabular}{|c|c|c|c|c|}
\hline D. & IMPOUNDMENT POOL & YES & NO & N/A \\
\hline 1. & \multicolumn{4}{|l|}{ Record staff gauge readings for pool el evation } \\
\hline 2. & Are depressions or sinkholes present? & & & \\
\hline 3. & Are pumps presently functioning to remove water? & & & \\
\hline 4. & Are any eddies or other signs of leakage or seeps present? & & & \\
\hline 5. & Is any superfluous material floating in the pool (trees, garbage, etc.)? & & & \\
\hline 6. & Are diversion ditches clear of obstructions, slides, and extraneous material? & & & \\
\hline 7. & Is water entering decant pipe but not exiting outlet? & & & \\
\hline 8. & Is water exiting decant pipe but not entering inlet? & & & \\
\hline 9. & Is water exiting decant outl et flowing clear and without debris? & & & \\
\hline & & & TO & \\
\hline
\end{tabular}




\begin{tabular}{|c|c|c|c|c|}
\hline E. & DOWNSTREAM FACE & YES & NO & N/A \\
\hline 1. & \multicolumn{4}{|l|}{ Record lift thickness and collect compaction information } \\
\hline & Is placement and compaction of material per approved plan? & & & \\
\hline 2. & Erosion, slides, cracks, depressions, bulging, or sloughing? (if yes, list below) & & & \\
\hline 3. & Are there any seeps present? (if yes, describe location and flow below) & & & \\
\hline
\end{tabular}

\begin{tabular}{|c|c|c|c|c|}
\hline F. & SPILLWAYS, DIVERSION DITCHES, AND GROIN TRENCHES & YES & NO & N/A \\
\hline 1. & \multicolumn{2}{|c|}{ Erosion, slides, cracks, depressions, bulging, or sloughing? (if yes, list below) } & & \\
\hline 2. & \multicolumn{2}{|c|}{ Are there any visible restrictions/obstructions (trees, garbage, etc.)? } & & \\
\hline 3. & \multicolumn{2}{|l|}{ Are there any tears in the lining? } & & \\
\hline 4. & Any signs of deterioration or erosion in the lining? & & & \\
\hline & & \multicolumn{3}{|c|}{ BACK TO MENU } \\
\hline
\end{tabular}

\begin{tabular}{|c|c|c|c|c|}
\hline G. & DOWNSTREAM TOE & YES & NO & N/A \\
\hline \multirow[t]{4}{*}{1.} & \multicolumn{4}{|l|}{ Check the outlets of decant pipes and underdrains } \\
\hline & Are the decant pipe/underdrain outlets deteriorated? & & & \\
\hline & Is the pipe bedding deteriorated? & & & \\
\hline & Any signs of seepage around the decant pipes/underdrains? & & & \\
\hline \multirow[t]{3}{*}{2.} & \multicolumn{4}{|l|}{ Examine the water discharge } \\
\hline & Is the color of the water uniform and free of unusually colored areas? & & & \\
\hline & Does the water contain sediment? & & & \\
\hline 3. & Is water impounded against the downstream toe? & & & \\
\hline 4. & Boils, discoloring, sloughing, backcutting, or obstructions? (if yes, list below) & & & \\
\hline \multirow[t]{2}{*}{5.} & Are the settling ponds functioning per design requirements? & & & \\
\hline & & \multicolumn{3}{|c|}{ BACK TO MENU } \\
\hline
\end{tabular}

\begin{tabular}{|c|c|c|c|c|}
\hline H. & BREAKTHROUGH & YES & NO & N/A \\
\hline 1. & Are any underground mines beneath or adjacent to the pool or embankment? & & & \\
\hline 2. & Any signs of subsidence on or adjacent to the embankment? & & & \\
\hline 3. & ne openings on adjacent or underly & & & \\
\hline & Has the flow significantly changed since the most previous measurement? & & & \\
\hline & & \multicolumn{3}{|c|}{ BACK TO MENU } \\
\hline
\end{tabular}




\begin{tabular}{|c|c|c|c|c|}
\hline I. & SLURRY/RETURN LINES & YES & NO & N/A \\
\hline 1. & Examine pipes for abnormalities (gouge marks, leaks, cracked joints, etc.) & & & \\
\hline 2. & Are slurry lines out of the traffic zone and clear of moving equipment? & & & \\
\hline 3. & Are the pipe supports sufficient and preventing significant sagging in the line? & & & \\
\hline & & \multicolumn{3}{|c|}{ BACK TO MENU } \\
\hline
\end{tabular}

\begin{tabular}{|c|c|c|c|c|}
\hline J. & ROADWAYS ADJACENT/ON EMBANKMENT & YES & NO & N/A \\
\hline 1. & Are roadways well-maintained and safe for travel? & & & \\
\hline 2. & Are berms installed and maintained where necessary? & & & \\
\hline 3. & Are there any means of dust control? & & & \\
\hline 4. & Are dump locations well lit and maintained? & & & \\
\hline & & \multicolumn{3}{|c|}{ BACK TO MENU } \\
\hline
\end{tabular}




\section{FIELD MONITORING INSTRUMENTATION FORM}

\section{A. COMPACTION TEST RESULTS}

\begin{tabular}{|l|l|}
\hline Crest & \\
\hline Upstream Face & \\
\hline Downstream Face & \\
\hline
\end{tabular}

\section{B. WEIR/PIPE FLOW INSTRUMENTS}

\begin{tabular}{|l|l|}
\hline & Flow (gpm) \\
\hline Weir No. & \\
\hline & \\
\hline & \\
\hline Pipe No. & \\
\hline & \\
\hline & \\
\hline
\end{tabular}

\section{FACE ANGLES (DEG)}

Upstream Face

Downstream Face

\section{PORE PRESSURE GAUGE}

\begin{tabular}{|c|c|}
\hline Gauge No. & Units \\
\hline & \\
\hline & \\
\hline & \\
\hline
\end{tabular}

\section{E. RAIN GAUGES}

\begin{tabular}{|c|l|}
\hline Gauge No. & Reading (inches) \\
\hline & \\
\hline & \\
\hline & \\
\hline
\end{tabular}

H. PIEZOMETERS

Have piezometers been monitored?

\begin{tabular}{|c|c|c|c|c|c|c|}
\hline ID No. & \begin{tabular}{|c|} 
Tip \\
Elevation \\
\end{tabular} & $\begin{array}{l}\text { Top of Pipe } \\
\text { Elevation (a) }\end{array}$ & \begin{tabular}{|l|} 
Depth to \\
Water $(b)$
\end{tabular} & $\begin{array}{c}\text { Water Level } \\
(\mathrm{c}=\mathrm{a}-\mathrm{b})\end{array}$ & $\begin{array}{c}\text { Max. Allowable } \\
\text { Phreatic Level }\end{array}$ & $\begin{array}{c}\text { Piezometric Surface Elevation } \\
\text { from Previous Visit }\end{array}$ \\
\hline & Units & Units & Units & Units & Units & Units \\
\hline & & & & & & \\
\hline & & & & & & \\
\hline & & & & & & \\
\hline & & & & & & \\
\hline & & & & & & \\
\hline & & & & & & \\
\hline
\end{tabular}

\begin{tabular}{|l|l|}
\hline Type of Inspection & Check Box with "X" \\
\hline 7-Day Inspection & \\
\hline Special Inspection & \\
\hline Date of Inspection & \\
\hline Signature & \\
\hline Counter Signature & \\
\hline & \\
& \\
& \\
& \\
\hline
\end{tabular}

\section{F. SEEPS}

\begin{tabular}{|l|l|}
\hline Location (Coordinates) & Estimated Flow (gpm) \\
\hline & \\
\hline & \\
\hline & \\
\hline & \\
\hline
\end{tabular}

\section{G. ELEVATION DATA}

\begin{tabular}{|l|l|}
\hline \multicolumn{1}{|c|}{ Location } & Reading \\
\hline Free Board & \\
\hline Pool & \\
\hline Current Fill & \\
\hline Decant Inlet & \\
\hline Lowest Point on Crest & \\
\hline Crest Width & \\
\hline Push-Out & \\
\hline
\end{tabular}

\begin{tabular}{l|l}
\hline Yes & No
\end{tabular} 
8.3 Example Access Database of Hibbs Run - Inspection 3

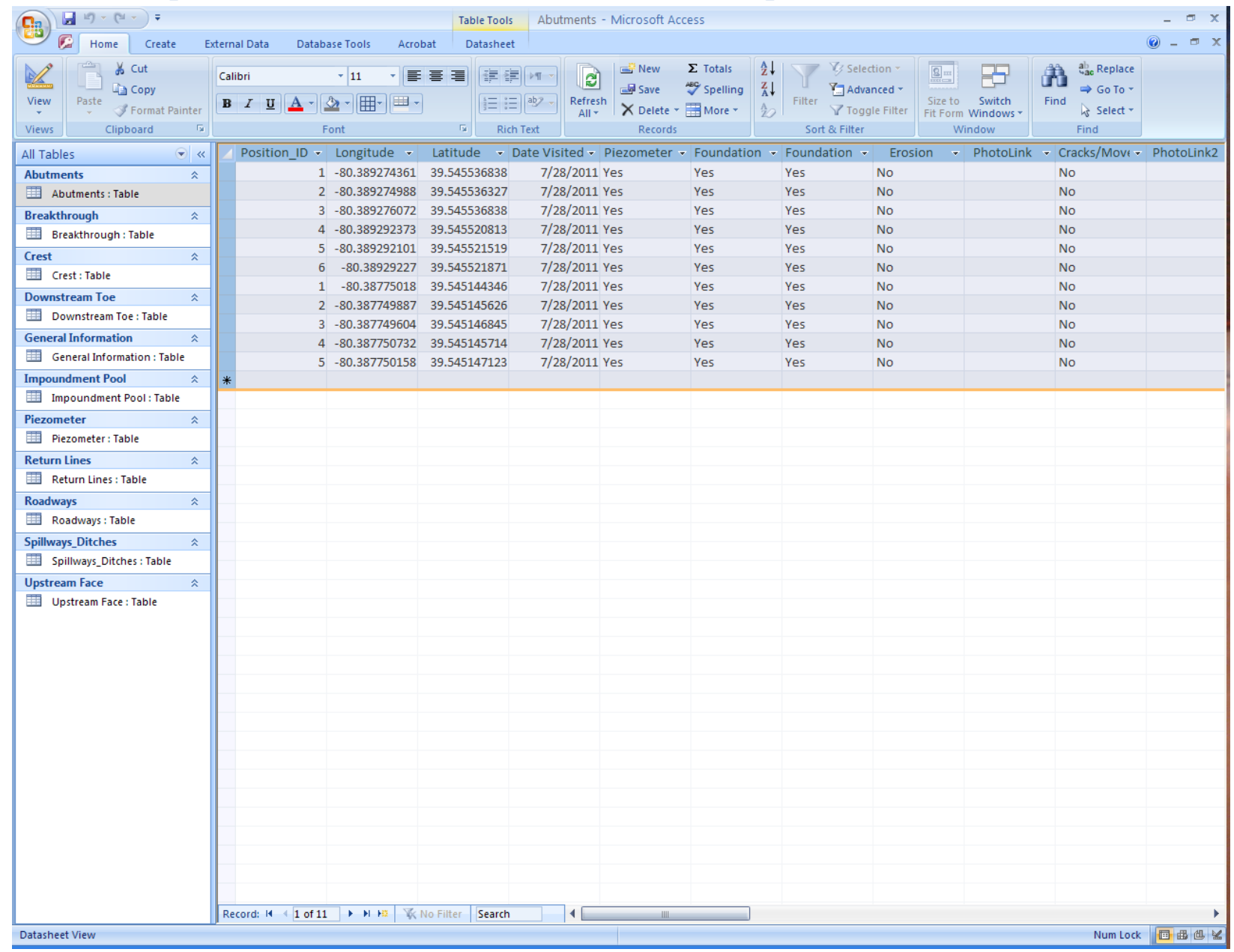




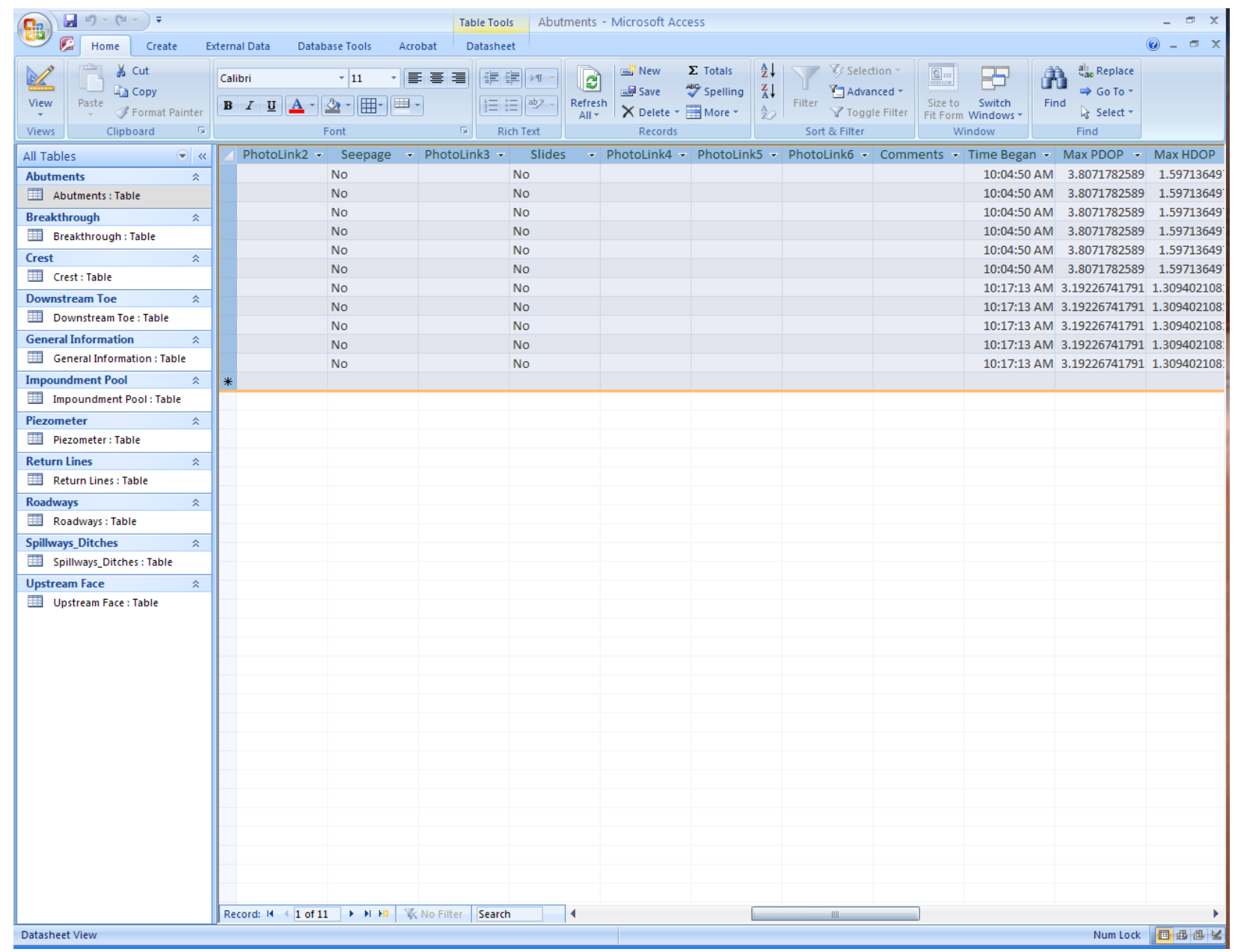




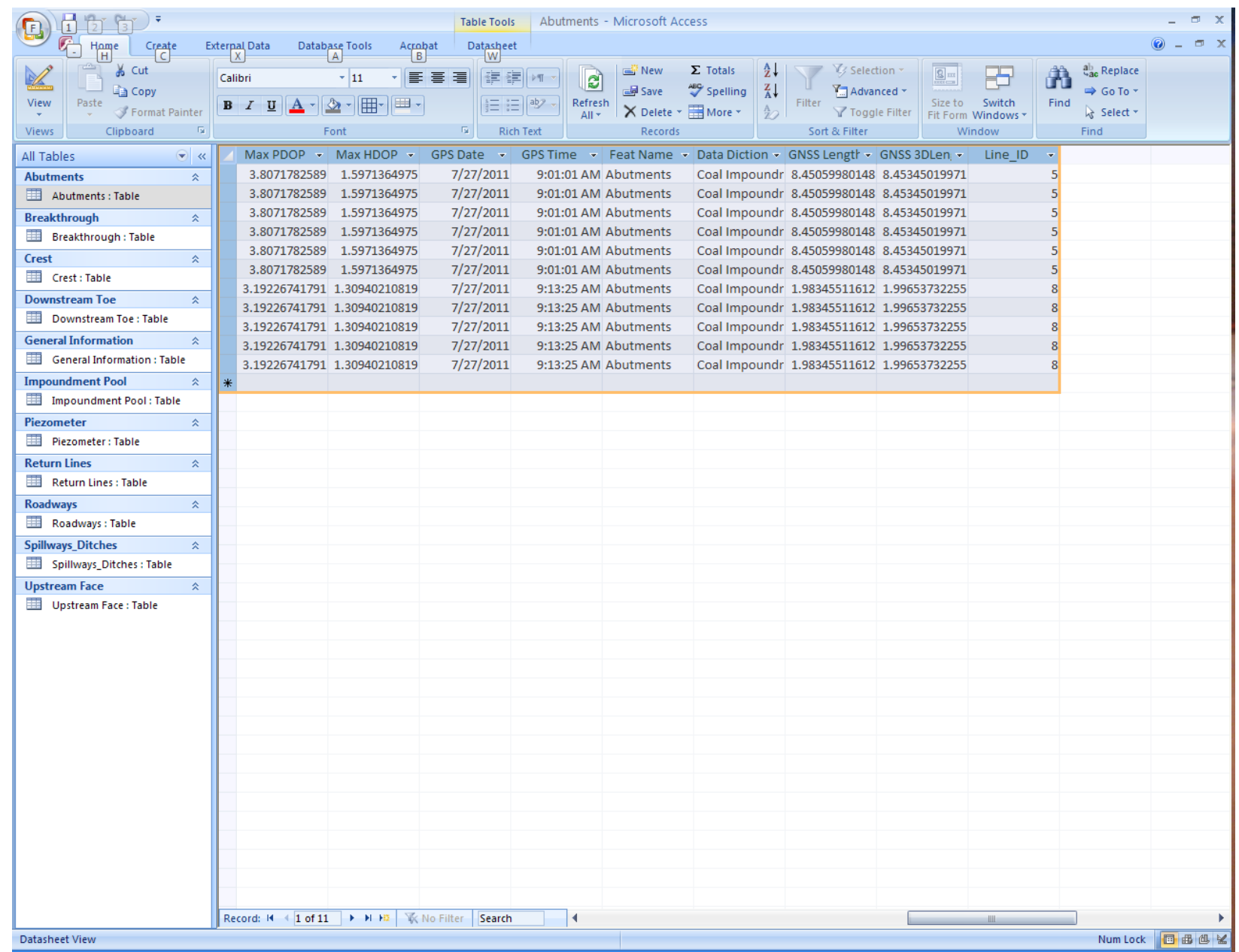




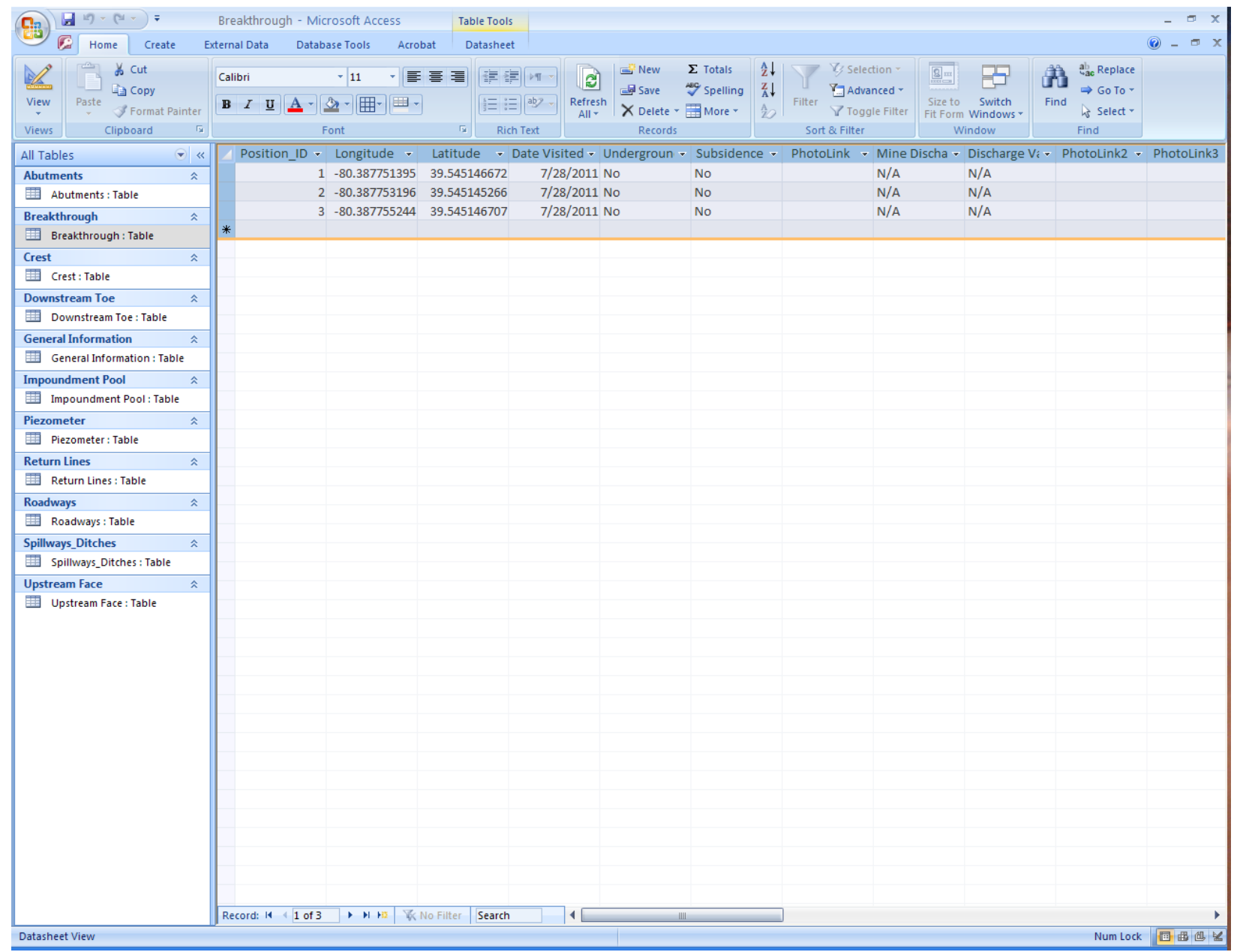




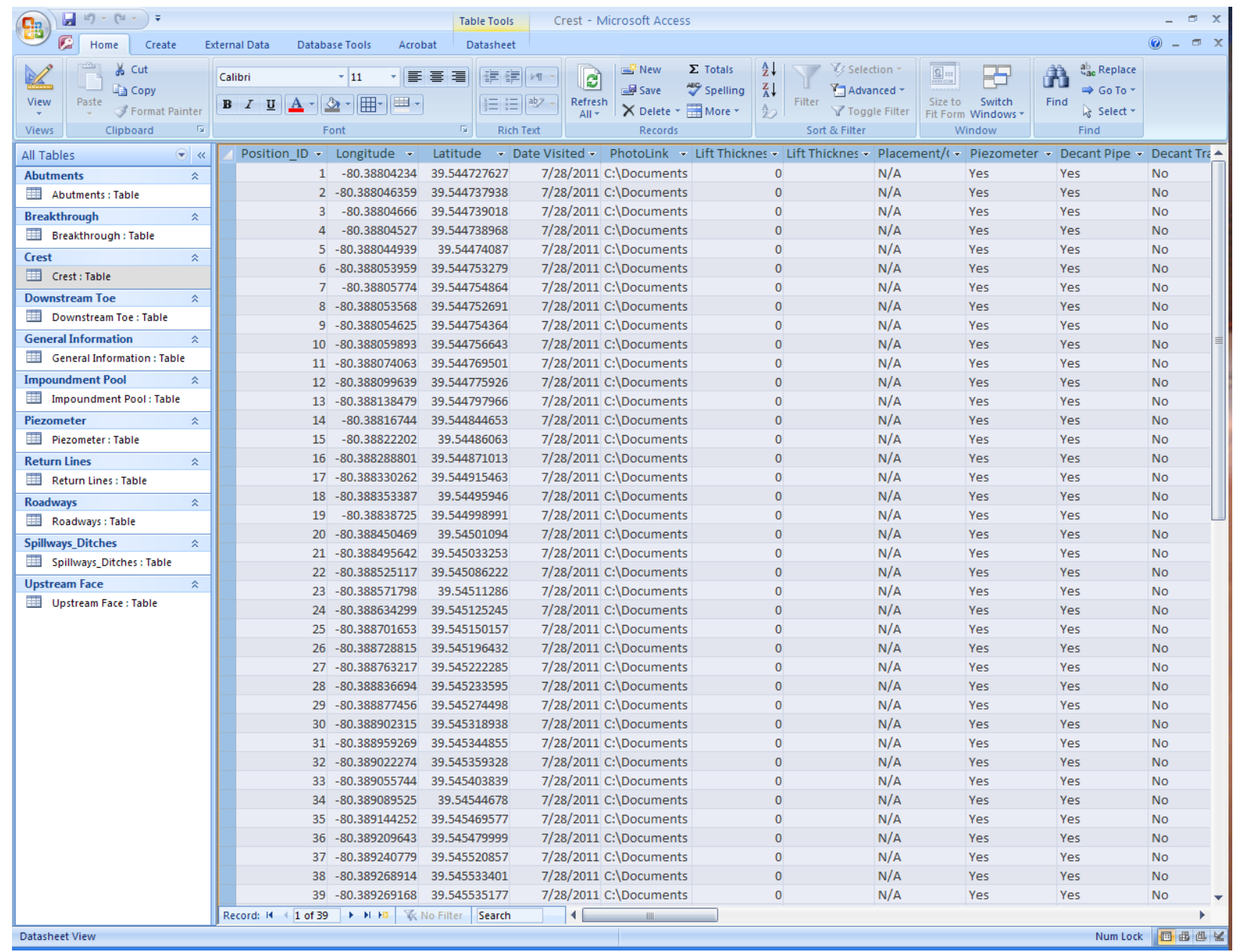




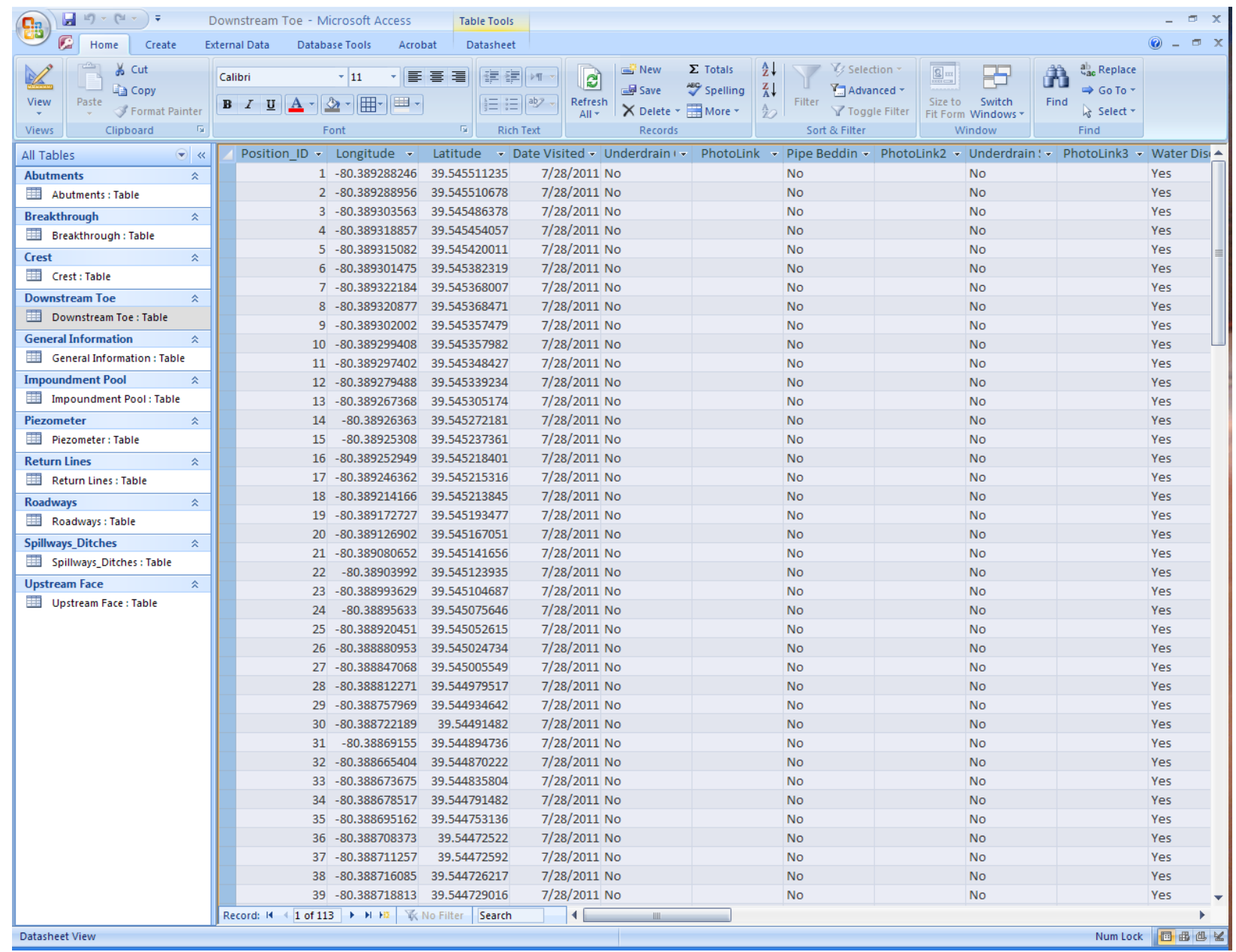




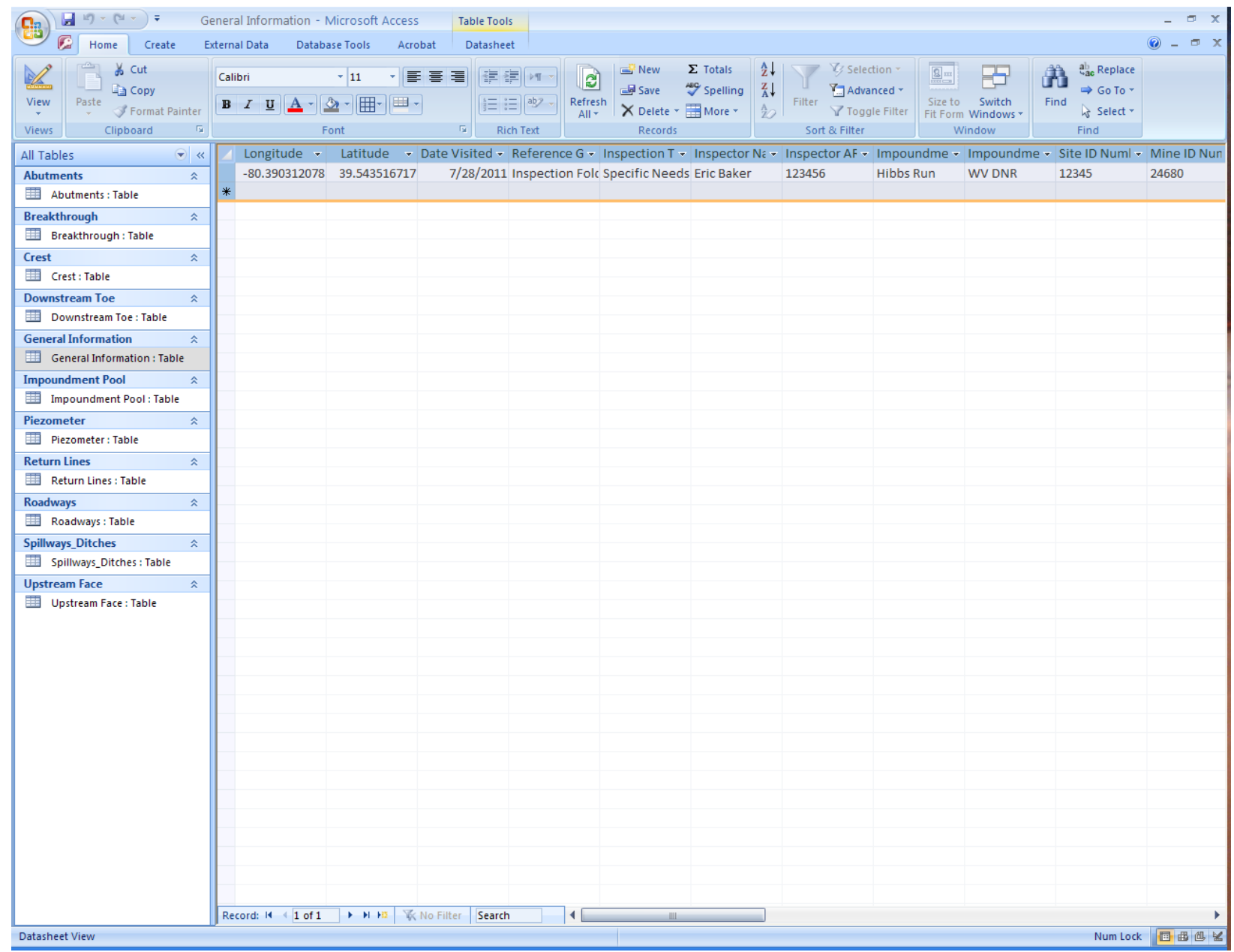




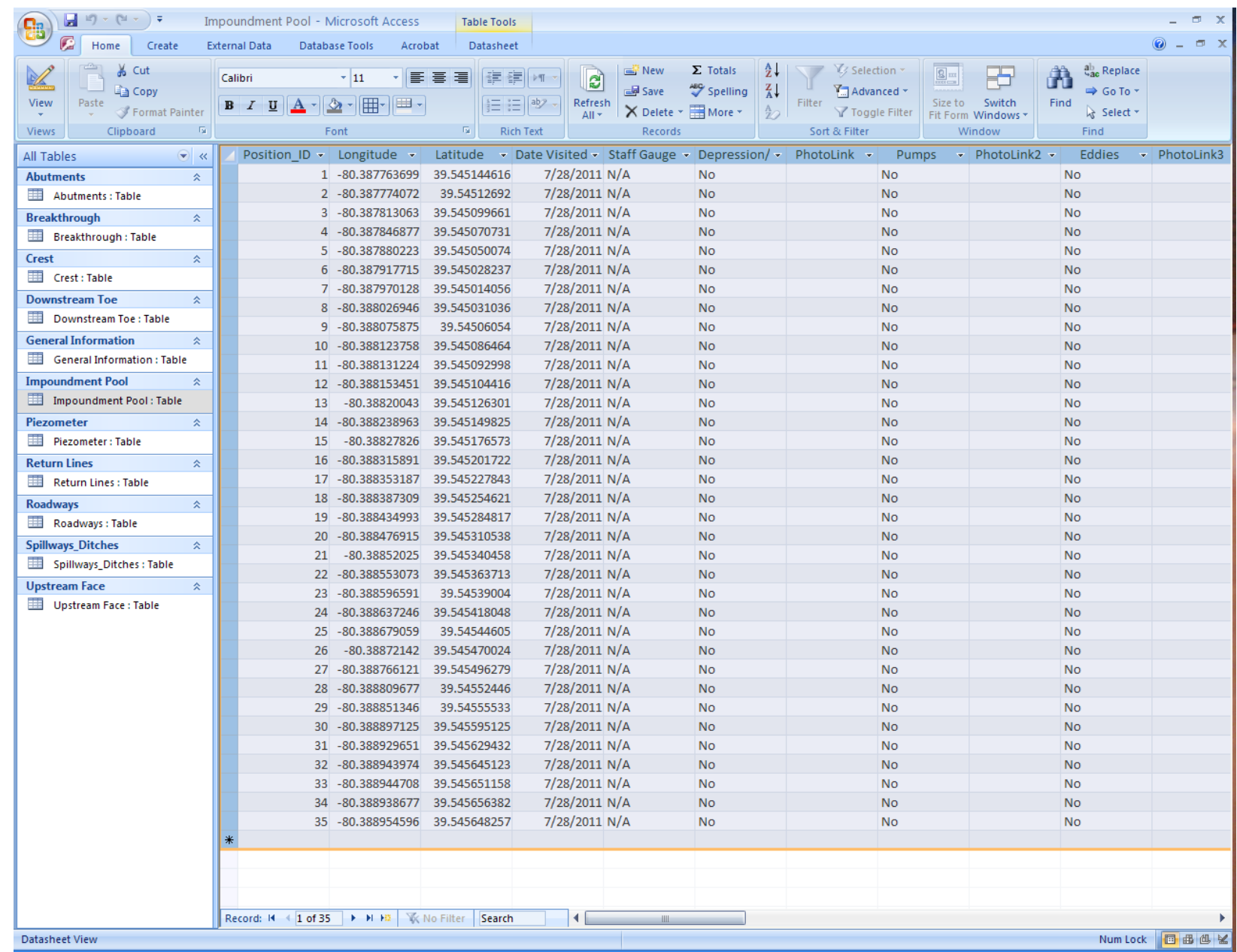




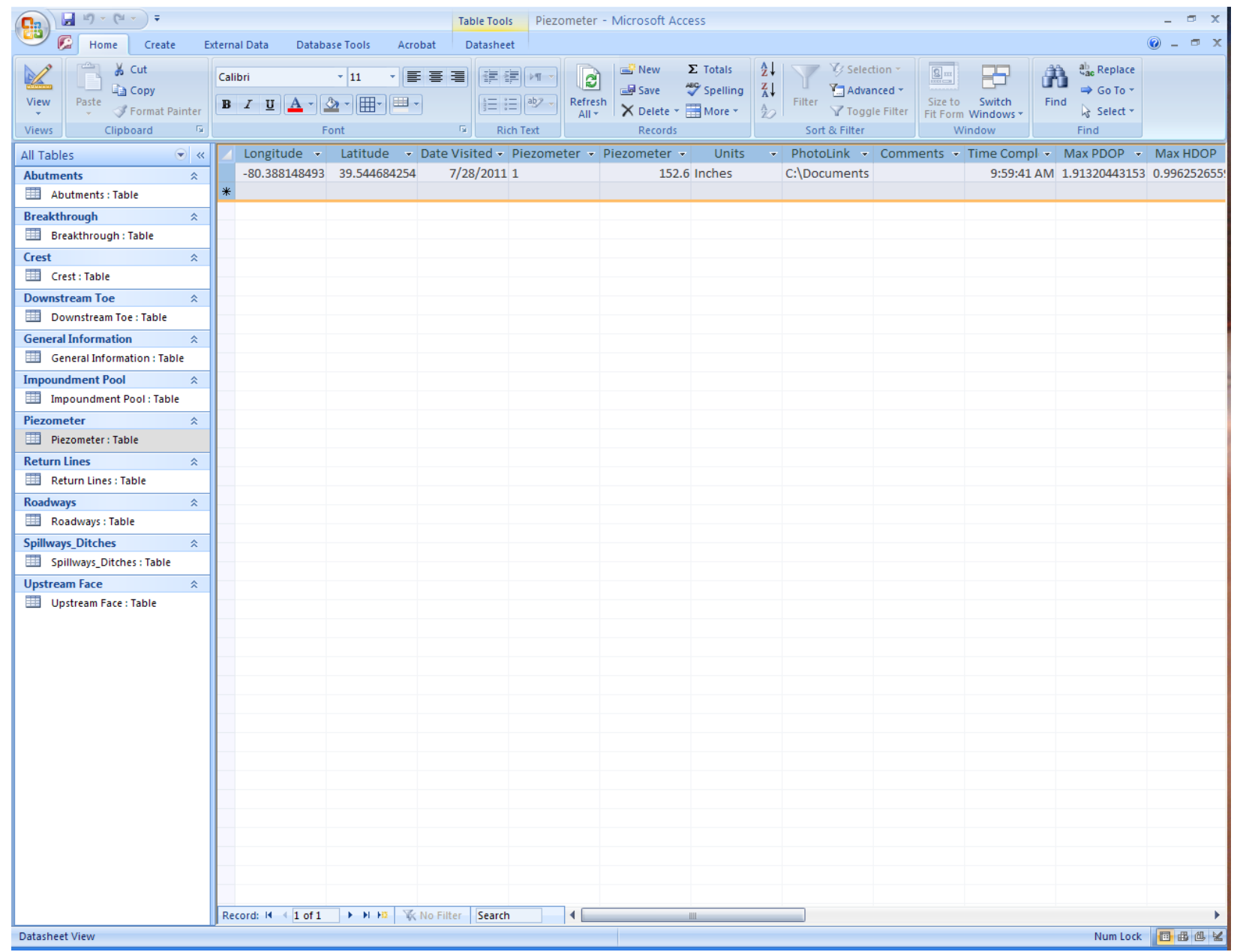




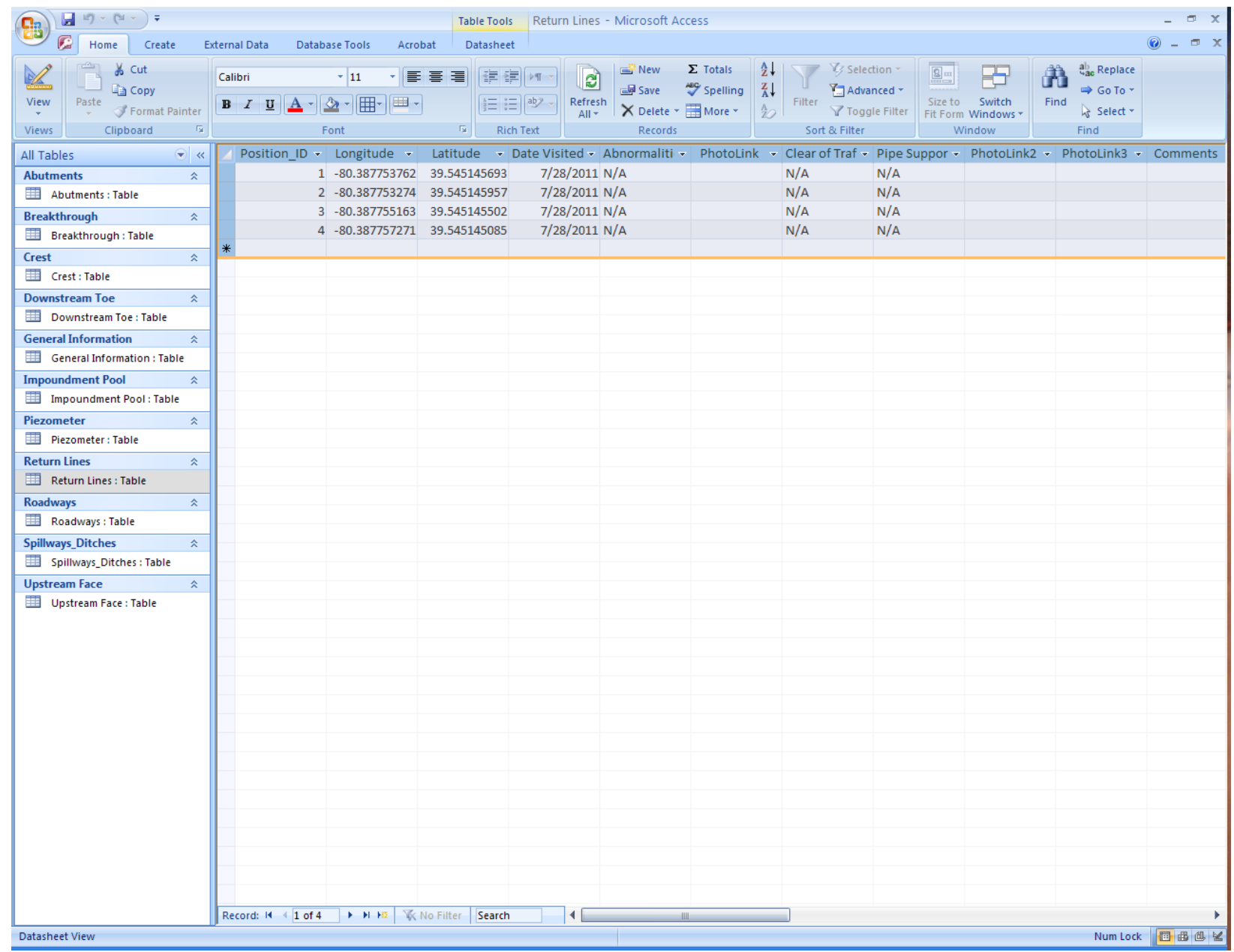




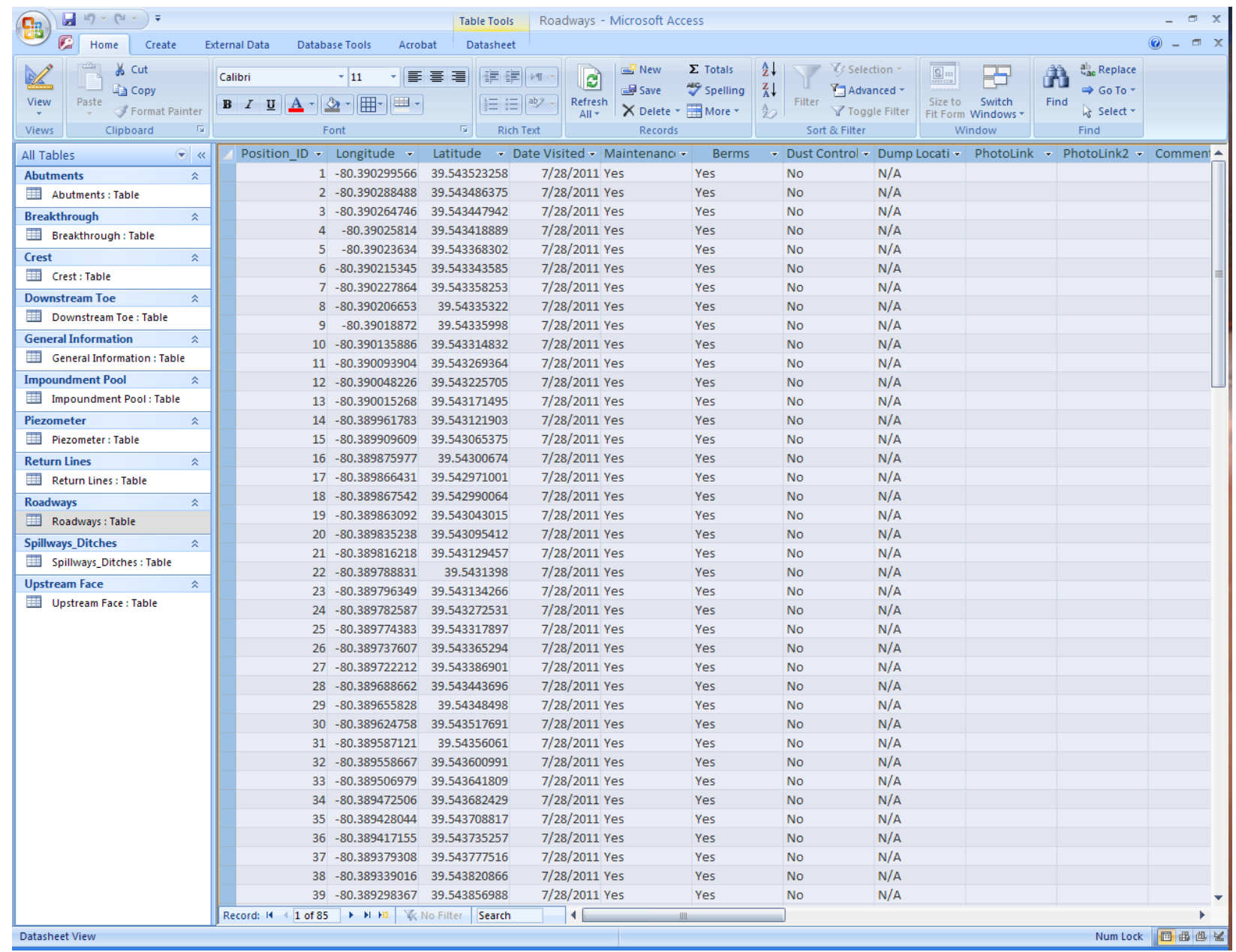




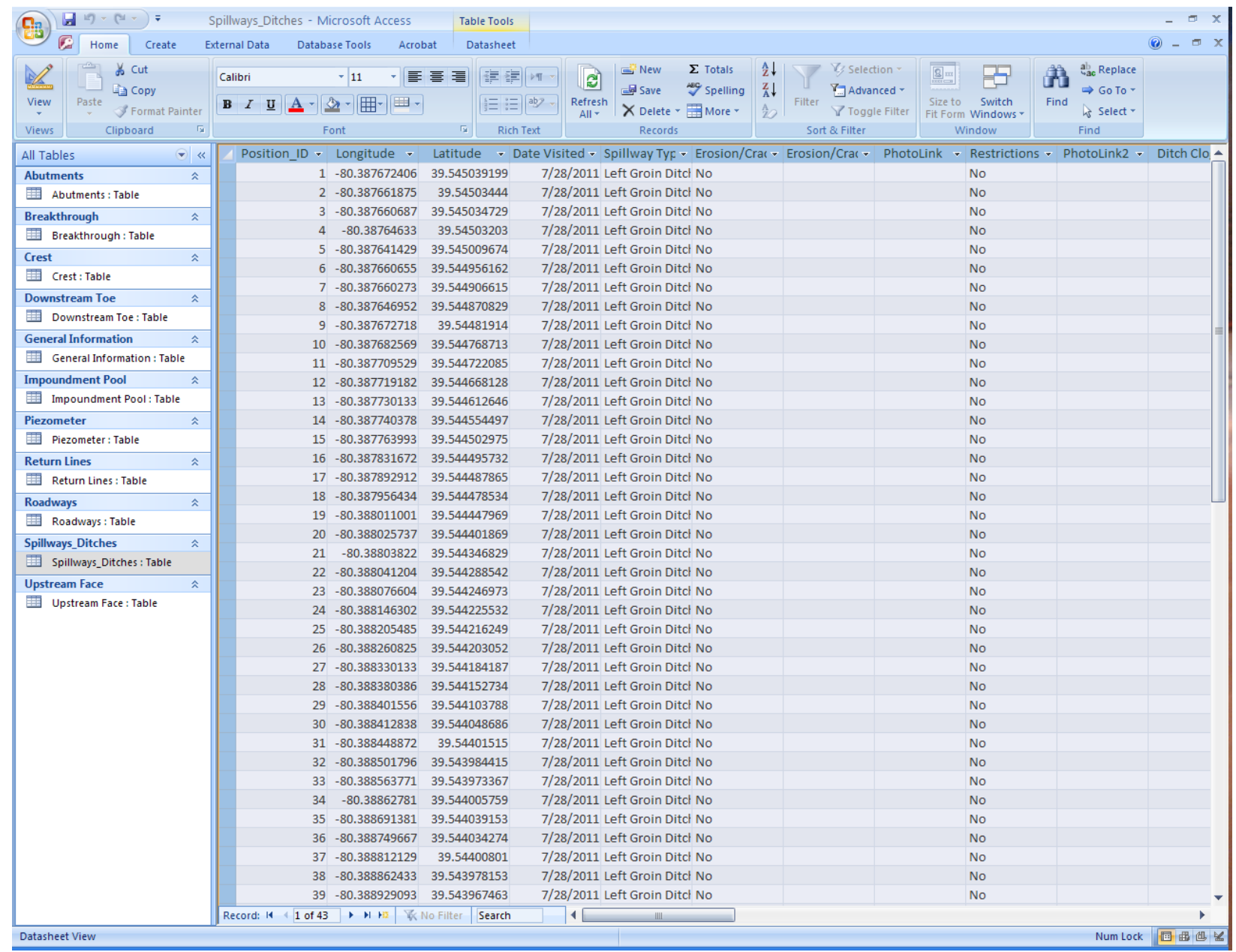




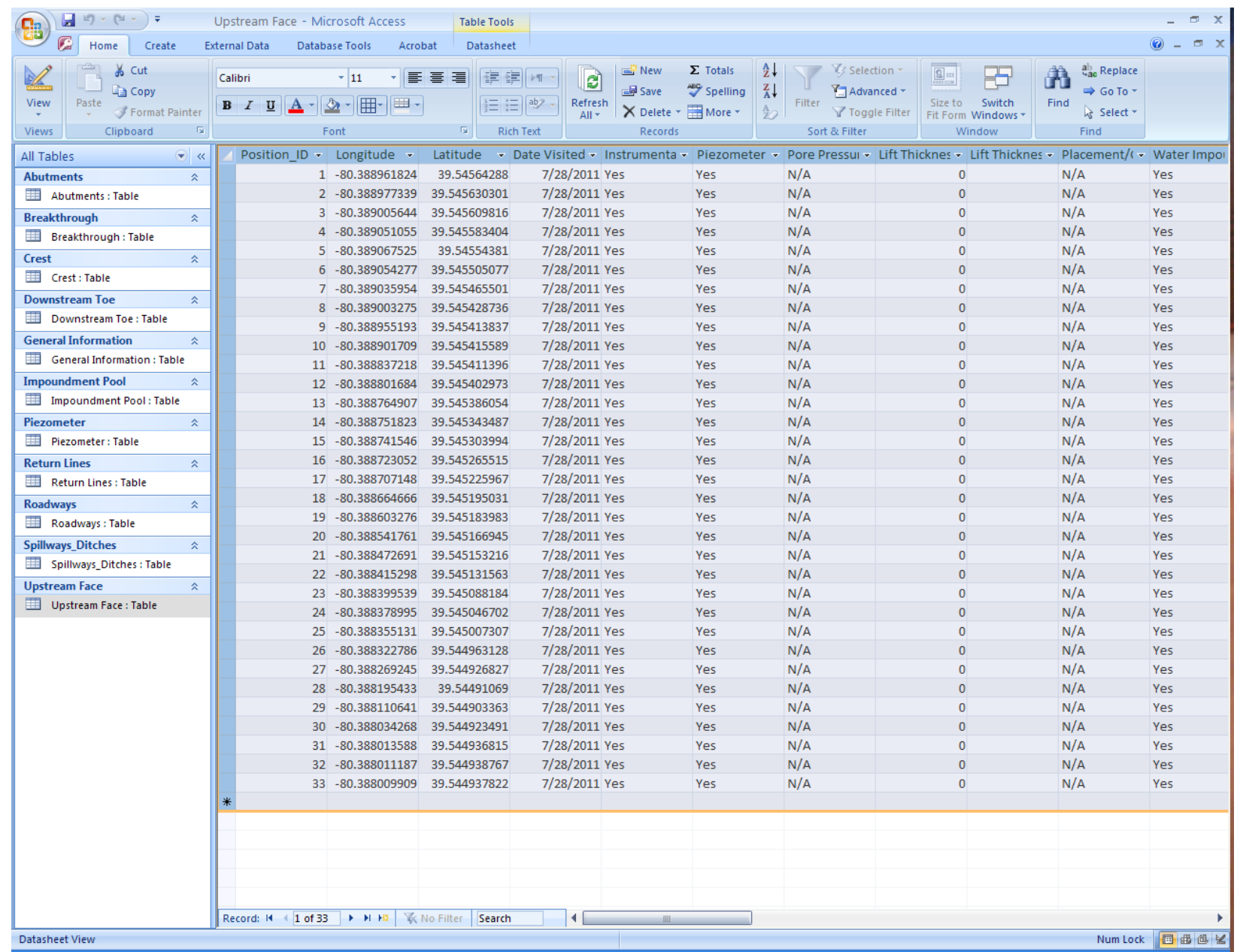

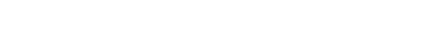

